\title{
A Framework for Evaluating the Total Value Proposition of Clean Energy Technologies
}

Technical Report NREL/TP-620-38597

February 2006

J.E. Pater

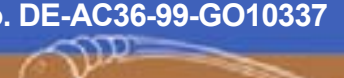




\section{A Framework for Evaluating the Total Value Proposition of Clean Energy Technologies}

Technical Report NREL/TP-620-38597

February 2006

\author{
J.E. Pater
}

Prepared under Task No. 6001.1104

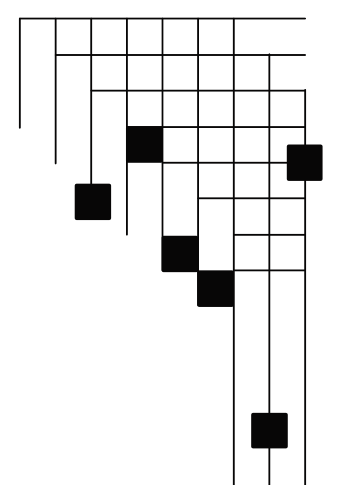




\section{NOTICE}

This report was prepared as an account of work sponsored by an agency of the United States government. Neither the United States government nor any agency thereof, nor any of their employees, makes any warranty, express or implied, or assumes any legal liability or responsibility for the accuracy, completeness, or usefulness of any information, apparatus, product, or process disclosed, or represents that its use would not infringe privately owned rights. Reference herein to any specific commercial product, process, or service by trade name, trademark, manufacturer, or otherwise does not necessarily constitute or imply its endorsement, recommendation, or favoring by the United States government or any agency thereof. The views and opinions of authors expressed herein do not necessarily state or reflect those of the United States government or any agency thereof.

Available electronically at http://www.osti.gov/bridge

Available for a processing fee to U.S. Department of Energy and its contractors, in paper, from:

U.S. Department of Energy

Office of Scientific and Technical Information

P.O. Box 62

Oak Ridge, TN 37831-0062

phone: 865.576 .8401

fax: 865.576 .5728

email: mailto:reports@adonis.osti.gov

Available for sale to the public, in paper, from:

U.S. Department of Commerce

National Technical Information Service

5285 Port Royal Road

Springfield, VA 22161

phone: 800.553 .6847

fax: 703.605.6900

email: orders@ntis.fedworld.gov

online ordering: http://www.ntis.gov/ordering.htm 


\section{Abstract}

Conventional valuation techniques fail to include many of the financial advantages of clean energy technologies. By omitting benefits associated with risk management, emissions reductions, policy incentives, resource use, corporate social responsibility, and societal economic benefits, investors and firms sacrifice opportunities for new revenue streams and avoided costs. In an effort to identify some of these externalities, this analysis develops a total value proposition for clean energy technologies. It incorporates a series of values under each of the above categories, describing the opportunities for recapturing investments throughout the value chain.

The framework may be used to create comparable value propositions for clean energy technologies supporting investment decisions, project siting, and marketing strategies. It can also be useful in policy-making decisions. 


\section{Acknowledgments}

The author wishes to thank Doug Arent, Dan Bilello, Marty Murphy, and Carol Tombari, all of NREL; and Walter Copan, of Clean Diesel Technologies Inc., for developing the concept for this project and providing an incredible amount of guidance throughout it. I also wish to thank the following people for discussing their areas of expertise with me, in an effort to make the paper as comprehensive as possible: Lori Bird, Adam Chambers, Dave Christensen, Kelly Ibsen, Robert Margolis, Judy Oberg, Matt Ringer, and Suzanne Tegen, all of NREL; Christy Herig, of Segue Consulting; and Jason Matlof, of Battery Ventures. And I offer many thanks to Michelle Kubik of NREL for her editorial assistance.

Special thanks also go to the following reviewers who provided thoughtful and thoughtprovoking comments on an earlier draft of this paper: Dan Adler, California Clean Energy Fund; Karlynn Cory, NREL; Kevin Doran, University of Colorado Law School; Dennis Fleming, New Commons Group LLC; Doug Henston, Domani LLC; Tom Lyon, University of Michigan Ross School of Business; Vicki McCarl, Xcel Energy; Alison Peters, University of Colorado Leeds School of Business; Ralph Overend, NREL; and Leanne Tobias, Malachite LLC. 


\section{Executive Summary}

Existing approaches to valuation fail to capture the full value of clean energy technologies. Investors typically consider only the direct return on their investment, rather than looking down the value chain to identify other financial benefits that increase the worth of clean energy technologies. Clean energy technologies deliver a total value proposition (TVP) far greater than their ability to generate electricity, reduce energy consumption, or fuel the world's growing transportation sector. Understanding the total value proposition of clean energy can help investors make better-informed decisions about project selection and implementation, as well as provide a more complete framework for effective business valuation.

The framework for the total value proposition presented in this paper can be applied to renewable electricity generation, distributed generation technology, energy efficiency, and clean fuels. While millions of dollars have been invested in these technologies, deployment has proceeded at a much slower rate than anticipated, primarily due to the fact that investors do not believe that they can monetize the full suite of benefits that these technologies present. Although the production processes and types of uses vary among these types of technologies, they offer a similar set of benefits, which are the focus of this paper.

These benefits could be grouped in any number of ways to create a framework for capturing total value. After considering several alternative structures for the value proposition, the direct financial benefits that firms and individuals can realize were classified into five main categories: Risk Management, Emissions Reduction, Direct Policy Incentives, Reduced Resource Use, and Corporate Social Responsibility. Most of the benefits included in these categories fit within the conventional definition of value, which includes revenue enhancement, cost reduction, and brand value. They do not, however, accrue only to the owners of intellectual property, manufacturers, or distributors of the technology. Because they accrue to a group of actors that conventional value chains define as "end users," investors often cannot predict how much end users will pay for the benefits. As a result, investors feel uncomfortable developing a business plan around such uncertain values, resulting in an undervaluation of clean energy technologies.

Another category of benefits accrues to a broader group of actors. Societal Economic Benefits generally accrue to many actors, but individual firms can also benefit from these societal gains (e.g., through tax breaks).

The value accumulation chain depicted in Figure E1 provides a snapshot of the benefits provided by clean energy technologies when used to generate electricity from a centralized location (e.g., utility-scale wind farm or solar application). The bottom row of the diagram identifies a subset of the actors in the clean energy sector that gain from the technology financially - the value chain has been simplified to eliminate the differences among technologies in the intermediate steps of production. Each bar in the diagram represents a different financial benefit of clean energy technologies. Calculating the value to a specific actor involves summing down the column; and calculating the total value proposition of the technology can be accomplished by summing the benefits that accrue to each actor. Similar diagrams are available for other classes of clean energy technologies, such as distributed generation or biorefineries. 
Figure E1: Summary value accumulation chain for centralized electricity generation technology.

To calculate the total value for one actor in the value chain, sum the values in a column.

To calculate the total value of the technology, sum the values for all actors in the value chain.

\begin{tabular}{|c|c|c|c|c|}
\hline \multirow{6}{*}{ 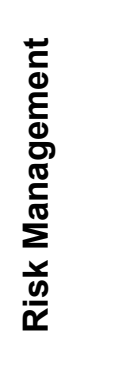 } & & & \multicolumn{2}{|c|}{ Hedge against fuel price volatility } \\
\hline & & & \multicolumn{2}{|c|}{ Hedge against grid outages } \\
\hline & & & \multicolumn{2}{|c|}{ Futures markets } \\
\hline & \multicolumn{4}{|c|}{ Prepare for requlatory chanqe } \\
\hline & \multicolumn{4}{|c|}{ Reduce insurance premiums } \\
\hline & & \multicolumn{3}{|c|}{ Reduce future risks of climate chanqe } \\
\hline \multirow{3}{*}{ 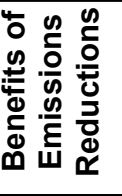 } & \multicolumn{4}{|c|}{ Emissions credits to trade } \\
\hline & & & Reduce emis. fees & Reduce emis. fees \\
\hline & & Avoided & diation costs & \\
\hline \multirow{8}{*}{ 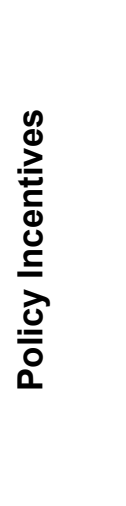 } & & & Production Tax & \\
\hline & & & Accel. depreciation & \\
\hline & RPS * & & RPS * & \\
\hline & & & RECs ** & \\
\hline & & & Feed-in tariffs & \\
\hline & & Prop. tax & & \\
\hline & & & \multirow{2}{*}{\multicolumn{2}{|c|}{ Sales tax exempt }} \\
\hline & Local R\&D & & & \\
\hline \multirow{3}{*}{ 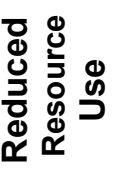 } & & & Reduce water use & \\
\hline & & & Reduce energy use & \\
\hline & & & Lower prod. costs & \\
\hline \multirow{2}{*}{ 悤 } & \multicolumn{4}{|c|}{ Imoroved relations with stakeholders } \\
\hline & \multicolumn{4}{|c|}{ Helo to pass throuah SRI investment filter } \\
\hline
\end{tabular}

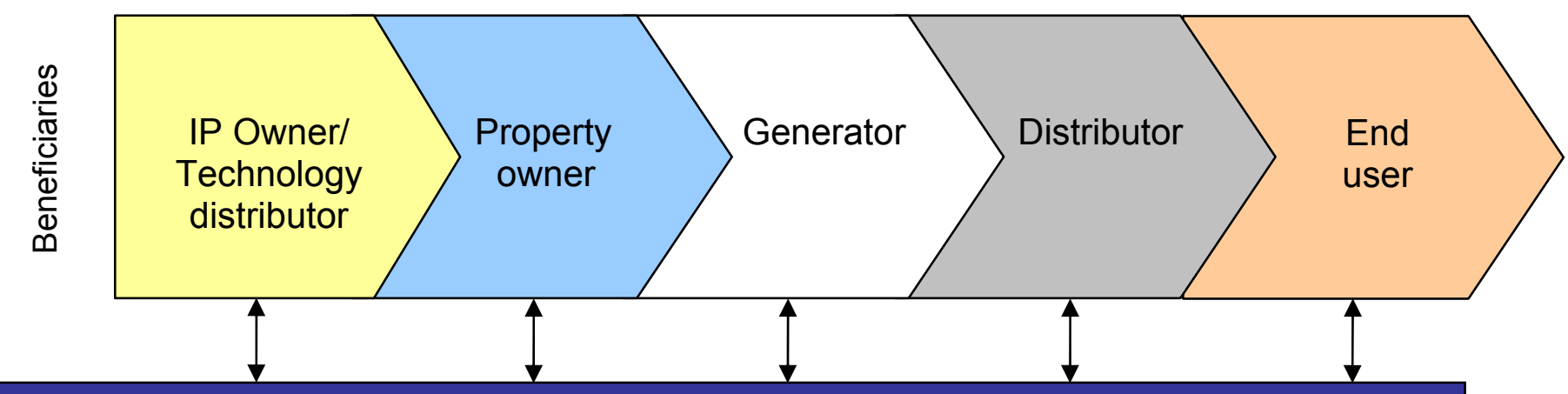

Society, Investors, Shareholders, Insurance companies

- Rural revitalization

- Jobs

- Economic development

- Avoided environmental costs of fuel extraction and transport

* RPS $=$ Renewable Portfolio Standard

** REC = Renewable Energy Certificate 


\section{The Framework}

The six categories of value outlined in Figure E1 are summarized here. Although these categories appear to distinctly delineate the types of values created by clean energy technologies, there is a significant amount of overlap among them. Rather than compartmentalizing the values, the categories provide "buckets" into which similar values can be grouped as appropriate for a given scenario. When applying the methodology to a specific technology, care will need to be taken to prevent double counting. The definitions of each individual value provided in this paper should help identify the uniqueness of the values as categorized.

Risk Management. The benefits that fall under the Risk Management category represent opportunities for firms to use clean energy technologies to hedge against future threats to income, capital, or escalating costs. Risk is inherent in the business world, and firms develop strategies for minimizing their exposure to it in every way possible. The energy sector is no different. Although some risks in the energy sector remain consistent - whether the technology used is conventional or clean (such as drops in demand) - clean energy technologies can help mitigate against some of the risks faced by firms involved in the energy sector.

Values

- Hedge against fuel-price

- Prepare for regulatory change volatility

- Reduce insurance premiums

- Hedge against grid

- Reduce future risks of climate outages change

- Getting ahead in the futures markets

Benefits of Emissions Reductions. Emissions reductions gained through the deployment of clean energy technologies or efficiency improvements help achieve risk-management goals and can enhance the bottom line, both immediately and over time. Firms can generate additional revenue by selling excess emissions reductions on existing markets, whether those markets are compliance-based or voluntary. On the other hand, firms can avoid costs associated with regulatory fees and taxes applied to emissions by utilizing clean energy technologies. In the long run, firms that avoid contaminating the land on which their operations are located avoid characterization as a brownfield and protect their property value.
Values
- Generate emissions
- Reduce fees for emissions
reduction credits / offsets
- Avoid remediation costs

Policy Incentives. Public policy has the power to jump-start markets. Most - but not all - of the policy incentives discussed in this section result in immediate revenue streams for either the developer, generator, end user, or others. Those benefits that do not bring revenue directly to these parties still play a vital role in the adoption of clean energy technologies, however. Regulations that require the adoption of clean energy technologies drive the market, creating demand where there was very little. These policy incentives help make clean energy technologies more cost-competitive with traditional energy sources and/or make the investment more attractive, expanding the technology market's penetration and visibility. 


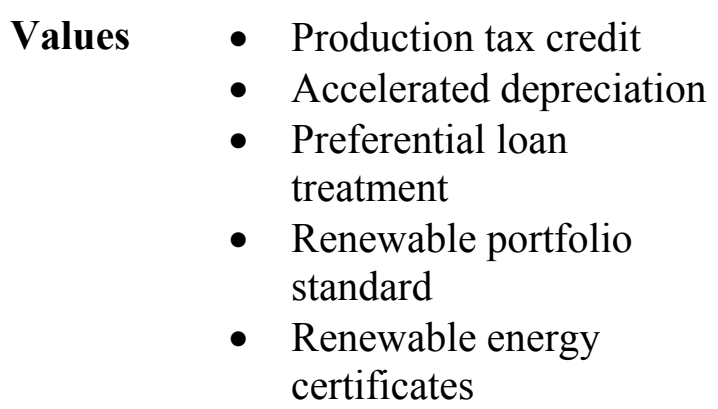

- System benefit funds

- Rebates

- Feed-in tariffs

- Net metering

- Property tax break

- Sales-tax exemption

- Local R\&D incentives

- Other financial incentives

Reduced Resource Use. The production of conventional energy is extremely resource intensive, which adds to the cost of the energy produced. As population and the demands on natural resources increase, the prices of these inputs will increase as well, as the oil markets have demonstrated recently. By reducing the amount of resources used and finding ways to utilize the by-products of clean energy production, firms can help reduce the cost of energy produced and generate new revenue streams with new products.
Values
- Reduce water use and consumption
- Decrease production costs
- Reduce energy use

Corporate Social Responsibility. In addition to the direct cost savings or revenue boosters discussed above, clean energy technologies create value for firms developing, distributing, or using these technologies, ultimately enhancing the firms' corporate social responsibility (CSR) practices. The value associated with CSR goes beyond the favorable public relations that it might generate. Indeed, proactive approaches to addressing stakeholder concerns - one aspect of CSR can help reduce transaction costs and avoid entangling lawsuits. Additionally, outstanding CSR performance can help boost a firm's stock price, creating value that conventional energy technologies would not be able to create.
Values
- Improve stakeholder relations

- Satisfy socially responsible investing (SRI) portfolio criteria

Societal Economic Benefits. The benefits in this societal category fall outside of the traditional value chain, almost as by-products of the benefits that are traditionally examined in a business case. Despite the fact that companies may not be able to calculate direct value in these cases, these by-products can help build support for the projects within the community, facilitating the process of stakeholder buy-in and reducing transaction costs. By building positive relationships early on, the company can avoid negative publicity from groups who protest the project or take legal action to prevent it. Alternatively, these values may be built into the price of the products.

Values

- Rural revitalization

- Jobs

- Economic development
- Avoided environmental costs of fuel extraction/transport

- Avoided costs of transmission and distribution infrastructure expansion 


\section{Next steps}

This paper develops a high-level framework for valuing clean energy technologies. If used to prepare case studies for specific technologies, the framework will provide a consistent methodology across technologies and enable comparison. Such case studies will build on the hundreds of existing studies that examine individual parts of the total value proposition, and they will also require some innovation on the part of those investigating the total value proposition of clean energy technologies.

Each technology and its setting presents unique advantages, and a comprehensive analysis of one will require the contributions from a large spectrum of experts in the field, as well as others who are well-versed in the general valuation methodologies. Moving forward, NREL will develop partnerships with representatives of industry to improve this framework and to apply it to specific scenarios. As a series of case studies is developed, results may be aggregated by technology or class of technologies to help develop a more general estimate of the TVP of these technologies. The extent to which industry is willing and able to integrate these values into its decision-making process will be the real test of this strategy's effectiveness. 


\section{Table of Contents}

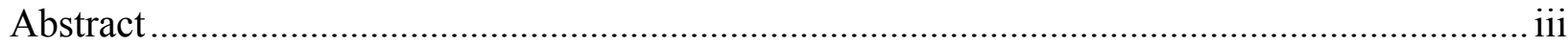

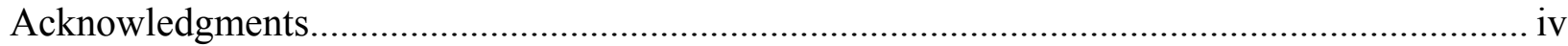

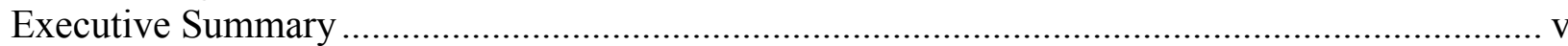

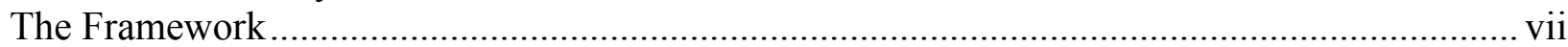

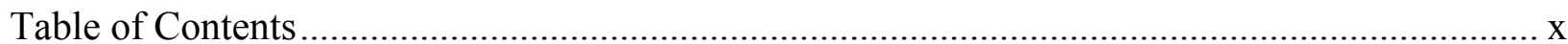

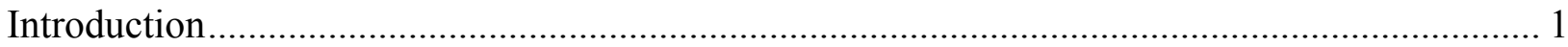

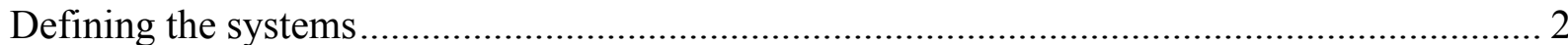

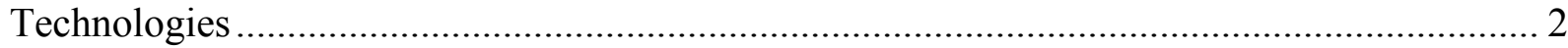

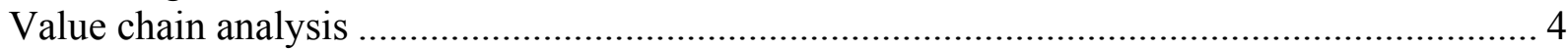

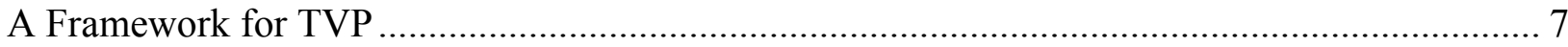

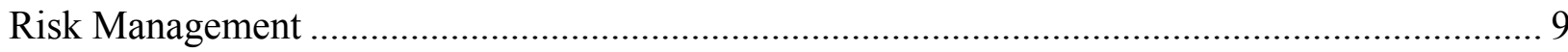

Hedge against fuel-price volatility .............................................................................. 9

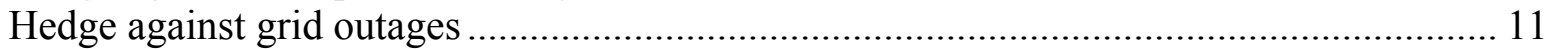

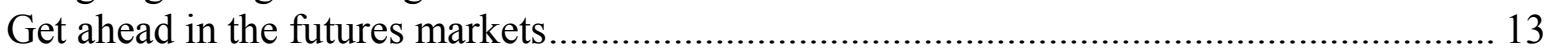

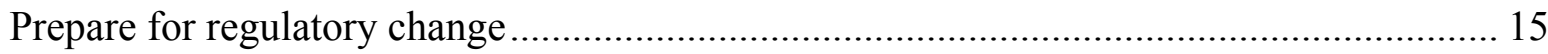

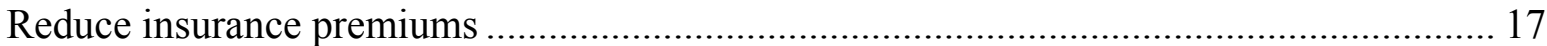

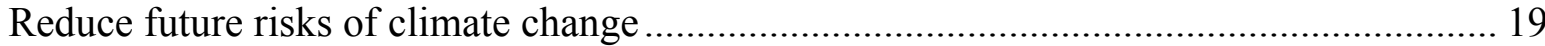

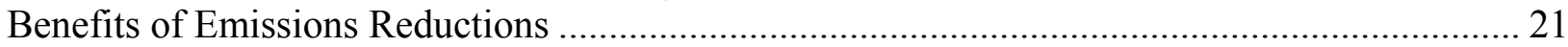

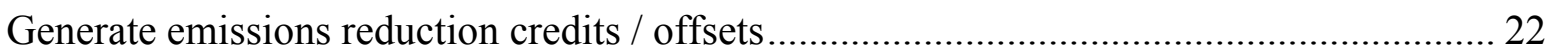

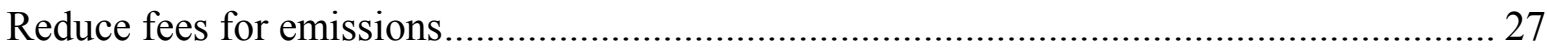

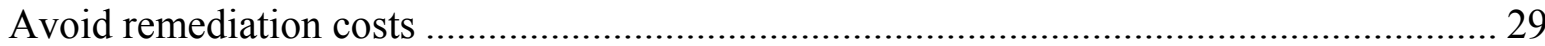

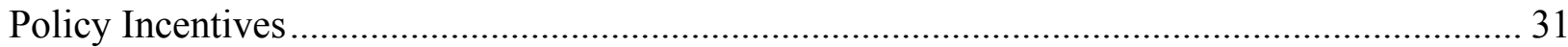

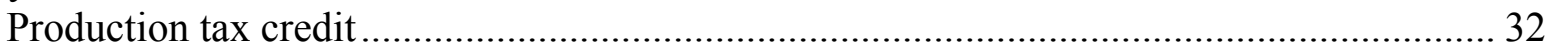

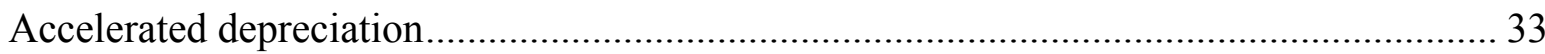

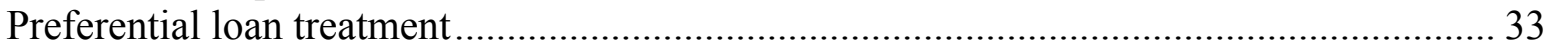

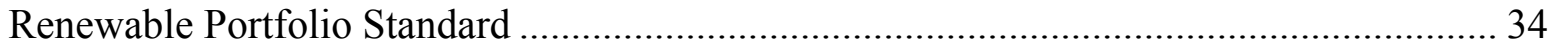

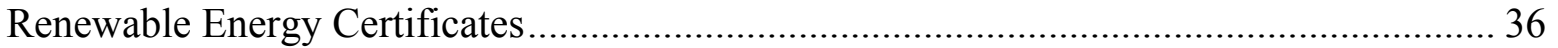

System benefit funds (or public benefit fund) .................................................................... 37

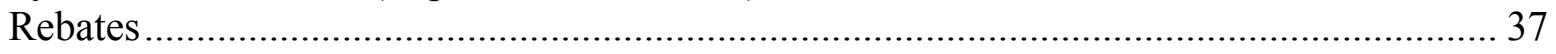

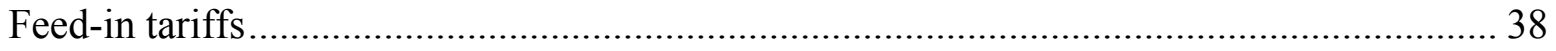

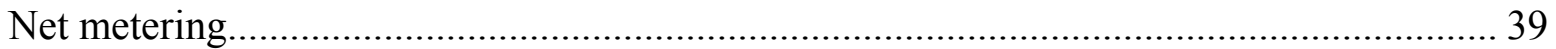

Property tax break

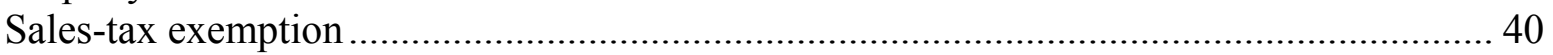

Qualification for local research and development incentives ............................................. 40

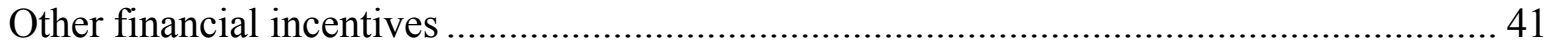

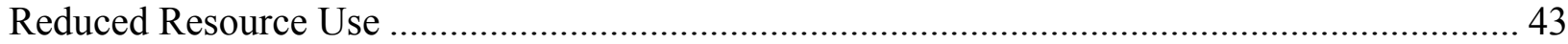

Reduce water use and consumption ............................................................................. 43

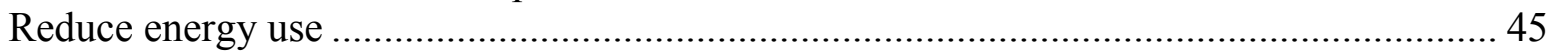

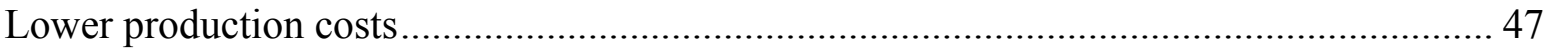

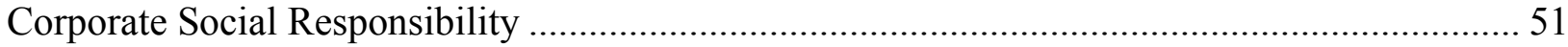

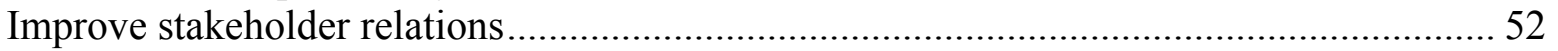

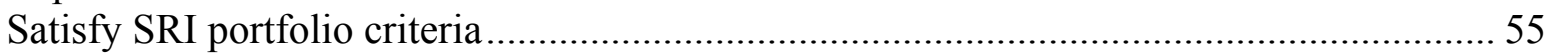

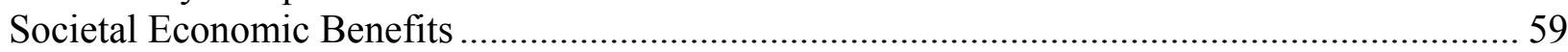

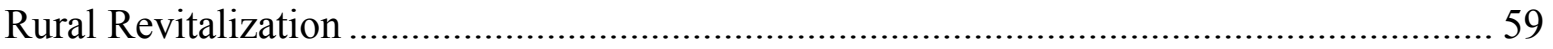


Jobs 60

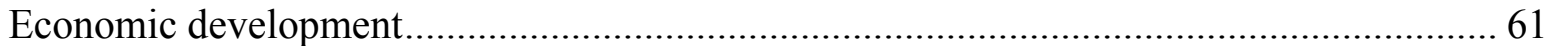

Avoided environmental costs of fuel extraction/transportation..................................... 62

Avoided costs of transmission and distribution infrastructure expansion .......................... 63

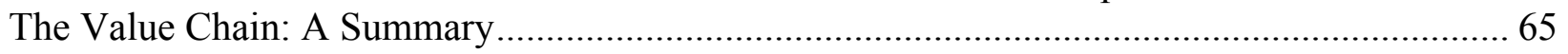

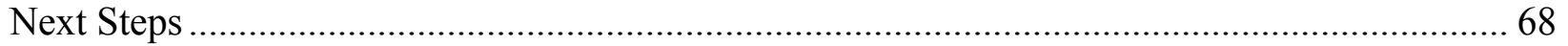




\section{Acronyms}

$\begin{array}{ll}\text { ACE } & \text { Austin Clean Energy } \\ \text { CFC } & \text { Chlorofluorocarbons } \\ \mathrm{CO}_{2} & \text { Carbon dioxide } \\ \text { DG } & \text { Distributed generation } \\ \text { DSIRE } & \text { Database of State Incentives for Renewable Energy } \\ \text { EE } & \text { Energy efficiency } \\ \text { EU ETS } & \text { European Union's Emissions Trading Scheme } \\ \text { GHG } & \text { Greenhouse gas } \\ \text { kWh } & \text { Kilowatt-hour } \\ \text { LEED } & \text { Leadership in Energy and Environmental Design } \\ \text { MACRS } & \text { Modified Accelerated Cost Recovery System } \\ \text { MWh } & \text { Megawatt-hour } \\ \text { NOx } & \text { Nitrogen oxides } \\ \text { NREL } & \text { National Renewable Energy Laboratory } \\ \text { PTC } & \text { Production tax credit } \\ \text { PV } & \text { Photovoltaic } \\ \text { RE } & \text { Renewable energy } \\ \text { REC } & \text { Renewable energy certificate } \\ \text { RPS } & \text { Renewable portfolio standard } \\ \text { SO } 2 & \text { Sulfur dioxide } \\ \text { T\&D } & \text { Transmission and distribution } \\ \text { TMDL } & \text { Total maximum daily load } \\ \text { TVP } & \text { Total value proposition } \\ & \end{array}$




\section{Introduction}

The value of clean energy technologies extends far beyond the ability to generate electricity, reduce energy consumption, or fuel the world's growing transportation sector. Tangible financial benefits accrue to all actors in the value chain, including reductions in emissions, policy incentives designed to facilitate the deployment of these technologies, and corporate social responsibility rewards that accrue to firms that utilize them in their operations.

The financial benefits of clean energy technologies are much greater than the cost-plus pricing structure that has traditionally been used to evaluate the value of these technologies. Understanding the total value proposition of clean energy can help investors make betterinformed decisions about project selection and implementation, as well as provide a more complete framework for useful business valuation. Many of the benefits of clean energy have historically been externalized, similar to the way in which negative externalities of conventional energy technologies (e.g., coal and oil) have been externalized.

In the case of clean energy, however, it is in the financial interest of the investors and firms working with these technologies to quantify those benefits and incorporate them into their pricing and valuation schemes.

The conventional energy industry is facing a host of threats that make clean energy technologies more attractive. Increasing costs of oil and natural gas are causing the energy industry to reevaluate plans for expansion in those sectors. In Europe and Japan, new regulations on greenhouse gas emissions will hit the energy industry harder than any other; and the speculation surrounding parallel regulation in the United States is increasing uncertainty within the industry regarding future costs. In response, different firms are formulating different plans for addressing this uncertainty, fracturing the usually unified front that the industry presents.

At the same time, new opportunities for clean energy technologies are making the technologies more affordable. Growing public support and regulations mandating the adoption of renewable energy technologies are driving the growth of markets for clean energy technologies. Building on the experiences in Europe and Japan, many of the technical hurdles associated with integrating clean energy technology into the electric grid are being overcome. The expansion in those markets and in the United States is helping the clean energy industry to achieve economies of scale, which has started to bring down prices into a range that is competitive with conventional energy sources. These opportunities have grown as the technology has matured, attracting new investment in clean energy.

Still, though, barriers to examining the full value of clean energy prevent the technologies from achieving higher market penetration. Part of the problem is that this requires a shift in the way that society thinks about energy - from looking at it as a commodity to a product that has fartherreaching effects on society. Doing so requires a dialogue about the full cost of energy. Yet, longtime critics of clean energy have expounded on its costs without fully exploring its value; and clean energy advocates have focused on its benefits without fully acknowledging the associated costs. While this paper focuses on the benefits provided by clean energy technologies, it aims to 
begin a dialogue between the two perspectives and provide a framework under which that dialogue may be organized.

Furthermore, existing valuations of clean energy technologies generally focus on only a fraction of the total value, providing a very limited view of the product's total worth. This analysis will demonstrate that the value proposition provided by clean energy technologies is much more robust than currently believed, building on existing value studies. Firms interested in clean energy technologies can capture value in more strategic ways than the simple cost-plus pricing that currently dominates the market. This paper will explore the sources of those additional values and suggest a framework for investors and firms to quantify the total value proposition of clean energy technologies in order to realize the full economic and financial potential of these products.

As outlined in this analysis, there are six main categories - or "buckets" - of value that are not typically captured when valuing clean energy technologies:

- Risk management

- Benefits of emissions reductions

- Policy incentives

- Reduced resource use

- Corporate social responsibility

- Societal economic benefits

The analysis will explain how the values within each of these categories can create additional revenue or avoid costs for firms in the industry and describe where in the value chain the value can be captured. This paper deals with the broad category of clean energy technologies, rather than one specific technology - some examples of values specific to a technology will be given throughout the paper. Fully developed applications of this framework to specific technologies will be encompassed in case studies to be developed in the future.

\section{Defining the systems}

Despite the fact that clean energy technologies can enhance the worth of firms and individuals throughout the products' life cycles, there has not yet been a comprehensive analysis of which firms benefit, from which values they benefit, or what that benefit means in terms of revenue or avoided costs. Before getting into too much detail about what the values are, however, it is important to define the boundaries of this analysis and to identify how the actors in the value chain fit together and how technologies are sorted.

\section{$\underline{\text { Technologies }}$}

Although methodologies based on life-cycle analysis and full-cost accounting can be applied to almost any technology, the methodology developed in this paper is focused on clean energy technologies. Clean energy technologies can include renewable energy, energy efficiency measures, combined heat and power, renewable fuels and products, and a host of other technologies. To make this methodology useful for future developments in the fields that fit within this context, we will not attempt to limit its application to a handful of existing technologies. Instead, this analysis will provide a way to classify clean energy technologies, 
based on current capacities - but with room to expand. Tables 1 and 2 suggest such a scheme, and illustrate where conventional energy supplies would fall as a basis of comparison.

The technologies in Table 1 include those that can be used at both the centralized and the distributed levels. Developers can implement wind, for example, at a utility scale or at a residential scale.

Table 1. Options for Electricity Generation

\begin{tabular}{|c|c|c|}
\hline \multicolumn{2}{|c|}{ Clean Power (Electricity) Generation } & $\begin{array}{c}\text { Conventional Power (Electricity) } \\
\text { Generation }\end{array}$ \\
\hline $\begin{array}{l}\text { Solar (PV) / CSP } \\
\text { Solar thermal } \\
\text { Wind } \\
\text { Geothermal } \\
\text { Biomass } \\
\text { Combined heat } \\
\text { and power }\end{array}$ & $\begin{array}{l}\text { Landfill methane } \\
\text { Operational } \\
\text { efficiency } \\
\text { Building efficiency } \\
\text { Wave } \\
\text { Tidal } \\
\text { Renewable- } \\
\text { fueled } \\
\text { microturbines }\end{array}$ & $\begin{array}{ll}\text { Fossil-fueled } & \text { Coal } \\
\text { microturbines } & \text { Natural gas } \\
\text { Reciprocating } & \text { Nuclear } \\
\text { engines } & \\
\text { Small gas turbines } & \end{array}$ \\
\hline
\end{tabular}

Fuels are generally employed in the transportation sector or for heating (see Table 2). To obtain these fuels, raw materials are refined, producing several coproducts (e.g., gasoline, propane, and kerosene from oil). Some of the coproducts may be used as raw materials for other finished goods, such as plastics from oil or chemical feedstocks from biomass.

Table 2. Options for Fuels

\begin{tabular}{|l|l|}
\hline Clean Fuels & Conventional Fuels \\
\hline Biofuels: bioethanol, & Oil \\
methanol, biodiesel & Gasoline \\
Hydrogen & Diesel \\
Fuel cells & Natural gas \\
Hybrid technologies & Propane \\
\hline
\end{tabular}

This analysis delineates among different types of technology within each of these classes: What does distributed generation mean? Is centralized electricity generation the same for clean energy technologies as it is for conventional systems? How do fuels fit in? To clarify, definitions of some of the key concepts follow:

Centralized electricity generation - The bulk of the U.S. and European power systems have been designed with large generating facilities, which provide most of the power to customers through an extensive (and expensive) transmission and distribution (T\&D) system. Some clean energy technologies can build on this established infrastructure, although additional T\&D infrastructure 
may be needed. For this paper, centralized electricity generation generally means that power is generated on a utility scale (i.e. on the order of megawatts, not kilowatts) at a central location and then transmitted to customers via the grid.

Distributed electricity generation (DG) - DG is electricity generation that occurs at the electricity consumer's facility, which could be industrial, commercial, or residential. Although DG applications may be able to sell power back to the grid when more electricity is produced than is needed (through net metering), the salient feature of DG is that it reduces or eliminates completely the need for electricity from the grid; DG capacity is also typically much smaller than at centralized facilities.

Energy efficiency (EE) - EE is also applied at the electric consumer's facility. EE efforts can focus on improving the efficiency of the physical facility itself (e.g., by utilizing passive solar technologies), the efficiency of the operations that require energy (e.g., boilers), or it could focus on designing a system that uses the waste products from electricity generation (e.g., steam) for other purposes. Instead of requiring additional electricity from the grid, energy efficiency measures help a facility to actually reduce its demand.

Fuels - Separate from the electricity-generation scheme, fuels are another form of energy that are used in their raw form at the point of application. Transmission of the energy from the point of combustion to the point of use is not needed. For example, gasoline and diesel fuels are combusted in a vehicle's engine and produce energy to move the vehicle. Similarly, a biorefinery produces fuels that can be used in a similar manner. Although the applications of fuels are very different from the application of power, this methodology can develop a total value proposition for both types of energy.

\section{$\underline{\text { Value chain analysis }}$}

Because the term "clean energy technologies" encompasses such a broad range of technologies, the value chain will vary slightly for each technology. Examining centralized electricity generating technologies (such as wind or biomass plants) involves a separate set of actors than distributed generation (such as solar PV or combined heat and power), which is much different than the value chain associated with fuel production at a biorefinery. There are parallels, however, in the types of actors involved with each technology.

Figure 1 illustrates the generic value chains for each class of clean energy technologies outlined in the previous section. The linear part of the value chain is limited to the parties directly involved in energy production - thus, it does not specifically mention investors, shareholders, or insurance companies. Instead, these actors are included, along with the broader category of Society, in the "bucket" at the bottom of the graphic to demonstrate that these groups are the foundation of the entire system; clean energy technologies benefit these groups, and each link in the value chain benefits from the monetary inputs of these groups.

The value chain for each classification of technology is stacked on top of the others to demonstrate the parallels among them. Each of them fits into a generic value chain consisting of intellectual property (IP) owner/technology distributor, land owner, generator, distributor, and 
end user - which actors specifically fill those roles depends on which class of technology is examined and, for even greater accuracy, which specific technology.

Throughout the paper, these general terms will be used for the Value Chain Analysis subsections in order to simplify the analysis. The use of the terms "generator" and "distributor" will refer mainly to the cases of centralized generation and biorefineries. In the case of DG, however, the end user is also the generator and distributor; in most cases, this actor will simply be called the "end user." 


\section{Figure 1. General Value Chains for Categories of Clean Energy Technologies}

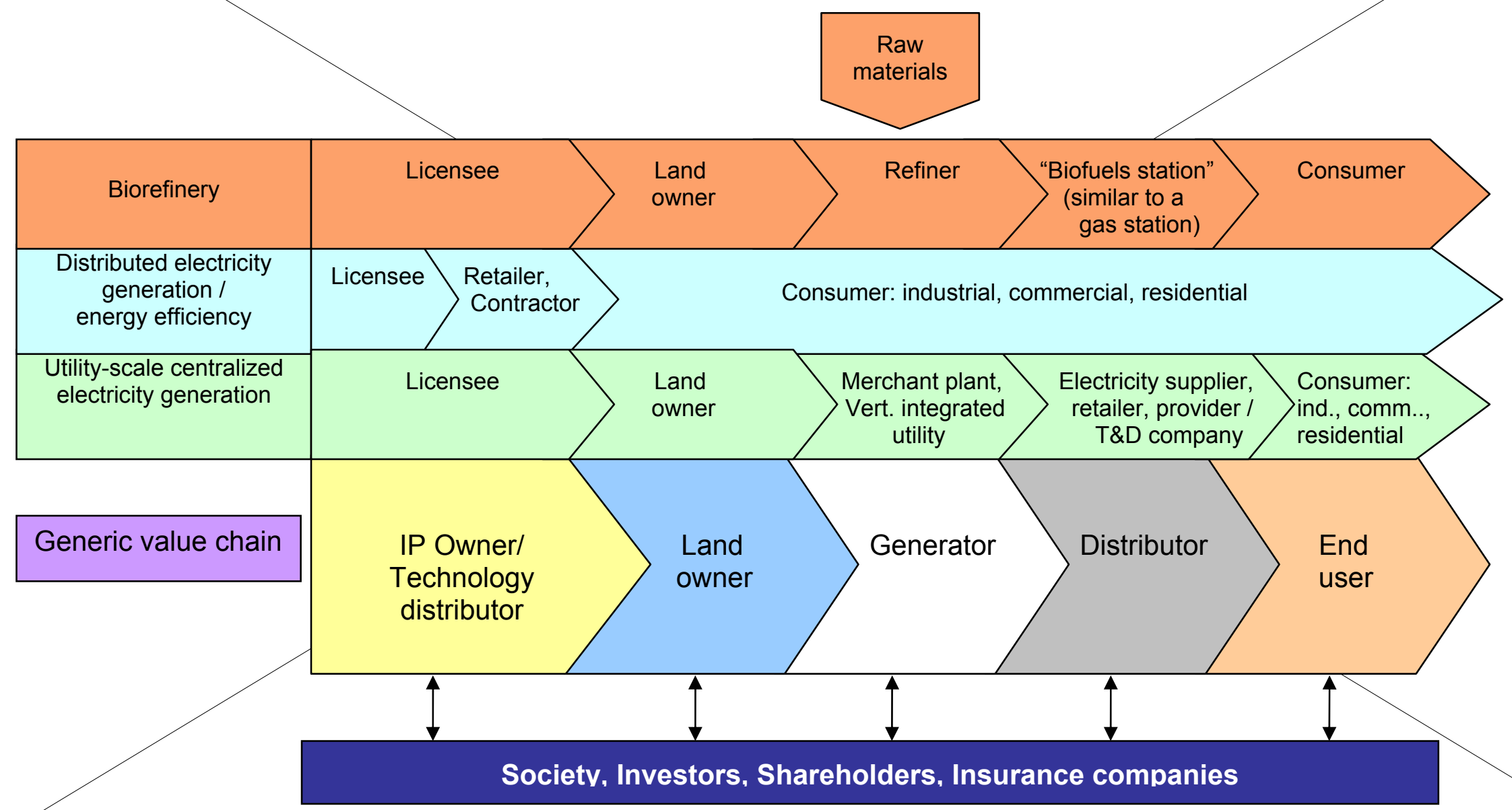

This figure presents some of the technology type-specific value chains - biorefineries, distributed generation, and centralized generation. Because many of the values discussed in this paper apply to more than one type of technology, a generic value chain (the bottom row) is presented here to provide a framework for the remainder of the paper. 


\section{A Framework for TVP}

Having defined the types of technologies that qualify as clean energy technologies for this paper and the actors in the value chain, we can begin to develop the framework for evaluating the total value proposition (TVP) for these technologies.

When valuing a new product, analysts typically identify its "conventional" business benefits expanded access to markets, new income streams, and other straightforward financial measures. With clean energy technologies, these analysts often overlook the additional opportunities for revenue, cost avoidance, and other financial benefits. Table 3 identifies the primary financial benefits of clean energy technology, organized according to six categories: Risk Management, Benefits of Emissions Reductions, Direct Policy Incentives, Reduced Resource Use, Corporate Social Responsibility (CSR), and Societal Economic Benefits.

Although these categories appear to distinctly delineate the types of values created by clean energy technologies, there is a significant amount of overlap among them. Emissions reductions credits are at once a benefit of emissions reductions and a risk management tool. The creation of a new market for agricultural waste products creates both a societal benefit and a benefit of emissions reductions.

Rather than compartmentalizing the values, the categories provide "buckets" into which similar values can be grouped as appropriate for a given scenario. When applying the methodology to a specific technology, analysts need to make efforts to prevent double counting. The definitions of each individual value provided in this paper should help identify the uniqueness of the values as categorized.

The remainder of this section explains these values and which actors in the value chain can capitalize on them. This is a high-level analysis that discusses the benefits of clean energy technologies, in general, rather than focusing on one specific technology. Anecdotes of how clean energy technologies have created value help illustrate applications of each of these values but these examples are by no means inclusive of all applications of the value. The framework leaves room for the inclusion of additional values as they are discovered, and it can be updated in future versions. 
Table 3. Total Value Proposition for Clean Energy Technologies

\begin{tabular}{|c|c|c|c|c|c|}
\hline Risk Management & $\begin{array}{l}\text { Benefits of } \\
\text { Emissions } \\
\text { Reductions }\end{array}$ & Policy Incentives & $\begin{array}{c}\text { Reduced } \\
\text { Resource Use }\end{array}$ & $\begin{array}{l}\text { Corporate Social } \\
\text { Responsibility }\end{array}$ & Societal Benefits \\
\hline $\begin{array}{ll}\text { - } & \text { Hedge against fuel } \\
\text { price volatility } \\
\text { - } & \text { Hedge against grid } \\
\text { outages } \\
\text { - } \text { Get ahead in the } \\
\text { futures markets } \\
\text { - } \quad \text { Prepare for } \\
\text { regulatory change } \\
\text { - } \quad \text { Reduce insurance } \\
\text { premiums } \\
\text { - Reduce future } \\
\text { risks of climate } \\
\text { change }\end{array}$ & 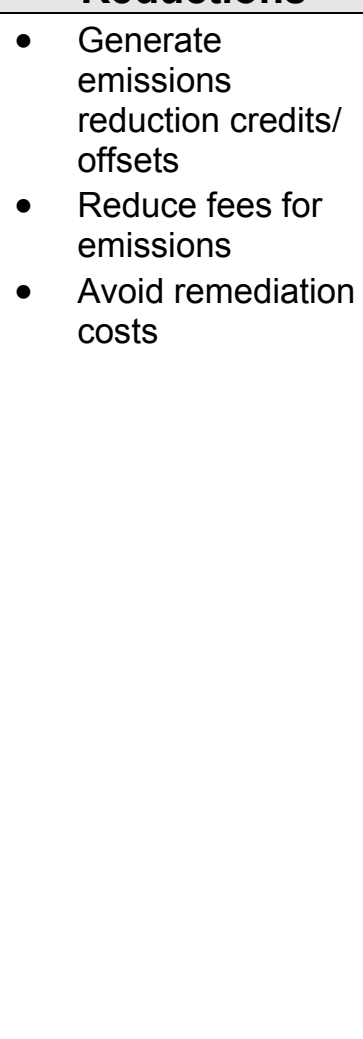 & $\begin{array}{ll}\text { - } & \text { Production Tax } \\
& \text { Credit (PTC) } \\
\text { - } & \text { Accelerated } \\
& \text { depreciation } \\
\text { - } & \text { Preferential loan } \\
& \text { treatment } \\
\text { - } & \text { Renewable Port- } \\
& \text { folio Standard } \\
& \text { (RPS) } \\
\text { - } & \text { Renewable Energy } \\
& \text { Certificates } \\
& \text { (RECs) } \\
\text { - } & \text { System Benefit } \\
& \text { Funds (SBFs) } \\
\text { - } & \text { Rebates } \\
\text { - } & \text { Feed-in tariffs } \\
\text { - } & \text { Net metering } \\
\text { - } & \text { Property tax break } \\
\text { - } & \text { Sales tax } \\
& \text { exemption } \\
\text { - } & \text { Qualification for } \\
& \text { local R\&D } \\
& \text { incentives } \\
\text { - } & \text { Other financial } \\
\text { incentives }\end{array}$ & $\begin{array}{ll} & \text { Reduce water use } \\
& \text { and consumption } \\
\text { - } & \text { Reduce energy use } \\
\text { - } & \text { Lower production } \\
& \text { costs }\end{array}$ & $\begin{array}{ll} & \text { Improve } \\
\text { stakeholder } \\
\text { relations } \\
\text { - } & \text { Satisfy socially } \\
\text { responsible } \\
\text { investment (SRI) } \\
\text { portfolio criteria }\end{array}$ & $\begin{array}{ll}\text { - } & \text { Rural revitalization } \\
\text { - } & \text { Jobs } \\
\text { - } & \text { Economic } \\
& \text { development } \\
\text { - } & \text { Avoided } \\
\text { environmental } \\
\text { costs of fuel } \\
\text { extraction / } \\
\text { transportation } \\
\text { - } & \text { Avoided cost of } \\
\text { transmission and } \\
\text { distribution } \\
\text { infrastructure } \\
\text { expansion }\end{array}$ \\
\hline
\end{tabular}




\section{Risk Management}

The benefits that fall under the Risk Management category represent opportunities for firms to use clean energy technologies to hedge against future threats to income, capital expenditures, or escalating costs. Risk is inherent in the business world, and firms develop strategies for minimizing their exposure to it on a regular basis. The energy sector is no different. Although some risks in the energy sector remain consistent - whether the technology used is conventional or clean (such as the risk of drops in demand from a power producer's perspective) - clean energy technologies can help mitigate against some of the risks faced by firms involved with the energy sector.

Due to the complex nature of the energy industry, it faces a complex set of risks. This section deals with risks from across the spectrum, demonstrating many of the financial risks that clean energy technologies can help mitigate against. The risks discussed early in the section including fuel price volatility, grid outages, and uncertainty in futures markets - are familiar to firms currently engaged in the energy sector and may seem rather straightforward.

Opportunities to reduce exposure to those risks discussed later - including climate change and insurance - have not traditionally been considered in energy-sector business decisions. Integrating these latter types of values into the decision-making process may seem unintuitive to many, but such integration is now required of investor-owned utilities during the procurement process by the California Public Utilities Commission; some of those utilities - such as PacifiCorp and PG\&E - have already been considering potential carbon costs. As better methods for estimating the value of such risks become more rigorous and integrate the input of energysector representatives, however, the justification for their inclusion should become clearer.

\section{Hedge against fuel-price volatility}

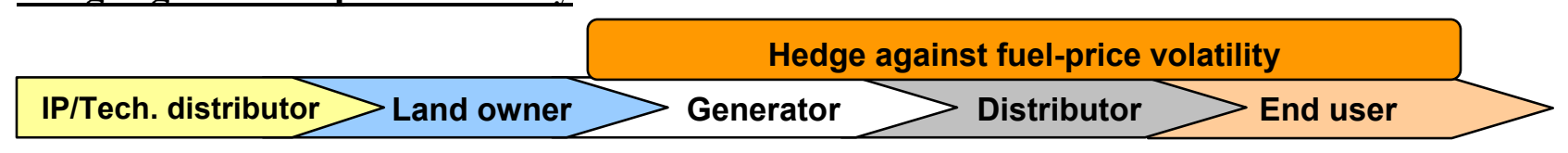

The first years of the 21 st century demonstrated how severe an impact fuel-price volatility can have on the cost of electricity and heating fuel in the retail market. Firms that choose to invest in clean energy technologies - especially those that do not require the purchase of fuel - can hedge against that volatility and ensure a constant cost of energy supplies; this holds true for the electricity market (e.g., wind and solar photovoltaic technologies in place of fossil and nuclear technologies), the energy market (solar thermal heating in place of natural gas), and the transport sector (hydrogen-based fuels in place of petroleum-based products). In doing so, firms can embark on financial-planning exercises with more certainty, earning the confidence of investors and protecting the firms from exposure to prices beyond their control.

However, some cleaner forms of energy require fuel inputs for operation. Energy products generated using biomass (e.g., ethanol or electricity from co-firing with biomass) require generators to obtain significant amounts of biomass. Because generators will need to obtain biomass grown in close proximity to the plant to control costs, however, most biomass will be 
produced domestically. This eliminates much of the risk associated with oil and natural gas price volatility.

Currently, the price of most utility-scale electricity generated by renewable technologies in the United States is locked in through long-term contracts. In fact, no information was available at the time of this study that any utility-scale projects in the United States had been financed without the long-term structure in place. In large part, this has been a requirement of those financing the projects, who see it as a way to secure their investment. Recently, Goldman Sachs purchased a utility-scale wind installation with the intent of employing it as a merchant power plant, which will sell electricity on the spot market; the firm also acquired a Zilkha Renewable Energy and the rights to more than 4,000 MW of wind projects under development. ${ }^{1}$ If investors are willing to accept the risk associated with short-term pricing schemes and the demand for electricity from renewable sources increases, the prevalence of long-term firm contracts may decrease. This may create some variability in price for renewables as well. The rate at which this change will take place, however, is uncertain.

\section{Value Chain Analysis}

The benefits of hedging against fuel-price volatility accrue to the generator of the electricity or fuel, the distributor, and to the end user.

In deregulated markets, electricity generators are not always able to pass along the full cost of fuel to their customers immediately, especially when high fuel prices are incurred on the dayahead or hour-ahead markets. Thus, generators of electricity that utilize clean energy technologies are able to avoid those losses.

In regulated electricity and energy markets, many regulatory authorities allow utilities to pass excess fuel costs to the customers. As a result, the end users (who do not participate in the decision about when to purchase fuel) pay for any fuel shortages through a supplemental charge on their monthly bill. Any avoided costs in a regulated market accrue to the end user.

As evidenced by soaring gasoline prices during the past couple of years, oil-price spikes are passed through the oil companies directly to the consumer. Oil giants do not have an incentive, therefore, to hedge against fuel-price volatility. Consumers, on the other hand, can achieve significant savings by utilizing clean energy technologies.

\section{Calculation}

- Bolinger, Wiser, and Golove ${ }^{2}$ recommend utilizing the guaranteed price of natural gas (or other fuels) as shown by existing market prices of futures, option, or swaps as the baseline for comparing the cost of clean energy technologies to conventional fuels. (In large part, this is due to the discrepancy between long-term natural gas price forecasts and forward natural

\footnotetext{
${ }^{1}$ Romero, S. (March 22, 2005) “Goldman Sachs Buys Zilkha, Expanding Interest in Wind Power." New York Times.

${ }^{2}$ Bolinger, M. and R. Wiser and W. Golove. (In Press) "Accounting for fuel price risk when comparing renewable to gas-fired generation: The role of forward natural gas prices." Energy Policy.
} 
gas prices of 2-10 years - the latter have been higher than the former.) By using the guaranteed prices, according to the authors, the comparison is between apples and apples (guaranteed prices and guaranteed prices) instead of between apples and oranges (guaranteed prices and forecast prices).

- Bolinger, Wiser, and Golove estimate that the premium currently paid for a 10 -year natural gas swap is approximately $\$ 0.005 / \mathrm{kWh} .^{3}$ The comparison is made to natural gas because, for electric generation, clean energy technologies are most likely to displace natural gas generation as a peaking fuel, rather than coal as a base-load fuel.

This premium can either be added to the cost of entering into a futures market contract, or it can be subtracted from the cost of fixed-price renewable energy investments.

- A methodology for calculating a least-risk portfolio of electricity generation can be found in Humphreys and McClain. ${ }^{4}$ Although this methodology would need to be updated to include developments in the generation technologies now considered viable on a utility level (e.g., wind and solar), it provides a basis for calculating the least-risk (rather than the least-cost) portfolio, based primarily on the level of risk associated with fuel price.

\section{Hedge against grid outages}

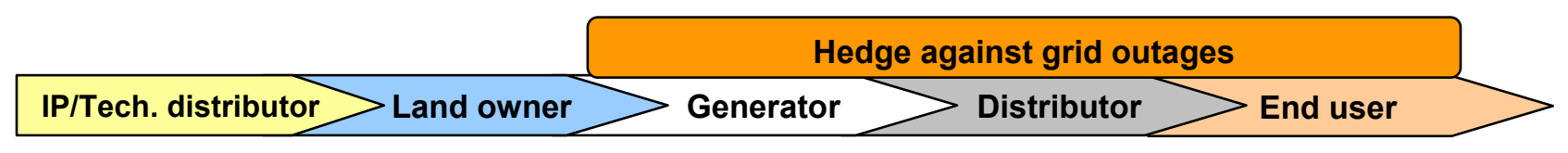

Even the most reliable electricity supply in the country is liable to experience an interruption in service at some point. Most power systems are between $99.9 \%$ and $99.99 \%$ reliable - meaning the average customer is without power for between 53 minutes per year and nine hours per year. ${ }^{5}$ Although it seems to be a small fraction of the year, outages of that magnitude can significantly impact operations for some customers. Furthermore, the United States has experienced several prolonged power outages in the past few years, e.g., California's rolling blackouts of 2000 and 2001, and the Northeast power outage of 2003 that left some customers without power for two days. If events of that magnitude continue to occur, end users whose businesses rely heavily on grid electricity will have an increased incentive to identify alternatives to conventional power supply.

In large part, companies interested in completely isolating themselves from the grid need to find distributed generation solutions that have higher levels of reliability than currently available renewable DG solutions provide. However, renewable DG solutions can serve to complement these more reliable conventional solutions. For example, renewable solutions may run side-byside with conventional $\mathrm{RE}$ in a form of cogeneration, which would reduce the fuel costs needed

\footnotetext{
3 Ibid.

${ }^{4}$ Humphreys, H.B. and K.T. McClain. (1998) "Reducing the Impacts of Energy Price Volatility Through Dynamic Portfolio Selection." The Energy Journal: 19(3): 107-131.

${ }^{5}$ Arthur D. Little. (2000) "Reliability and Distributed Generation." http://www.encorp.com/dwnld/pdf/whitepaper/wp_ADL_4.pdf
} 
to operate on-site power facilities. Alternatively, combined heat and power systems allow firms to utilize some of the by-products of power generation to heat facilities or processes, which reduces other energy costs. While renewables may not be a stand-alone solution to grid outages, they can be an integral part of the solution.

The technologies that do the most to hedge against grid outages - distributed generation (DG) and energy efficiency (EE) - also have what some utilities see as negative impacts on the utility industry. Because these technologies limit the amount of grid electricity needed by customers, utilities see these technologies as threats to their core business. ${ }^{6}$ Although a reduction in load helps reduce the cost of grid outages, allows utilities to push back the timeline for system upgrades during times of financial hardship, and can provide peak-shaving services, these technologies essentially compete with utilities for market share. From a generator's perspective, the benefits and costs of DG and EE technologies must be carefully weighed. From a societal perspective, however, a wider range of benefits and costs should be considered, which substantially changes the overall cost-benefit analysis.

\section{Value Chain Analysis}

Depending on the types of constraints on an existing power system - generation, transmission, and/or distribution - the level of financial viability for distributed generation technologies may vary. In general, however, the primary benefits for hedging against grid outages accrue to the electricity generator, distributor, and the end user.

Distributed generation and energy-efficient technologies reduce the load for generators - which can be especially critical during peak times, and can actually supply some power to the grid during outages. ${ }^{7,8}$ Because outages are a significant cost to a utility in terms of time, resources, and reputation, the ability to provide some customers with power through the backup distributed generation resources can reduce the impact. This can be especially critical because utilities are operating on increasingly smaller margins of excess capacity, due to a shortage of upgrades to generation, transmission, and distribution systems in the past decade. However, many utilities see the promotion of DG or EE technologies as a threat to their revenues and profits. ${ }^{9}$ Determining the economics on a case-by-case basis will help to clarify that statement.

In industries that are highly dependent on a consistent supply of electricity, even a brief power outage can cost millions of dollars ${ }^{10}$ (see Table 4 for examples). By taking advantage of the independence that distributed generation technologies offer, firms can mitigate against the risk of a power outage (similar to the one that crippled the Northeast in the summer of 2003) and take control of their own power supply.

\footnotetext{
${ }^{6}$ Note: A generator may employ EE technologies and practices internally, which would afford it the same benefits as other end users utilizing EE.

${ }^{7}$ Ibid.

${ }^{8}$ Perez, R. et al. (2005) “Availability of Dispersed Photovoltaic Resources During the August $14^{\text {th }} 2003$ Northeast Power Outage.” Proceedings of the American Solar Energy Society.

9 Arthur D. Little. (1999) "Distributed Generation: Understanding the Economics."

${ }^{10}$ Arthur D. Little. (2000) "Reliability and Distributed Generation." http://www.encorp.com/dwnld/pdf/whitepaper/wp_ADL_4.pdf
} 
Table 4. The Costs of Outages for Selected Commercial Customers ${ }^{11}$

\begin{tabular}{|l|l|}
\hline Industry & Average cost of downtime \\
\hline Cellular communications & $\$ 41,000$ per hour \\
\hline Telephone ticket sales & $\$ 72,000$ per hour \\
\hline Airline reservations & $\$ 90,000$ per hour \\
\hline Credit card operations & $\$ 2,580,000$ per hour \\
\hline Brokerage operations & $\$ 6,480,000$ per hour \\
\hline
\end{tabular}

\section{Calculation}

In general terms, Arthur D. Little analysts estimate that the cost of one severe outage for a business, regardless of the number of employees, can range from $75 \%$ to $150 \%$ of total annual energy expenditures; the extent of the authors" "severe" outage varies from one industry to another. ${ }^{12}$ Based on the targeted industry's reliance on reliable electricity supply and expected duration of the outage, economic losses may be estimated using that range.

More specifically, LaCommare and Eto estimate that grid outages cost the country about $\$ 80$ billion per year with a range of $\$ 30$ billion to $\$ 130$ billion. ${ }^{13}$ The authors cite other existing studies with best estimates ranging from $\$ 26$ billion per year to $\$ 150$ billion per year. The wide range of estimates indicates the importance of further studies in this area, based on more comprehensive and updated data on costs to individuals and to businesses. In the absence of such data, estimates from industry and firm-level analyses are the most reliable data available for lower-level analyses.

\section{Get ahead in the futures markets}

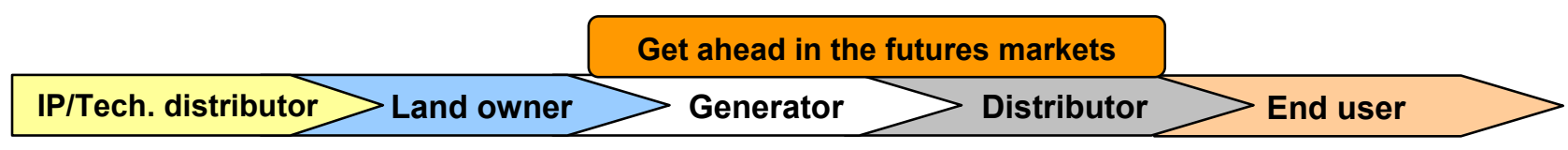

Going a step beyond avoiding costs by hedging against fuel-price volatility, firms can actually earn additional revenue in the futures markets by investing in some clean energy technologies. Knowing that the cost of fuel will remain relatively stable or will always be zero, generators with clean energy technologies can enter into futures contracts with great certainty about the price of

\footnotetext{
${ }^{11}$ Leiter, D. (10 May 2000) "Distributed Energy Resources." Prepared by the U.S. Department of Energy for Fuel Cell Summit IV, Washington, D.C., as cited in Little, Arthur D. (2001) Reliability and Distributed Generation. http://www.encorp.com/dwnld/pdf/whitepaper/wp_ADL 4.pdf

${ }_{12}$ Arthur D. Little. (2001) Reliability and Distributed Generation. http://www.encorp.com/dwnld/pdf/whitepaper/wp_ADL 4.pdf, analysis of California Energy Commission. (1997) "A survey of the implications to California of the August 10, 1996, Western States Power Outage." P700-97-003. http://www.energy.ca.gov/reports/70097003.html

A study completed by ICF Consulting considered a similar range of estimates $-80 \%-120 \%$ of electricity costs. ICF Consulting. (2003) "The Economic Cost of the Blackout: An issue paper on the Northeastern blackout, August 14, 2003.” http://www.icfconsulting.com/Markets/Energy/doc files/blackout-economic-costs.pdf

${ }^{13}$ LaCommare, K.H and J.H. Eto. (September 2004) Understanding the Cost of Power Interruptions to Electricity Consumers. Lawrence Berkeley National Laboratory, Doc. No. 55718.
} 
their electricity. Furthermore, these firms can avoid the costs associated with purchasing supplemental electricity supply through futures contracts to avoid running expensive units during times of higher fuel prices because their costs are constant over time. To the extent that merchant power plants can firm up the power they trade, they can take advantage of this certainty in the day-ahead and hour-ahead markets as well.

The level of success that a renewable generator can achieve in the futures market doesn't depend only on fuel costs. Futures contracts require that the generator be able to guarantee a fixed amount of electricity delivery. Currently, this remains a challenge for renewable sources such as wind and solar. The development of more accurate resource-prediction technologies and storage technologies that allow the energy produced by intermittent renewable resources to be stored and drawn on when demand is high will help to lower this hurdle. Concerns about intermittency are not as central for other renewables, such as biofuels and eventually hydrogen; these renewable sources will meet the firm quantity requirements of futures contracts with less difficulty.

In the forward markets, a variety of products are available to help firms hedge against risks associated with fuel-price volatility, changes in demand, and temporary changes in the supply mix (e.g., lower hydropower production in drought years). ${ }^{14}$ The following four products are the most popular:

- Futures are legal contracts that treat energy as a commodity in which the delivery date, location, quality, and quantity are specified. Parties agree on a price for the standardized unit of energy as a way to hedge against changes in fuel price.

- Price swaps are traded over the counter, which allow a buyer to pay a fixed price for energy, while a seller pays a variable price for the fuel (usually based on an index).

- Basis swaps lock in a fixed price at a location other than the standard delivery point (e.g., Henry Hub for natural gas), in an effort to eliminate the price difference between the physical delivery point and the price paid at the standard delivery point.

- Options allow generators to establish a minimum price for which they will sell electricity at a given time and allow end users to establish a maximum price that they will pay. Parties retain the flexibility ("option") to sell or buy energy at the market price, if it is more advantageous by paying a premium up front.

Because these products all serve essentially the same purpose - to hedge against the risk of market volatility going forward - they are all different types of forward markets.

\section{Value Chain Analysis}

Distributors, generators, and over-the-counter traders can all realize benefits on the electricityforward markets if they invest in clean energy technologies. Greater certainty about the price of fuel for clean energy technology (often zero) enables these market players to better evaluate their ability to profit from the sale or purchase of forward contracts backed by clean energy technologies.

\footnotetext{
${ }^{14}$ Background on derivatives markets in the energy industry is based on Stoft, S., T. Belden, C. Goldman, S. Pickle. (January 1998) Primer on Electricity Futures and Other Derivatives. Lawrence Berkeley National Laboratory, Document No. 41098.
} 
- For distributors or generators choosing to sell forward contracts, the ability to generate electricity at a cost below the cost of natural gas generation would provide two types of benefits. First, they could attract more buyers than natural gas generators. Second, depending on the price of natural gas, the price paid for clean energy-forward contracts could exceed the cost of generating the electricity, enabling clean energy generators to enhance their profits.

- Distributors purchasing forward contracts would be shielded from some of the risk because of the absence of fuel price volatility. If the electricity is actually delivered, they are assured that the spot market price at the time of delivery will not be significantly lower than the price they paid to secure their forward contract. Thus, the distributor will have a smaller risk of losing money through the contract, making them more attractive.

- Similarly, over-the-counter market makers would have the opportunity to make better decisions about when to buy or sell forward contracts. In this case, the absence of fuelprice volatility would enable the market makers to buy and sell forward contracts with lower risk, stabilizing their long-term profits.

\section{Prepare for regulatory change}

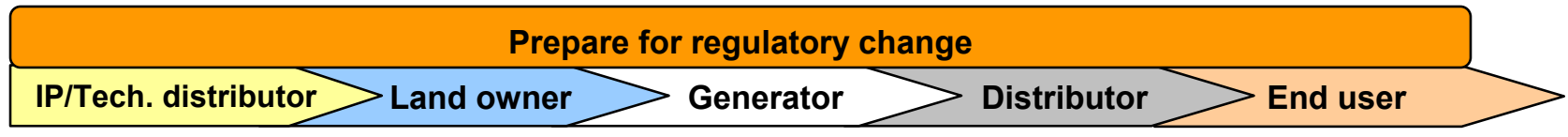

Anticipating that U.S. legislation will eventually restrict the emission of GHGs - and further restrict emissions of other pollutants - early adopters of clean energy technologies can mitigate the risk associated with tight compliance schedules by integrating clean energy technologies into their portfolios prior to the implementation of regulation. Studies have shown that early adoption can result in a cost savings after the implementation of new regulation, due to the avoidance of transaction costs. ${ }^{15}$ Furthermore, as leaders in the clean energy-technology sector, early adopters become the experts in costs, feasibility, and implementation and can help shape more effective regulation.

Any regulatory change will result in some costs to a business, especially the types of emissions regulations mentioned earlier. Some will require the installation of new technology, and nearly every regulation requires additional administrative costs for affected firms. At times, regulations lay out accelerated compliance schedules - firms that have not begun to consider the impacts of such regulations will have to make changes in a short amount of time, preventing them from taking advantage of lower costs associated with strategically planned changes.

Generators that are bound to comply with renewable portfolio standards (RPSs), for example, can benefit from early adoption. When regulations go into effect, there is a surge in demand for the renewable technologies, driving up prices and increasing the cost of compliance. If firms can

\footnotetext{
15 Pan, H. and D. Van Regemorter, “The costs and benefits of early action before Kyoto compliance," Energy Policy, Volume 32, Issue 13, September 2004, Pages 1477-1486. (http://www.sciencedirect.com/science/article/B6V2W-48PDB4T-8/2/6e6d60f19e1886a7fc779ed2c4d90962)
} 
plan their acquisition strategies far enough in advance, they can reduce their costs of compliance as well.

The institutional learning associated with some types of regulatory change - emissions trading, for example - may take many years; and companies that have found ways to integrate the requirements of the legislation will benefit from the experience. British Petroleum and Shell, among others, have demonstrated innovative strategies through their preparation for the GHG regulatory scheme in Europe. Its internal GHG trading scheme helped the company achieve reductions prior to regulatory enforcement, learn about its internal capability to reduce GHG emissions, and gain experience in how to profit from the carbon markets. ${ }^{16}$ Additionally, the favorable public relations that the approach generated helped BP take a leadership role in the public's eyes. Putting a dollar value on the extent to which the internal experience proved financially beneficial in the European markets is difficult, and much of the information that would be needed to calculate such a value is confidential. Working together with experienced partners, however, could facilitate an exchange of this type of detail.

A classic case put forward by advocates of early adaptation is DuPont's development of an alternative to chlorofluorocarbons (CFCs) prior to the international community's efforts to outlaw the chemical because of its toxic effects. Not only did DuPont meet reduction targets more quickly than its competitors, it was one of two companies with a market-ready replacement, giving it a competitive advantage and market dominance.

\section{Value Chain Analysis}

Any actor along the value chain who is facing limits on emissions or requirements to integrate clean energy technologies into their portfolio can benefit from an early response to regulation, even if it is a response to anticipated - rather than guaranteed - regulation.

Licensees will be in a better position than others to take advantage of the emissions-saving characteristics of their technology, if they understand the emerging markets and identify additional revenue streams for their technology. ${ }^{17}$ Understanding that a technology can help manufacturers in Europe meet their GHG emission reduction targets by 2012 would make a technology more attractive than one that had no effect on emissions reductions.

Generators and distributors may also benefit from early action, if they are subject to RPS requirements. Early adoption will help distribute the cost of compliance over more years, creating a smaller single-year impact on the financial statements; this would be beneficial for cash-strapped firms or those wishing to demonstrate consistent performance over time. Further, if a state RPS requirement changes or is delayed in processing, early actors can hedge themselves by picking a technology that is eligible for an RPS in a neighboring state or (potentially) region. Many states with RPSs allow renewables located in neighboring states to be eligible to help in-

\footnotetext{
${ }^{16}$ Cooper, G. (October 2002) “Jam tomorrow?” Environmental Finance. Available: http://www.environmentalfinance.com/2004/0410oct/carbon.htm

${ }^{17}$ Legal precedent has granted the rights to emissions-reduction credits to the firm that owns the intellectual property rights to the piece of technology that creates the emissions reductions. See Benefits of Emission Reductions section.
} 
state power providers meet their targets; ${ }^{18}$ thus, these technologies add more value for the firm that installs them, even in the absence of direct, in-state regulation.

\section{Reduce insurance premiums}

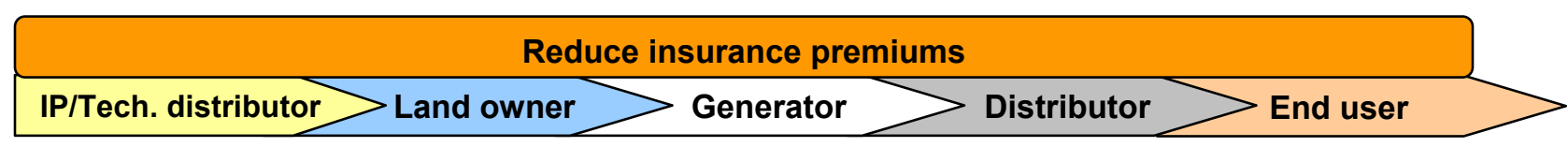

Although not a very widespread practice, insurance companies have provided discounts to customers investing in clean energy technologies in the past. ${ }^{19}$ Because global climate change is predicted to cost the insurance/reinsurance industries $\$ 150$ billion per year by $2014,{ }^{20}$ the industry stands to benefit from the reductions in GHG emissions realized by clean energy technologies and may reward companies that promote their adoption. In this sense, investing in clean energy technologies can be seen as a hedge against future payout by the insurance industry.

Clean energy technologies often span the divides among traditional insurance underwriting classes, however, posing unique challenges to developers seeking comprehensive insurance. In response, the insurance industry is considering potential Alternative Risk Transfer arrangements (e.g., captives, catastrophe bonds, and weather derivatives) as strategies for extending the bounds of insurability. ${ }^{21}$

In another effort to encourage the reduction of GHGs, SwissRe has introduced products that provide clearing and delivery guarantees on GHG emissions reduction projects; Aon and Storebrand (a Norwegian insurer) have similar programs. ${ }^{22,23}$ For firms involved in emissions trading - either in the European Union Emissions Trading Scheme (EU ETS) or for other reasons - this insurance will reduce the risk associated with entering into such agreements. Under such an arrangement, insurance companies agree to purchase (on the open market) any emissions reductions credits that the project fails to achieve. In doing so, the insurance company helps to reduce the risk for the project, thereby reducing the cost of capital and ensuring that the buyer will acquire the emissions reductions promised.

\footnotetext{
${ }^{18}$ Grace, B. and M. Bolinger. (May 2002) "Renewable Portfolio Standards: Background and Analysis for New York State.” Available: http://www.dps.state.ny.us/rps/rpsbackgroundpaper.pdf

${ }^{19}$ Mills, E. (2003) "The Insurance and Risk Management Industries: New Players in the Delivery of Energy-

Efficient and Renewable Energy Products and Services." Energy Policy 31: 1257-1272.

${ }^{20}$ Innovest, prepared for United Nations Environment Programme. (2002) Climate Change and the Financial Services Industry - Module 1: Threats and Opportunities. Available: http://www.unepfi.org/fileadmin/documents/cc fin serv ind module1 2002.pdf

${ }^{21}$ UNEP Finance Initiative Climate Change Working Group. (June 2004) "CEO Briefing: Renewable Energy." Available: http://www.unepfi.org/fileadmin/publications/cc/CEO briefing renewable energy 2004.pdf

${ }^{22}$ Walker, C.T. (17 February 2005) "Managing Risk in a Carbon Constrained World." Swiss Re. Presented at the UN Foundation's “One Day After Kyoto: Next Steps on Climate” conference, New York, NY. Available: http://www.swissre.com/INTERNET/pwsfilpr.nsf/vwFilebyIDKEYLu/ALIY69VCLD/\$FILE/OnedayafterKyotopresentation.ppt

${ }^{23}$ Mills, E. (2003) "The Insurance and Risk Management Industries: New Players in the Delivery of Energy-

Efficient and Renewable Energy Products and Services." Energy Policy 31: 1257-1272
} 
Generators that use clean energy technologies may try to negotiate better terms with the provider of their employees' health insurance, because it reduces the release of pollutants that are harmful to the health of humans and the environment. Because many of the firm's employees are likely to live in the area surrounding the plant, their health would be affected by the plant's emissions; ${ }^{24}$ their risk of illness due to the plant's emissions would likely decrease as well. Although this strategy may be a bit of a stretch in today's market, the value is available if a firm and its health insurance provider are willing to work through the complex process of assigning a monetary value to it.

\section{Value Chain Analysis}

Due to the diversity of products available from insurance companies, the types of value that will fit under this category are quite disparate. Depending on which technology is examined, the financial benefits may go to almost any actor in the value chain.

Investors may be able to benefit from a higher credit rating resulting from risk assessment assistance from the insurance industry. ${ }^{25}$ Alternately, they may be able to earn a small discount on one or more types of insurance for their business, because they are promoting clean energy technologies (which reduce more greenhouse gas emissions than conventional technologies).

Whichever party has ownership rights over the emissions-reductions credits created by a clean energy technology may benefit from clearing and delivery guarantees, if they decide to sell the credits to another party. These guarantees help reduce risk and can, as a result, help reduce the cost of capital. Because ownership of the emissions-reduction credits are originally assigned to the owner of the technology - but can be sold or passed along to other actors in the value chain this can affect almost any actor, depending on how the ownership issue is handled.

Lower health-insurance premiums would benefit both the generator and its employees, assuming that the two parties share the cost of the monthly health-care premium. In a sense, it could also accrue to society as a whole; but attempting to quantify that value is beyond the scope of this type of effort.

Vine, Mills, and Chen ${ }^{26}$ outlined more than a dozen types of insurance losses that energyefficient and renewable energy technologies enable firms to avoid. Some of the avoided losses included boiler and machinery risk, builder's risk, business interruption coverage, environmental liability, and contractor's liability. The report also details the extent to which national laboratories had examined the financial value associated with these benefits at the time of the report. Some additional work has been done since then.

\footnotetext{
${ }^{24}$ Vhrovcak, M.B. and Tomsic, Z. and Debrecin, N. (2005) "External costs of electricity production: case study Croatia." Energy Policy: 33:1385-1395.

${ }^{25}$ UNEP Finance Initiative Climate Change Working Group. (June 2004) "CEO Briefing: Renewable Energy." Available: http://www.unepfi.org/fileadmin/publications/cc/CEO briefing renewable energy 2004.pdf

${ }^{26}$ Vine, E., E. Mills, and A. Chen. (August 1998) Energy Efficient and Renewable Energy Options for Risk Management and Insurance Loss Reduction: An Inventory of Technologies, Research Capabilities, and Research Facilities at the U.S. Department of Energy's National Laboratories. Lawrence Berkeley National Laboratory, Document No. 41432.
} 


\section{Calculation}

When calculating the health-insurance portion of the insurance benefits, many available studies identify the impacts that fossil-fuel burning has on human health. Some of these assign a value to the injury based on the Value of a Statistical Life Year (VSLY), while others assign damage based on health-care costs required to treat the conditions that the pollutants cause - and others examine the cost based on lost productivity. Depending on the circumstances, it is almost guaranteed that a study with a cost savings estimate can be found, showing relevance to specific geographic location, type of combustion, fuel used, and other characteristics.

States considering implementing an RPS have also assigned value to the improvement in public health. New Jersey, for example, conducted a comprehensive economic analysis of the impact that the RPS would have on several aspects of morbidity and mortality within the state. ${ }^{27}$ Calculating the costs of such reductions would need to be done at a state or local level for greatest accuracy.

Once these values have been estimated, the firm must try to determine how much this would be worth to a health-insurance provider. Until further research is conducted, a collaborative effort with a willing health-insurance provider would probably be the most effective way to calculate that figure.

\section{$\underline{\text { Reduce future risks of climate change }}$}

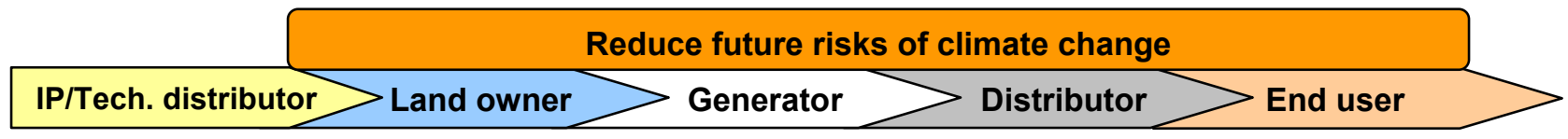

Employing clean energy technology can help a firm reduce its contribution to global climate change by reducing its emissions of GHGs. The increase in climate variability has increased the risk of disaster for many firms, especially those involved in agriculture-dependent industries and those conducting business in developing countries. Some of the more proactive firms have already analyzed the effect that climate change might have on their operations. At the country level, such studies are even more prevalent, due to obligations for all countries participating in the United Nations Framework Convention on Climate Change (UNFCCC) - the convention that set the stage for the Kyoto Protocol - to submit regular reports. ${ }^{28}$ In other cases, such as the agriculture sector, academics have conducted the analysis on behalf of an industry at the state or national level. Consequently, firms realize that climate change will not be free, especially in coastal and equatorial regions.

\footnotetext{
${ }^{27}$ Center for Energy, Economic and Environmental Policy. (December 8, 2004) Economic Impact Analysis of New Jersey's Proposed 20 Percent Renewable Portfolio Standard. Prepared for NJ Board of Public Utilities - Office of Clean Energy. Available: http://www.cleanenergystates.org/library/nj/RPS Report NJ-Final.pdf

${ }^{28}$ See, for example, the United States Climate Action Report 2002: Third National Communication Under the UNFCCC, Chapter 6: Impacts and Adaptation. http://www.usgcrp.gov/usgcrp/Library/thirdnatcom/chapter6toc.htm An index of all National Communications for developed countries, which are due for updates by January 1, 2006, is available at http://unfccc.int/national_reports/annex i natcom/submitted natcom/items/1395.php

An index of all National Communications for developing countries is available at http://unfccc.int/national_reports/non-annex_i_natcom/items/2979.php
} 


\section{Value Chain Analysis}

It is true that a given firm's impact on the global climate depends on its industry, size, and existing environmental ethic; and any one firm's impact on climate is tiny compared to the rest of Earth's human population. Further, a firm's impact may not be proportional to the relative impact that climate change will have on its operations. However, the fact that this may be a consideration in some cases does warrant the inclusion of this value here. For example, farmers have the opportunity to mitigate some of their impact on climate by utilizing their residual corn stover as a biofuel, or by leasing out part of their land for a wind turbine. In doing so, they reduce their dependence on fossil fuels and their impact on climate.

The benefits of reducing the impacts of a firm's operation on global climate will accrue both to society and to the firm itself. Determining the level of impact on the firm will require an examination of the extent to which the firm's activities depend on climate and the extent to which the operations impact climate change. Some industry-level studies have been completed and may serve as a starting point. ${ }^{29}$

The difficulty with quantifying the benefits associated with reducing a firm's contribution to climate change is that the benefits are widely dispersed, such that those firms that fail to act still reap the benefits created by the compliant firms. In other words, it is a free-rider problem, and climate is a public good. That does not negate the benefits associated with acting to reduce impacts on climate, but it may explain some firms' reluctance to even consider this as an additional value to their investment in clean energy technologies. This value may more appropriately be considered a Societal Economic Value, but some firms have demonstrated the potential to calculate the value at the firm level. Thus, it is placed in this section instead.

\footnotetext{
${ }^{29}$ See, for example, Kelly, D.L. and C.D. Kolstad and G.T. Mitchell. (Forthcoming) “Adjustment costs from environmental change." Journal of Environmental Economics and Management (for an assessment of costs to agriculture in the Midwestern United States); Sohngen, B. and R. Alig. (October 2000) "Mitigation, adaptation, and climate change: results from recent research on U.S. timber markets." Environmental Science and Policy 3(5): 235248 (for an assessment of costs in the timber sector).
} 


\section{Benefits of Emissions Reductions}

In addition to the power they generate, conventional energy technologies - including transportation fuels, utility-generated electric power, and those that generate power on-site at industrial and commercial firms - generate a variety of air, water, and solid-waste emissions. Local, state, and/or national governments regulate all of these emissions in one way or another, but not all levels of government regulate all emissions. For example, in the United States, the federal Clean Air Act has provisions for toxic air emissions (such as mercury and dioxins) and criteria air pollutants (such as sulfur dioxide and particulate matter); and the federal Clean Water Act regulates toxic water pollutants and thermal discharges. But states are responsible for implementing both sets of regulations; and local governments often regulate solid waste, either at the source or at the landfill. Carbon dioxide $\left(\mathrm{CO}_{2}\right)$ is not currently regulated in the United States, but it is regulated European Union-wide.

Although $\mathrm{CO}_{2}$ is not recognized as a pollutant in the United States from a policy perspective, many firms are taking action to evaluate their emissions of this greenhouse gas in anticipation of future regulation. Conventional sources of energy are responsible for emitting more GHGs than any other sector worldwide ${ }^{30}$ - the U.S. energy and transport sectors accounted for more than $86 \%$ of all GHG emissions nationwide in $2003 .{ }^{31}$ Thus, any future rulemaking will impact the energy sector more than any other. In anticipation of such regulation, different methodologies have been developed for valuing carbon in the United States. Some closely resemble the carbon markets in Europe, while others are uniquely American. Because many firms currently using or interested in using clean energy technologies are multinational in nature, this analysis will examine strategies for valuing carbon emissions in both the regulated and unregulated markets.

Emissions are regulated in a variety of ways; some are aimed at reducing the absolute amount of emissions released to the environment, while others aim to reduce the intensity of emissions (e.g., per unit of GDP). ${ }^{32}$

- Command and control. Legislation may specify that all firms in an industry must achieve a specific level of emissions reductions by a specific date with no flexibility on the location or amount of those reductions.

- Emissions caps/cap and trade. Alternatively, market-based regulations place a cap on the volume, weight, or concentration of a substance that may be emitted, either at the firm level or at a state, regional, or national level. Regulated firms may be responsible for achieving those reductions on their own, or they may be allowed to trade emissions reduction credits (ERCs) within specific geographic boundaries (anything from a watershed to the entire globe). The latter system, known as a cap-and-trade system, is ostensibly more economically efficient than command and control, because it allows firms with higher marginal abatement costs to pay firms with lower compliance costs to achieve the emissions reductions. In the

\footnotetext{
${ }^{30}$ Intergovernmental Panel on Climate Change (IPCC). (2001) Third Assessment Report (Section 3.4.1). Available: http://www.grida.no/climate/ipcc tar/wg1/109.htm

${ }^{31}$ U.S. Environmental Protection Agency. (April 2005) Inventory of U.S. Greenhouse Gas Emissions and Sinks: 1990-2003. EPA Document No. EPA 430-R-05-003.

${ }^{32}$ This framework of policy options, though a common one, was adapted from Hobbs, B.F. and P. Centolella. (1995)

"Environmental Policies and Their Effects on Utility Planning and Operations." Energy 20(4): 255-271.
} 
United States, the cap-and-trade system has become more popular in the past decade (especially in the context of the Acid Rain Program), and it is only recently gaining popularity in Europe.

- Emissions taxes. As a check on firms that release emissions deemed hazardous to human or environmental health, the government may assess fees for emissions on a per-ton or perconcentration basis, another form of market-based regulation. Firms that reduce emissions avoid the regulatory costs associated with them.

Emissions can also be regulated in more indirect ways. Firms that fail to prevent spills of - or adequately contain - toxic and hazardous material stored on-site run the risk of impairing the future use of their property for other purposes. The federal government may hold property owners liable for damage through the Comprehensive Environmental Response, Compensation, and Recovery Act (CERCLA); the Resource Conservation Recovery Act (RCRA); Superfund; and other laws. For example, old gas stations - which make up more than half of the brownfields in the United States - required millions of dollars of remediation to repair the damage done by leaky underground storage tanks. ${ }^{33}$ If the property owner seeks to sell such contaminated sites, remediation must be completed prior to the sale, or else the value of the property is reduced significantly. Clean energy technologies can help avoid such contamination.

In short, emissions reductions gained through the deployments of clean energy technologies or efficiency improvements help to achieve risk-management goals and can enhance the bottom line, both immediately and over time. Firms can generate additional revenue by selling excess emissions reductions on existing markets, whether those markets are compliance-based or voluntary. On the other hand, firms can avoid costs associated with regulatory fees and taxes applied to emissions by utilizing clean energy technologies. In the long run, firms that avoid contaminating the land on which their operations are located, avoid characterization as a brownfield and protect their property value.

\section{Generate emissions reduction credits / offsets}

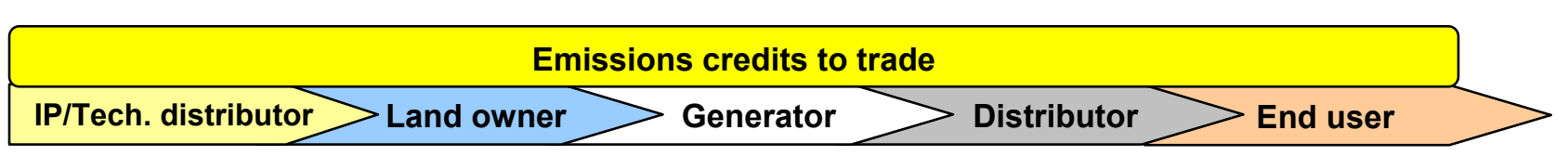

The primary way that firms utilizing clean energy technologies can take advantage of lower emissions relative to conventional energy technologies is through cap-and-trade emissions markets. In the United States, compliance markets currently exist for emissions of sulfur dioxide $\left(\mathrm{SO}_{2}\right)$ produced by power plants, as well as for nitrogen oxides (NOx) produced by large stationary sources in regional markets. More robust markets are developing for water pollutants tracked under the Environmental Protection Agency's Total Maximum Daily Limits (TMDL) program (specifically nutrients and sediment load); and the Bush Administration included provisions for trading airborne mercury produced by new and existing coal-fired power plants in

\footnotetext{
${ }^{33}$ Truini, J. (July 22, 2002) “EPA Gives \$3.8 million for Petrol Cleanups.” Waste News 8(6): 12.
} 
the Clean Air Mercury Rule of 2005. ${ }^{34}$ Markets for trading other types of air emissions and criteria pollutants other than $\mathrm{NOx}$ and $\mathrm{SO}_{2}$ currently do not exist.

Examples of regulatory programs at the state, regional, and local level that complement these national structures include

- Southern California (RECLAIM) - cap-and-trade for $\mathrm{SO}_{2}$ and $\mathrm{NOx}$

- Western States (WRAP) - cap-and-trade for regional haze

- Chicago - cap-and-trade for volatile organic compounds (VOCs)

- New Hampshire - NOx

- Connecticut and New York - non-ozone season NOx

- Ozone Transport Commission's NOx Budget Program

- Massachusetts and New Hampshire - power-sector caps on $\mathrm{CO}_{2}$

- Northeastern states - Regional GHG (RGGI) cap-and-trade initiative (not finalized)

An important differentiation needs to be made when accounting for emissions reductions in a trading scenario. Firms that release the pertinent emission are allotted (or purchase) emission allowances. For each allowance, the firm is permitted to release a specific amount of the emission (e.g., one ton of $\mathrm{SO}_{2}$ or one pound of mercury). If a firm reduces its emissions below the level of emission allowances that it holds, then it may sell the excess allowances on the market. For example, if a firm reduces its overall consumption of electricity generated on-site by implementing energy efficiency measures, it will have excess emission allowances to sell.

Firms that do not release the regulated emission may also participate in the market. Because they do not emit the pollutant, however, they do not need to obtain emission allowances. Instead, if a firm implements a project that produces fewer emissions than would be produced in performing the same task in the absence of the project, the firm generates emission offsets or certified emissions reductions. ${ }^{35}$ In the case of clean energy technologies, firms may generate emissions reduction credits and they may reduce the level of emissions released, freeing some emission allowances for sale on the market; of course, there would need to be some care taken to avoid double counting. Both emissions-reduction credits and emission allowances have value associated with them that should be captured in a total value proposition.

Emissions of GHGs have been addressed separately in the United States and the rest of the world. In the absence of U.S. regulations, a voluntary market for GHGs began in late 2003 - the Chicago Climate Exchange (CCX). Through CCX, firms make a legally binding commitment to reduce their GHG emissions by $1 \%$ in $2003,2 \%$ in $2004,3 \%$ in 2005 , and $4 \%$ in $2006 .{ }^{36}$ As of mid-July 2005, nearly 100 organizations had joined the exchange; and 1 metric ton of $\mathrm{CO}_{2}$ -

\footnotetext{
${ }^{34}$ U.S. EPA. (2005) “Clean Air Mercury Rule: Basic Information.” Available: http://www.epa.gov/oar/mercuryrule/basic.htm

${ }^{35}$ The term "certified emissions reductions" is unique to the Kyoto Protocol, while emission offsets is a more general term.

${ }^{36}$ The baseline used is the annual average of emissions of included facilities in the years 1998, 1999, 2000, and 2001. Source: Chicago Climate Exchange. (Undated) “Chicago Climate Exchange: About: Program.” Available: http://www.chicagoclimateexchange.com/about/program.html [Accessed July 14, 2005]
} 
equivalent (the unit used for trading GHG emissions), vintage 2005, was selling for $\$ 2.01 .^{37}$ As noted above, states in the Northeast United States have also begun to implement limited statelevel $\mathrm{CO}_{2}$ regulation.

Another option for selling emissions in the United States is through The Climate Trust, an Oregon-based nonprofit organization that helps finance projects based on their potential to reduce GHG emissions. In this case, it is not allowances that are for sale but emissions offsets. As of this writing, The Climate Trust had saved 1.6 million metric tons of $\mathrm{CO}_{2}$-equivalent emissions by investing $\$ 4$ million.

The European Union's Emissions Trading Scheme (EU ETS) went online in early 2005 as the first international compliance market for GHGs; multinational companies also may be able to take advantage of profit opportunities in this market. Each country in the EU developed a national allocation plan (NAP) that identified which industries would be subject to the cap-andtrade system and how the emissions credits would be assigned. The EU ETS, however, is an EUwide market - the emissions allowances from all member countries are aggregated and can be traded without regard for national borders. Entities that implement GHG offset projects in certain qualifying countries (such as Eastern Europe or the developing world) may generate certified emissions reductions that can also be sold on the EU ETS; joint project development work with these two groups of countries is allowed under provisions of the Kyoto Protocol called Joint Implementation and the Clean Development Mechanism, respectively. As of mid-July 2005, 1 metric ton of $\mathrm{CO}_{2}$-equivalent, vintage 2005, was trading for $€ 24.67 .^{38}$

As the first compliance-oriented online trading system, the ETS is encountering challenges related to quantification and certification. While investors had submitted more than 170 Clean Development Mechanism projects to the UN-appointed approval body, the board had only approved 12 methodologies as of July 2005. With few offset projects available for traders to buy, the price of one ton of carbon-equivalent on the ETS increased from \$9 initially to more than \$26 in late October 2005. ${ }^{39,40}$

\section{Value Chain Analysis}

Depending on the type of emissions considered, the rights to any revenue generated by trading emissions-reduction credits will belong to different actors along the value chain. In welldeveloped markets, such as the $\mathrm{SO}_{2}$ and $\mathrm{NOx}$ markets in the United States, market rules and experience have clarified which firms receive the proceeds associated with selling emission allowances. In other areas, such as GHG emissions and watershed trading, the markets are still in the development stage, and the rules for allocating rights to the emission allowances are still

\footnotetext{
${ }^{37}$ Chicago Climate Exchange. (2005) Home Page. Available: http://www.chicagoclimateexchange.com/ [Accessed July 14, 2005]

${ }^{38}$ The price difference between CCX and EU ETS prices is likely dependent on the compliance-based nature of the ETS market and the level of reductions required. In total, the EU committed to an $8 \%$ reduction in GHG emissions by 2012, which requires a more aggressive reduction timeline. Source of ETS pricing data: Point Carbon. (2005) Home page. Available: http://www.pointcarbon.com/category.php?categoryID=364 [Accessed July 15, 2005]

${ }^{39}$ Gibbs, W.W. (September 2005) “How should we set priorities?” Scientific American, 293(3): 108-115.

${ }^{40}$ October 2005 price obtained from www.pointcarbon.com
} 
evolving. With few exceptions, however, market rules generally dictate that the generator of emissions owns the emission allowances and, therefore, can benefit from emissions reductions.

The EPA created the NOx Budget Trading Program to help states subject to regulation under the NOx State Implementation Plan (SIP) Call and those involved in the Ozone Transport Commission (OTC)'s NOx Budget Program. ${ }^{41}$ During the NOx Budget Trading Program's first year (2003), emissions in states required to comply were down by $30 \%$ compared to 2002 levels. ${ }^{42}$ The parties required to participate in this trading scheme are the firms that emit NOx emissions; thus, the emitters (usually electric generators or other industrial facilities) that reduce their NOx releases are able to generate revenue through the NOx Budget Trading Program. The savings may be retained at the firm or redirected to consumers downstream.

In a similar way, the primary financial benefits in the EPA's $\mathrm{SO}_{2}$ market (under the Acid Rain Program) accrue to the owner of an electric-generating unit. ${ }^{43}$ Any individual or firm may participate in the market, but entities other than electric-generating units are not guaranteed allowances up-front; nongenerators must buy-in to the market or create offset projects that they can sell to generators needing additional credits. In this case, the market gives the rights for emissions allowances to the generator (or trader), not to the firm that created the technology. In the case of the $\mathrm{SO}_{2}$ market, tech firms can capitalize on part of the value of the emissions credits by integrating it into their pricing.

Rights to emission allowances on the GHG markets are neither clearly defined nor consistent across markets. Emissions from electric-generating units, fossil fuel combustion, and industrial processes are eligible for trade on the CCX; in this case, the generator/manufacturer owns title to the emission allowances. ${ }^{44}$ In the EU, the directive governing the allocation of GHG emission allowances specifies that each country will issue emissions allowances to the operators of GHGemitting equipment. ${ }^{45}$

Other $\mathrm{CO}_{2}$ markets may have different specifications about ownership of the emission allowances. In Canada, for example, legal precedent has determined that ownership of the $\mathrm{CO}_{2}$ emissions-reductions credits begins with the firm that owns the technology responsible for

\footnotetext{
${ }^{41}$ Note: The NOx Budget Trading Program is a successor to the OTC NOx Budget Program and is a seasonal program only. The compliance period is the same as the ozone season - May 1 to September 30 - and the states subject to this regulation include all states east of the Mississippi River except Vermont, Maine, and Wisconsin; in addition to Missouri and the District of Colombia. Facilities subject to regulation under the Acid Rain Program may have additional targets above and beyond those established by the NOx Budget Trading Program.

${ }^{42}$ U.S. EPA Office of Air and Radiation - Clean Air Market Programs. (August 2004) NOx Budget Trading Program: 2003 Progress and Compliance Report. Available: http://www.epa.gov/airmarkets/cmprpt/nox03/noxreport03.pdf

43 "Acid Rain Program: 1998 Reallocation of Allowances." (September 28, 1998) Federal Register 63(187): 5170551766. Available: http://www.epa.gov/fedrgstr/EPA-AIR/1998/September/Day-28/a25317.htm

${ }^{44}$ Chicago Climate Exchange. (2005) "Frequently Asked Questions." Available: http://www.chicagoclimateexchange.com/about/faq.html\#4 [Accessed July 15, 2005]

${ }^{45}$ European Parliament and Council. (October 13, 2003) "Directive 2003/87/EC of the European Parliament and of the Council establishing a scheme for greenhouse gas emission allowance trading within the Community and amending Council Directive 96/61/EC." Official Journal of the European Union L 275: 32-46.
} 
creating the emissions reductions. ${ }^{46}$ These emissions reductions can then be transferred when the technology is sold for use; as a result, this added benefit can enhance its marketability and be incorporated into the price of the technology by the IP owner.

Although EPA's Water Quality Trading Policy was adopted in 2003, the small number of trades that have occurred do not provide adequate guidance for generalizing about which actor in the value chain can profit from these types of trades. Currently, trading systems exist on a watershed level, and each program includes different types of dischargers. The Connecticut Nitrogen Exchange, for example, primarily involves municipal wastewater treatment facilities. ${ }^{47}$ The San Joaquin Valley Grasslands Program involved all entities holding NPDES permits. ${ }^{48}$

\section{Calculation}

It is not possible to estimate an "average emissions reduction" figure, because of the diversity of clean energy technologies available and the range of baselines that can be used to compute such reductions. On a case-by-case basis, however, emission reductions may be calculated based on the project size and lifetime, the baseline case including what is being offset by the technology, and the technologies being used. Life-cycle analyses of each technology provide an excellent source of information to calculate the level of emissions reductions that can be expected.

To place a value on the emissions reductions, it is necessary to obtain the market prices for emissions at the time of the project:

- $\mathbf{S O}_{2}$ : Futures prices for $\mathrm{SO}_{2}$ on the $\mathrm{CCX}$ can be found at www.chicagoclimateexchange.com $;{ }^{49}$ historic $\mathrm{SO}_{2}$ prices can be found at the EPA's Web site, http://www.epa.gov/airmarkets/trading/so2market/alprices.html; information on clearing prices at auction for $\mathrm{SO}_{2}$ allowances can be found at http://www.epa.gov/airmarkets/auctions/2005/index.html;

daily price quotes are available from Evolution Markets (http://www.evomarkets.com/emissions/index.php?xp1=so2) and other brokerage firms

- NOx: Historic prices for NOx emission allowances can be found in the annual NOx Budget Trading Program Progress Report (http://www.epa.gov/airmarkets/fednox/index.html); real-time pricing is available through Evolution Markets (http://www.evolutionmarkets.com/emissions/index.php?xp1=sipnox) and other brokerage firms.

\footnotetext{
${ }^{46}$ Chant, P. (2004) "Environmental Growth Strategy.” Presentation to The Licensing Executive Society's 2004 Annual Meeting 2004 in Boston, MA, on behalf of The FReMCO Group.

${ }^{47}$ Johnson, G. (2003) "Reducing Hypoxia in Long Island Sound : The Connecticut Nitrogen Exchange." Presented on behalf of the Connecticut Department of Environmental Protection at the EPA National Forum on Water Quality Trading, July 22-23, 2003. Available: http://www.epa.gov/owow/watershed/trading/johnson.ppt

${ }^{48}$ Young, T. (2003) "Protecting a Wildlife Refuge Through Selenium Reductions." Presented on behalf of Environmental Defense at the EPA National Forum on Water Quality Trading, July 22-23, 2003. Available: http://www.epa.gov/owow/watershed/trading/young.ppt

${ }^{49}$ See Hedge Against Fuel Price Volatility section above for discussion about the validity of using futures pricing as a basis of comparison.
} 
- CO2: $\mathrm{CO}_{2}$ emissions prices are posted for the EU ETS at www.pointcarbon.com, and prices on the U.S. voluntary market can be found at www.chicagoclimateexchange.com. Other methods of valuing carbon, such as through renewable energy certificates (RECs) and public utility commission regulation, can be found in the Policy section of this report.

- Watershed trading: Since trading on EPA's Watershed market for TMDL pollutants is not commodified like the other markets identified in this section, it will be more difficult to establish market value. Some case studies have been conducted, however, with some including estimates of expected financial benefits from the trades. Those case studies can be found at http://www.epa.gov/owow/watershed/trading/traenvrn.pdf. More recently updated links to specific trading programs can be found at http://www.epa.gov/owow/watershed/trading/tradelinks.html.

Some utilities are concerned about the effect on quantifiable emissions reductions of the predictability of wind and solar resources and its impact on dispatch planning. Prediction systems are rapidly improving, allowing utilities to schedule renewable resources as part of their regular dispatch. However, utilities may keep some additional (nonrenewable) units "on" to avoid dropping load, in the event that the renewable resource does not provide the expected generation. Variation in this practice from one utility to the next can affect the actual amount of emissions reductions realized by a specific renewable installation. As the prediction methodologies continue to improve and utilities become more comfortable working with renewable resources, however, this challenge should diminish.

\section{$\underline{\text { Reduce fees for emissions }}$}

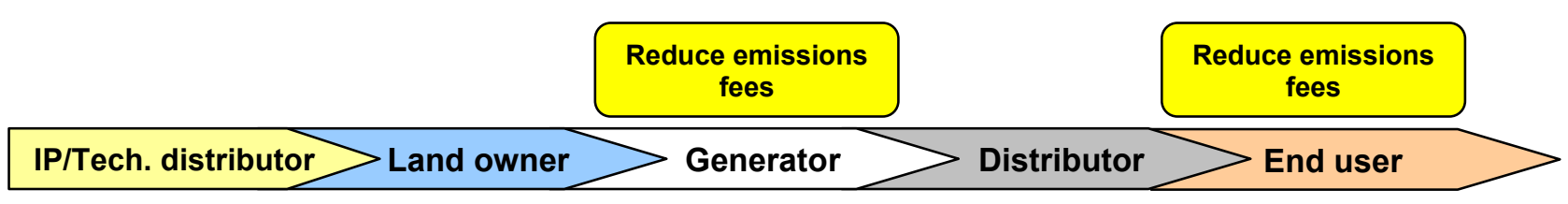

International treaties and domestic laws have recognized the damages to human and environmental health that many of the air, water, and waste emissions associated with the production of energy can impose. Yet, in the absence of regulation, the costs of these damages are not fully captured in the cost of goods sold; hence, no tangible incentive exists for firms to reduce emissions in this context. In response, many governments have established limits on the concentration of these pollutants in the atmosphere or water to protect human health and the environment. As a way to recover the costs of administering those regulatory programs or the costs of removing the wastes from the public sphere, governments assess fees (taxes) on firms that exceed certain emissions limits. While the fee structure usually does not capture the full cost of the emissions to society, this market-based mechanism does create some economic incentive for reducing emissions. By switching to clean energy technologies, firms can avoid these costs, adding to the value of the technology.

Air emissions: In the United States, states are responsible for achieving the goals of the Clean Air Act, which establishes a process for imposing limits on emissions from significant sources 
and quantifies clean air standards. ${ }^{50}$ Most states in the United States apply the fee-for-emissions strategy, and a parallel scheme exists in the United Kingdom (UK) through the Local Authority Pollution Control process; other EU member states have similar systems in place to achieve emissions targets established in the European Commission's Air Quality Framework Directive. The level of fees assessed differs from one jurisdiction to the next, but the principle is the same. Air emissions fees can apply to both stationary (e.g., power plants) and mobile (e.g., vehicle) sources.

Water emissions: Wastewater emissions are regulated in one of two ways, depending on how a firm deals with its effluent. For sites that release waste to the sewer system - allowing a municipal wastewater treatment to treat it before re-release to the open waters - a local wastewater treatment plant is responsible for regulation. For large industrial customers, the municipal wastewater treatment plant generally conducts regular facility inspections to assess compliance and may require additional end-of-pipe treatment or levy fines if the effluent fails to comply with established limits.

On the other hand, firms that treat large volumes of wastewater on-site must obtain a National Pollution Discharge Elimination System (NPDES) permit from the relevant state agency and pay associated fees. Reductions in the amount of wastewater emitted can result in reductions in the cost of permitting. Cleaner wastewater can reduce the costs associated with in-house treatment as well.

Solid-waste disposal: Conventional energy generation requires the disposal of several different types of waste, each of which requires a fee. Some materials can be disposed of as municipal waste; firms generally negotiate rates directly with the waste hauler with few associated administrative requirements. Disposal of toxic and hazardous wastes, however, entails the submission of reports to state and federal regulatory agencies under several different statutes. Coal plants, for example, must dispose of large amounts of barium, copper, and manganese compounds and mercury; oil refineries must dispose of a slew of toxic chemicals. Disposal fees for such wastes are significantly higher than those for traditional solid waste, because of the precautions that must be taken to contain them.

Clean energy technologies can help firms avoid or reduce many of the costs associated with emissions. At the site of generation, technologies such as wind and solar release no emissions. Other technologies present different opportunities for avoided costs.

\section{Value Chain Analysis}

Almost all of these avoided costs can be calculated at the point of generation. Firms that choose to install clean energy technologies in place of conventional systems receive these benefits, because fees are generally calculated by the amount of emissions released at a particular facility. These savings may be captured by the firm, or they may be passed along to downstream customers.

\footnotetext{
${ }^{50}$ U.S. EPA. (1993, updated 2002) "Plain English Guide to the Clean Air Act.” Available: http://www.epa.gov/oar/oaqps/peg_caa/pegcaain.html\#index [Accessed July 15, 2005]
} 
In two instances, end users of the clean energy technology may reap the benefits of emissions reductions. States and some counties require vehicles to undergo emissions testing prior to registration and assess a fee when the testing is performed. Vehicles using cleaner-burning fuels may be exempted from undergoing such emissions tests, enabling owners to avoid the associated fees. The state of Washington, for example, exempts all vehicles with fuel economy better than 50 miles per gallon from emissions testing. ${ }^{51}$ In this case, the vehicle's end user finds value in the clean energy technology.

In the other instance of end-user benefit, firms implementing energy efficiency measures that do not generate electricity on-site may be able to benefit directly from some of the savings in water and solid-waste emissions, depending on the type of technology used.

\section{Calculation}

Life-cycle assessments will be useful in calculating the amount of waste (including air emissions, wastewater, and solid waste) reduced by utilizing clean energy technologies instead of conventional technologies. ${ }^{52}$ In the case of energy efficiency, it may even be possible to directly calculate the number of $\mathrm{kWh}$ saved and translate that into the other three factors.

- Fees for air emissions can be found at the Web site of the appropriate state regulatory agency (e.g., Illinois Environmental Protection Agency, Colorado Department of Public Health and Environment).

- Fees for industrial wastewater disposal are generally negotiated at the local level with a wastewater treatment plant, for firms that do not treat wastewater on-site. NPDES permitting for firms that treat wastewater on-site is handled at the state level. Permitting fees can generally be found at the Web site of the responsible agency. See, for example, the Ohio Environmental Protection Agency's fee schedule at http://www.epa.state.oh.us/dsw/permits/individuals.html.

- Solid-waste disposal charges will range from county to county, from municipality to municipality, and from one waste hauler to another. Determining the exact value of these two waste streams will require some estimation and averaging - further work in this area is needed.

\section{Avoid remediation costs}

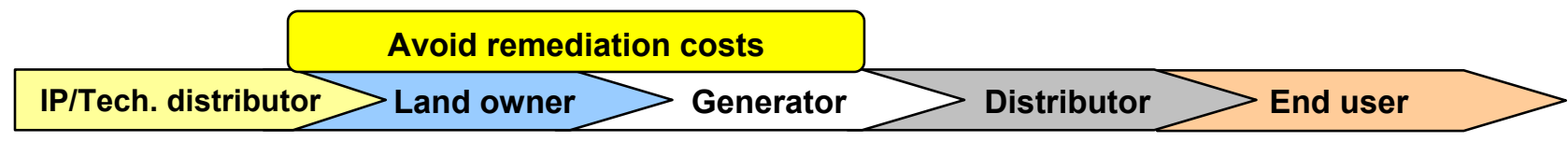

Conventional energy technologies generate significant amounts of waste that can harm the environment - spent nuclear fuel, leaky gasoline storage tanks, etc. By utilizing clean energy

\footnotetext{
${ }^{51}$ Washington State Department of Ecology. (undated) "Air Quality Program: Frequently Asked Questions." Available: http://www.ecy.wa.gov/programs/air/cars/emischeckfaqs.htm\#Hybrid\%20exemption [Accessed July 15, 2005]

${ }^{52}$ A series of life-cycle assessments can be found by searching the Publications Database on the National Renewable Energy Laboratory Web site at http://pix.nrel.gov:8020/BASIS/nich/www/nrel/SF.
} 
technologies, a firm can reduce the level of pollutants released or stored on-site, preventing the accumulation of toxic or hazardous wastes that would eventually require property remediation.

Because sites that are declared brownfields (properties where expansion, development, or reuse would be complicated by the presence or potential presence of a hazardous substance, pollutant or contaminant $)^{53}$ - or even suspected to be brownfields - are much more difficult to sell, financial benefits accumulate. In part, this is due to the fact that the cost of remediation is deductible for tax purposes, only in the event that the firm remediating the property is the same firm that contaminated it; if the property changes hands, the firm that actually remediates the property must capitalize the cost. ${ }^{54}$ As a result, firms that own property that has been used for any type of questionable activity must go through costly environmental assessments to prove that the property is not contaminated; additional costs are incurred if it is found to be contaminated. More immediately, the property value may be reduced, either by damage to the property or by reputational harm - "stigma." balance sheet, which hurts the property owner's financial status.

\section{Value Chain Analysis}

Thus, the firm that owns the property on which extraction (e.g., oil extraction) or generation (e.g., nuclear or coal plants) occurs - and its shareholders - receive the financial benefits of avoiding remediation costs. This land-owning firm may itself be the generator, or the generator may be a separate entity.

Furthermore, insurance companies benefit from the avoidance of remediation costs, because firms often take out liability insurance to protect them in the event that the site requires remediation, which is often extremely expensive.

\section{Calculation}

Estimating the cost to remediate contaminated property is difficult to attempt on a general level. Costs depend on the type of contaminant, the geology of the land, local standards for cleanup, and whether or not the contamination is contained within the property boundaries.

- EPA has, however, developed estimates based on RCRA and CERCLA estimation models. ${ }^{56}$

- Some states and counties have developed detailed cost estimates of different components of a site remediation. The Site Assessment and Mitigation (SAM) Program in San Diego County, California's Department of Environmental Health annually updates its guide ${ }^{57}$ The updated manual is at http://www.sdcounty.ca.gov/deh/lwq/sam/manual_guidelines.html

\footnotetext{
${ }^{53}$ U.S. Environmental Protection Agency. (October 2004) “About Brownfields.” Available: http://www.epa.gov/swerosps/bf/about.htm

${ }^{54}$ Reichert, C.J. (February 2002) “Tax Cases: Deducting Environmental Cleanup Costs.” Journal of Accountancy 193(2): 64.

${ }^{55}$ Veysey, S. (May 2000) "Property Buyers May be Acquiring Pollution Liabilities." Business Insurance 34(20): 1213.

${ }^{56}$ Ross, D. (September/October 2002) “Appraising Environmentally Contaminated Property and Tax Reduction.” Assessment Journal 9(5): 63-74.

${ }^{57}$ Ross, D. (September/October 2002) “Appraising Environmentally Contaminated Property and Tax Reduction.” Assessment Journal 9(5): 63-74.
} 


\section{Policy Incentives}

Existing federal and state policies financially reward firms that develop, utilize, and/or implement clean energy technologies. Without these policies, the barriers to entry to the energy sector would be too great to overcome, because of the sunk costs already invested in existing infrastructure and the absence of competition in many markets. These policy incentives help make clean energy technologies more cost-competitive with traditional energy sources and/or make the investment more attractive, expanding the technology market's penetration and visibility.

In essence, public policy has the power to jump-start markets. Most - but not all - of the policy incentives discussed in this section result in immediate revenue streams for either the developer, generator, end user, or others. However, those benefits that do not bring revenue directly to these parties still play a vital role in the adoption of clean energy technologies. Regulations that require the adoption of clean energy technologies drive the market, creating demand where there was very little. They may not require the government to write a check directly to one of the actors along the value chain, but they mandate that the demand necessary for market growth is present - and they facilitate the growth of markets much more quickly than would be done in their absence.

Governments at the federal, state, county, and local levels have adopted policies that promote the adoption of clean energy technologies. Policies adopted at the federal level in one country may be adopted at more local levels in another; in either case, however, the policies attempt to encourage the development of clean energy technologies within the jurisdiction. If lawmakers consider how to most effectively integrate the benefits provided by these laws when writing them, the combination of these policies can add up to significant incentives to develop, distribute, or install the relevant technologies.

Federal policies create a coherent set of economic incentives nationwide, enabling clean energy technology developers and users to plan for wider-scale implementation of their technologies than can be accomplished with state-level incentives. At the same time, however, the bulk of U.S. policies written to encourage clean energy have been written and implemented at the state and local levels; these state-level policies go a long way toward promoting clean energy. In both cases, however, policies change very quickly and go into effect for a very specific duration, often for fewer than five years (except for mandatory renewable standards and system benefit funds). ${ }^{58}$ This creates some uncertainty in the market, which decision makers must consider when evaluating business decisions. ${ }^{59}$

\footnotetext{
${ }^{58}$ Most states do not have expiration dates for either the mandatory renewable standards or the system benefit funds.

${ }^{59}$ The most up-to-date information about specific incentives is available through regularly updated databases. For example, the Million Solar Roofs program updates its list of incentives for solar technologies in the United States on an annual basis, and the Database of State Incentives for Renewable Energy (DSIRE) is updated as new information about incentives becomes available. The DSIRE database can be found at www.dsireusa.org, and the Million Solar Roofs tables can be found at http://www.millionsolarroofs.org/outreachtools_publications/?PHPSESSID=092a500fcd2d6839208a0443afa6a34f
} 
The remainder of this section will provide an overview of the policy incentives used to promote clean energy at any level of government. Some of them apply only to the electric power industry, others only to fuels, and some of them apply to all types of clean energy technologies. The important thing to keep in mind while reading this section is the tremendous amount of variability in the details of these types of policies from one country to the next, from one state to the next, and from one local government to the next. This analysis will describe the concepts behind each type of policy incentive and, in most cases, provide examples of the policy at work. Beneficiaries may vary, depending on the specifics of the policy, but an attempt is made to generalize where possible.

\section{Production tax credit}

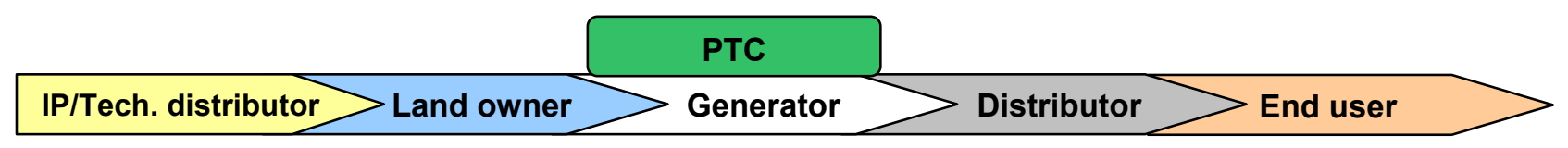

Beginning with the Energy Policy Act of 1992, Congress instituted a production tax credit (PTC) for renewable energy, which provided a tax credit of 1.5 cents per kilowatt-hour $(\mathrm{kWh})$ of electricity produced; it was renewed for 1999, 2001, 2003, 2004, 2005, and 2006-07. ${ }^{60}$ As a result of annual adjustments for inflation, the PTC payment will be 1.9 cents per $\mathrm{kWh}$ for wind, geothermal, and solar generation in 2005 ; and 0.9 cents per $\mathrm{kWh}$ for biomass generation. ${ }^{61}$

The technologies currently eligible for the tax credit are wind, closed-loop biomass, open-loop biomass, geothermal energy, solar, small irrigation power, municipal solid waste, incremental hydropower, and coal produced from reserves owned by Native American tribes. ${ }^{62}$ Nearly any tax-paying entity generating electricity using one of the technologies mentioned in the legislation is eligible to receive the tax credit for 10 years after the start of generation.

The PTC has been subject to frequent Congressional approval and has been in force erratically during the past decade. The Energy Policy Act of 2005 extended the period of eligibility for two years, through December 31, 2007. Extension beyond one to three years would provide greater certainty for developers planning eligible projects. However, the renewal of the PTC is often complicated by the fact that it is often folded into other, more controversial, measures as a sweetener. Planning to include the PTC in a business plan must be done with caution and awareness of the political situation.

Additionally, some states have instituted production tax credits with provisions unique to their state's situation. These need to be identified on a state-by-state basis; the DSIRE Web site provides such detail at www.dsireusa.org.

\footnotetext{
${ }^{60}$ The 2005 Act extended the sunset date to December 31, 2007, for all technologies except solar; to receive the tax incentives for solar, facilities must be placed into service on or before December 31, 2005.

${ }^{61}$ Chadbourne and Park. (April 2005) "In other news." Project Finance News Wire.

${ }^{62}$ Information about the PTC legislation taken from U.S. Congress. $109^{\text {th }}$ Congress, $1^{\text {st }}$ session. Public Law No. 109-58. Energy Policy Act of 2005. ONLINE. GPO Access. Available: http://energycommerce.house.gov/108/0205_Energy/conference/EnergyConf_report.pdf
} 


\section{Value Chain Analysis}

Identifying beneficiaries of the PTC is quite simple. The tax credit is awarded to the firm that generates the energy. In the event that the generator's tax liability is less than the tax credit, the generator may sell the rights to the tax credit to a firm with sufficient tax liability, often for a discount. For 501(c) 3 corporations interested in developing and operating these technologies, such a strategy could change the financial dynamics of a project.

\section{$\underline{\text { Accelerated depreciation }}$}

Accel. depreciation

IP/Tech. distributor $>$ Land owner $>$ Generator Distributor $>$ End user

The Internal Revenue Code provides that the costs of any solar, wind, or geothermal property can be recovered through depreciation more quickly than allowed for most traditional equipment. Under the Modified Accelerated Cost Recovery System (MACRS), solar, wind, and geothermal equipment that meet specific eligibility standards can be depreciated over five years, instead of over 10 years. ${ }^{63}$ A provision that was added to the tax code at about the same time also allowed owners of solar, wind, and geothermal equipment to take an additional $30 \%$ depreciation on these items during the first year, creating an even larger incentive for the technology. ${ }^{64}$

\section{Value Chain Analysis}

The party that owns the equipment that generates the solar, wind, or geothermal power is eligible for the accelerated depreciation. Most wind turbines are operated by a developer, as are some solar and some geothermal technologies; in these cases, the generator/developer can take advantage of the accelerated depreciation.

In many cases, however, solar and geothermal equipment is located on the property of the end user of that electricity, whether it is a residence or a business. In these cases, the end user/generator receives the benefits.

\section{Preferential loan treatment}

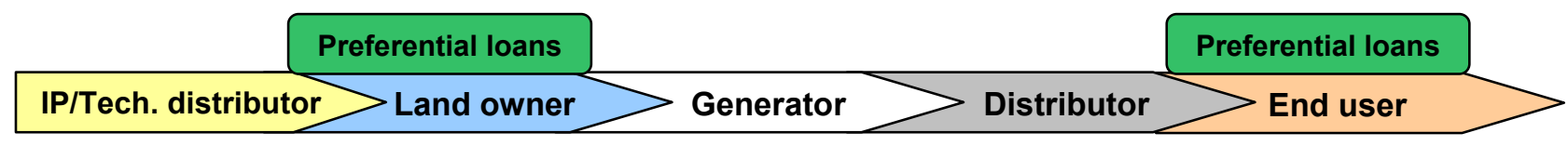

\footnotetext{
${ }^{63}$ U.S. Department of Energy, Energy Efficiency and Renewable Energy. (December 2003) "Financial Incentives for Business Investments in Renewable Energy." Available: http://www.eere.energy.gov/consumerinfo/factsheets/la7.html; Internal Revenue Service. "Table B-2. Table of Class Lives and Recovery Periods. Renewable energy technologies used to generate electricity are under Asset Class 35.0: Manufacture of Electrical and Non-Electrical Machinery and Other Mechanical Products." Available: http://www.irs.gov/publications/p946/13081f35.html See also: Internal Revenue Code Title 26, Section 168 (e)(3)(B)(vi).

${ }^{64}$ Database of State Incentives for Renewable Energy (2004) "Modified Accelerated Cost Recovery System (MACRS) with 50 percent bonus depreciation.” Available: http://www.solarsupply.com/federal incentives.htm
} 
Both federal and state governments have already established loan funds for renewable energy. By providing low-interest loans or loan backing, loan funds for clean energy technologies can help reduce the cost of capital significantly. The federal "green bonds" program was established under the same legislation that extended the PTC - the American Jobs Creation Act of 2004. This program authorized up to $\$ 2$ billion in tax-exempt bond financing, which will enable developers of large-scale building projects to acquire low-interest loans. Although the primary eligibility requirements are focused on meeting Leadership in Energy and Environmental Design (LEED) standards, as well as job creation and partnership with a state or local government, the benefits created for the developer by the tax-exempt status of the bond can be spent on acquiring renewable energy technologies, one of only three authorized expenditures for these funds.

Twelve states have established incentive programs for low-interest loans for renewable energy technologies, including California, Connecticut, Illinois, Massachusetts, Minnesota, New Jersey, New York, Ohio, Oregon, Pennsylvania, Rhode Island, and Wisconsin - several of which have established more than one program. Eligible technologies vary by state, as do the types of financing available. Some states offer grants, others offer low-interest loans, and others provide subordinated debt for renewable energy projects.

In any event, developers taking advantage of these preferential loan treatments must be aware of the implications for eligibility for the PTC. The IRS does not allow recipients of governmentsubsidized loans to take advantage of the PTC; ${ }^{65}$ for projects below the threshold requirements for the PTC or projects that are implemented by firms that are too small to take advantage of the tax credits, however, these low-interest loans provide additional low-cost financing.

\section{Value Chain Analysis}

In the case of federal green bonds programs, the party that owns the property being developed receives the advantages of the federal program. At the federal level, land owners of very large developments (larger than 1 million square feet) receive this benefit if they meet the requirements. In the case of large commercial spaces, the land owner may or may not also generate electricity for the property. Depending on that status, the financial benefits may also accrue to the generator.

At the state level, the end user is often the beneficiary of the low-interest loans because the end user is also the owner of the equipment, especially in the case of a residential system. In the case of a larger property, such as an apartment complex or other commercial or industrial facility, the owner of the renewable energy technology may not be the same as the end-user. In these cases, the benefits accrue to an intermediary, what we will call for these purposes "the land owner."

\section{Renewable Portfolio Standard}

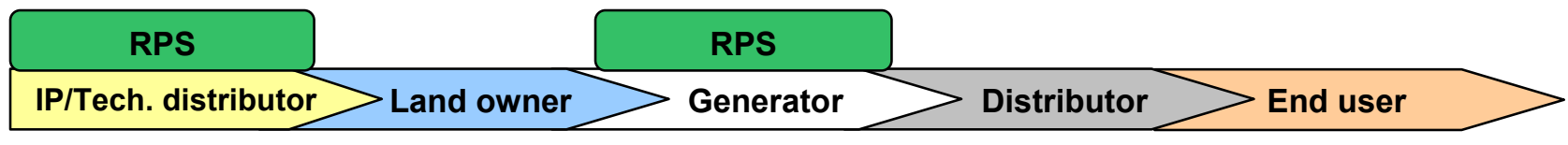

\footnotetext{
${ }^{65}$ Ing, E. (March 2002) The Effect of NYSERDA's Wind Project Assistance on the Federal Production Tax Credit. Prepared for NYSERDA. Available:
} 
By some accounts, the renewable portfolio standard (RPS) is the most powerful policy tool a state can implement to ensure the development of clean energy sources. An RPS mandates that electricity retailers (or sometimes distributors) obtain a certain percentage of electricity from renewable sources. ${ }^{66}$ Although states may define their portfolio of "renewable" sources differently, the policy creates incentives for moving away from conventional sources of electricity such as coal and natural gas. Currently, states in the United States are pushing RPSs; in Europe, RPSs are generally implemented at the national level.

Compliance with RPSs generally occurs in one of two ways:

(1) power providers purchase enough renewable energy certificates (RECs) to account for the generation from renewable sources as required by law (see the following subsection for a full discussion); or

(2) power providers must pay a penalty, generally set at a level per MWh that is designed to encourage compliance through the market.

Through the first of these mechanisms, the RPS creates a market for clean energy technologies; power providers are required to devise a cost-effective strategy for acquiring an established amount of electricity from renewable sources. Purchasing the clean electricity does not have to be the least-cost alternative, which is a step away from the least-cost planning that many public utility commissions required of utilities during the 1990s and early 2000s. Although renewable technologies may cost more than conventional technologies, privately owned and publicly owned utilities alike must make provisions for meeting these requirements. States with RPSs choose to develop new rules under which the utilities must operate; because the utilities' first obligation is to comply with legal requirements, implementing clean energy technologies is prioritized over profits, and it is no longer simply a "luxury" that only the richest firms can choose.

\section{Value Chain Analysis}

In the absence of a direct cash flow associated with the RPS, value is still transferred along the value chain. If the RPS establishes a goal that appropriately exceeds the level of existing renewable generation in the state, the immediate benefits will accrue to the producer of the renewable energy technology. The RPS immediately increases the demand for renewable technologies, bringing the market a step closer to generating an economy of scale. It enables renewable energy technology producers and purchasers to quickly gain experience in the market, which the producers can then apply to other markets, either domestically or internationally. Because the market expands so quickly, it also provides the opportunity for new tech firms to get a piece of the pie, increasing the amount of competition in the industry, which drives innovation.

Other benefits accrue to both the producer of the renewable energy technology and to the generator. If the date established for accomplishing the goal is ambitious enough to trigger

\footnotetext{
${ }^{66}$ In the case of regulated markets where vertically integrated utilities are still the norm, the retailing and distributing aspects of the business are still integrated with the generating function. In these cases, it is the integrated utility that is responsible for procuring the required portion of their electricity from renewable sources.
} 
activity - but reasonable enough to be achieved - it will prompt cooperation among interested parties that may not have occurred otherwise. Regulators, generators, and transmission and distribution companies will need to work together to establish protocols for project approval, connecting the renewable technologies to the grid in a timely manner, and monitoring and compliance. Generally, these steps create hurdles to the adoption of renewable energy technologies, but the RPS helps utilities overcome them more quickly. Thus, the technology producer benefits, because its product can be installed more quickly; and the generator using the technology benefits, because demand for electricity generated by renewable sources has expanded overnight. This generates new revenue for both the tech firm and the generator, and also enables the firms facing regulation (retailers or distributors) to meet their targets in a more efficient manner.

\section{$\underline{\text { Renewable Energy Certificates }}$}

IP/Tech. distributor > Land owner $>$ Generator $>$ Distributor $>$ End user

Renewable energy certificates (RECs) represent the characteristics of renewable energy that create environmental benefits. ${ }^{67}$ These characteristics - or attributes - can be sold either together with the electricity that is generated (for a premium) or as a stand-alone product to consumers. While there is no standardized U.S. market for RECs, the majority of states with an RPS allow (or require) the mandated levels of renewable energy to be met using RECs; these compliance markets were valued at approximately $\$ 137$ million in 2004 and are expected to grow to $\$ 608$ million by 2010 . A voluntary market in which customers purchase RECs separate from their electricity - either to gain emissions credits associated with the RECs or in a socially responsible effort - is also growing rapidly in the United States; in 2004, the estimated market value was \$3 million, anticipated to grow to $\$ 20$ million by 2010 .

\section{Value Chain Analysis}

It appears that the clearest benefit of RECs is to utility-scale generators, which are able to charge a premium for the RECs, either to a retailer/electricity provider that must comply with a renewables mandate or to a customer who would like to take credit for the green power. Regardless of which of these two entities purchases the RECs from the utility-scale generator, the associated electricity is generally sold separately. Which entity benefits financially from RECs created by residential installations of renewable energy is much less clear.

Unlike $\mathrm{CO}_{2}$ credits, which any entity in the value chain can claim, ownership for RECs is inconsistent among states (and national governments in the EU) and unclear in the legal system. In the past, some utilities have tried to claim ownership for any RECs that are generated within their territory. For example, in a state where the utility issues a rebate to cover part of the costs of installing a residential solar PV system, the utility is claiming full ownership of any RECs

\footnotetext{
${ }^{67}$ Information about the RECs market is drawn from Holt, E. and Bird, L. (January 2005) Emerging Markets for Renewable Energy Certificates: Opportunities and Challenges. National Renewable Energy Laboratory: Golden, $\mathrm{CO}$.
} 
generated by the residential system. In other cases where utilities have offered their customers green pricing options, some utilities want to maintain ownership of the RECs associated with the power generated through such programs. Whether or not a court of law would support either of these claims is unclear; and existing laws ,thus far, have not made a clear conclusion about the matter. Recognizing the ambiguity is important for companies wanting to include this benefit in a value proposition.

\section{$\underline{\text { System benefit funds (or public benefit fund) }}$}

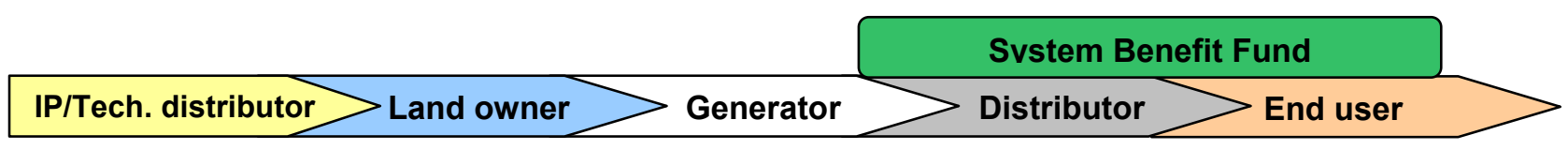

Most often, states will establish a system benefit charge to ensure that clean energy technologies, education/outreach programs, and low-income assistance are funded. The fund is generated by applying a small charge per $\mathrm{kWh}$ to residents' electric bills. Restrictions on how the money may be used are often established; regulators may permit the initiation of refund programs for residents that purchase on-site renewable or energy-efficient technologies or the issuance of a request for proposals to a distributor of an energy-efficient technology to facilitate deployment within the state. In either case, a specific value is established that may be recouped earlier in the value chain.

\section{Value Chain Analysis}

Revenue from system benefit funds can benefit clean energy technology in one of two ways:

- If a request for proposals is issued to identify a company that will carry out a contract to distribute the technology, the recipient of the contract will receive a payment in exchange for services, which can further enhance the distributor's revenue.

- In another case, the regulatory authority may simply issue rebates for purchasing energyefficient or distributed clean energy technologies. In this case, the benefits accrue directly to the end user, although the technology distributor may enjoy higher sales due to the lower actual price paid by the consumer when the rebate is applied.

\section{$\underline{\text { Rebates }}$}

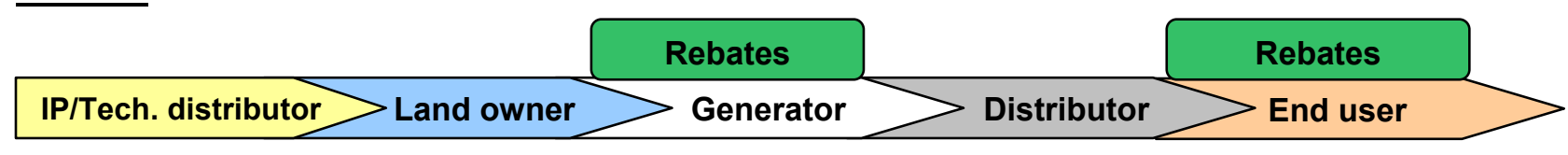

In the United States, rebates are paid by the utility or a state agency to customers who install onsite renewable energy generation, most often in the form of solar PV or solar thermal. State RPSs often establish the buy-back rate for such installations. In New Jersey, the rate is $\$ 5.50$ per watt; in Minnesota, the rate is $\$ 2$ per watt; in Connecticut and Rhode Island, it is $\$ 5$ per watt; sometimes, in place of a per-watt rebate, a state will agree to pay a percentage of the installation 
costs up to a certain amount. ${ }^{68}$ Although the grid does not always directly receive that electricity, the policy forces the utility to pay the customer for the electricity that he/she generates on-site. As a result, the renewable source is partly supported by either ratepayers or taxpayers rather than that individual customer.

\section{Value Chain Analysis}

In both the U.S. and European cases, the benefits of rebates accrue directly to the technology owner, whether it is a utility-scale or residential-scale installation. In the U.S. market, it is most common for the rebates to be paid to a residential customer who installs clean energy technology; hence, he/she is also the end user of the technology. The cost of utility scale installations in the United States is more often negotiated through a long-term contract with one or more utilities.

\section{$\underline{\text { Feed-in tariffs }}$}

\section{Feed-in tariffs} Feed-in tariffs

IP/Tech. distributor > Land owner $>$ Generator

Distributor $>$ End user $>$

Feed-in tariffs generally require utilities to purchase electricity generated by renewable sources at a fixed price, often at or near the retail cost of electricity. For example, Germany's 2000 Renewable Energy Law required utilities to buy back solar power at the equivalent of $\$ 0.43$ per $\mathrm{kWh} .{ }^{69}$ At this rate, it was much more economical for proponents of renewable energy to install solar, which promoted the development of the solar industry in Germany. The same law mandated buy-back of wind energy at $\$ 0.097$ per $\mathrm{kWh}$, which helped expand wind capacity in Germany from a few megawatts in 1990 to 12,000 MW in 2002.

Although feed-in tariffs entail a financial exchange, they are not really market mechanisms, because the price is set by an outside entity (the government). They fail to encourage competition among technology producers because the buy-back rate is guaranteed; thus, it does not create incentives for the tech firms to reduce costs. As a result, the price of electricity increases. However, the stability created by the guaranteed price reduces risk significantly for renewable generators, encouraging development and reducing the cost of capital.

\section{Value Chain Analysis}

Benefits accrue primarily to renewable generators and the producers of the technology. Generators benefit from reduced risk, lower costs of capital, and a guaranteed return on investment. As a result, they build more renewable generation, building a market for the tech firms, which then enjoy higher revenues.

\footnotetext{
68 "State by State Incentives for Residential Solar PV Projects." (June 2005) Million Solar Roofs. Available: www.millionsolarroofs.org

${ }^{69}$ Komor, P. (2004) Renewable Energy Policy. The Diebold Institute for Public Policy Studies: New York.
} 
On the other hand, however, if the government-set feed-in rate is higher than the technology cost, the cost of electricity increases, increasing costs to retailers and end users.

\section{Net metering}

IP/Tech. distributor $>$ Land owner $>$ Generator

Net metering

Net metering is another production incentive for distributed clean power technologies. For end users with on-site renewable generating capacity below certain limits, any electricity produced on-site that is not used on-site can be sold back to the grid. Special meters are installed at such facilities, which keep track of how much electricity the customer uses as well any excess that is returned to the grid. The amount of electricity that is returned to the grid is subtracted from the amount of electricity purchased by the customer, either daily, monthly, or annually; that is, the customer is only billed for the net amount of electricity required. Hence, the term "net metering."

Some utilities see net metering as a threat - or at least as an inconvenience - because without the net-metering laws, they could keep the electricity that gets returned to the grid and bill the customer for the full amount of grid electricity used during the billing cycle. Net metering can also benefit utilities, because it reduces transmission losses and helps improve the voltage profile. $^{70}$ Distributed generation is more efficient in these respects and can enable the grid to make the most efficient use of the electricity generated.

\section{Value Chain Analysis}

The direct financial benefits accrue to the end user of electricity, because they will have lower demand for grid energy - and their electricity bills will decrease even further as the on-site systems return unused portions of the energy to the grid. Because net-metering policies help offset the costs of renewable energy technologies over time, they help to build demand for the technologies, the benefits of which are returned to the producer of the technology in the form of higher sales.

\section{Property tax break}

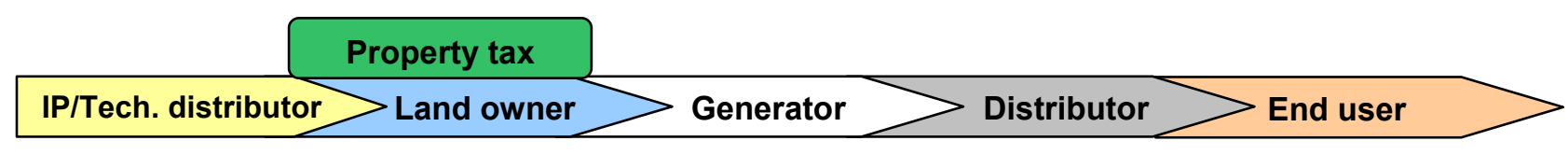

Some state and local governments also provide property tax incentives for clean energy technologies. In Ohio, land used for select renewable energy technologies is exempt from the property and use tax; the improvements associated with these technologies are not considered

\footnotetext{
${ }^{70}$ Ackermann, T., G. Andersson, L. Soder. (2001) “Overview of Government and Market-Driven Programs for the Promotion of Renewable Power Generation." Renewable Energy 22: 197-204.
} 
improvements for the purposes of property taxation; and the improvements are not considered in the assessment of Ohio's franchise tax. ${ }^{71}$ Other states have similar provisions.

\section{Value Chain Analysis}

The owner of the property on which the clean energy technology is located can reap the benefits of the property tax incentives. In some cases, the generator may own the land on which the technology is located (e.g., a biorefinery or large solar PV installation). In other cases, the landowner is completely separate from the generator or distributor (e.g., farmers who own the land on which wind turbines are located). In residential applications, the end user generally owns the property on which the technology (e.g., solar PV or solar thermal) is located.

\section{$\underline{\text { Sales-tax exemption }}$}

IP/Tech. distributor

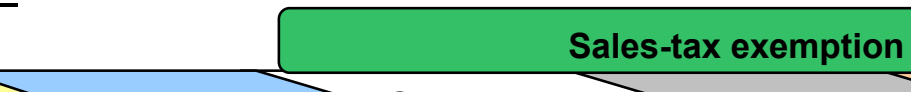
Land owner Generator Distributor End user

Some states and local governments will exempt projects involving clean energy technologies from sales tax. Depending on the size of the project and the level of taxation, this can amount to a significant savings, which can reach $7.25 \%$ of project costs. ${ }^{72}$ The state of Utah, for example, exempts a wide range of materials and equipment used to generate electricity from renewable resources installed between July 2004 and July $2009 .^{73}$

\section{Value Chain Analysis}

Benefits in this category accumulate to whomever purchases the equipment for a clean energy installation. Two different scenarios dominate in this case:

- In the case of centralized clean energy technologies, the generator purchases the equipment, either directly or through a contractor;

- In the case of distributed generation, the end user is purchasing the equipment, either directly or through a contractor.

\section{Qualification for local research and development incentives}

\begin{tabular}{|l|l|l|}
\hline R\&D incentives & R\&D incentives \\
\hline IP/Tech. distributor $>$ Land owner $>$ Generator $>$ Distributor $>$ End user \\
\hline
\end{tabular}

\footnotetext{
${ }^{71}$ Database of State Incentives for Renewable Energy. (2005) “Conversion Facilities Property Tax Exemption.” Available: http://www.dsireusa.org/library/includes/GenericIncentive.cfm?Incentive Code=OH02F\&currentpageid=3

72 "State Sales Tax Rates." (January 1, 2005) Federation of Tax Administrators. Available: http://www.taxadmin.org/fta/rate/sales.html

${ }^{73}$ Database of State Incentives for Renewable Energy. (2005) "Renewable Energy Sales Tax Exemption." Available:

http://www.dsireusa.org/library/includes/GenericIncentive.cfm?Incentive_Code=UT09F\&currentpageid=3
} 
In areas that want to expand the development of clean energy technology locally, creating incentives - often grants - for research and development (R\&D) can provide additional income for firms involved in premarket R\&D. As with other incentives, the exact details of these programs vary by state.

\section{Value Chain Analysis}

Any company involved in R\&D may be eligible for the economic incentives, if they locate within a designated area. The R\&D operations also may be integrated with a firm's operations as a generator, distributor, or an end user (although this last case is infrequent). Thus, the value may occur anywhere in the value chain, as indicated in the diagram.

\section{Other financial incentives}

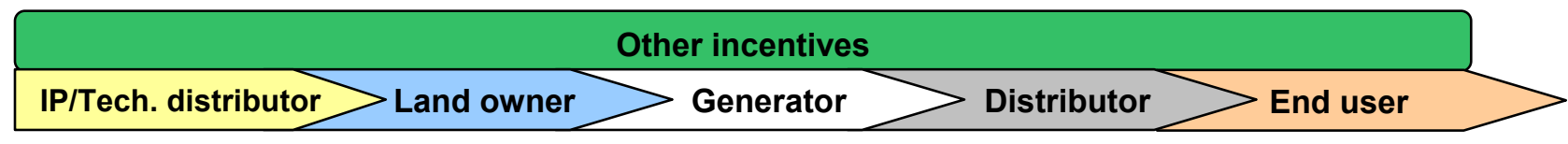

Some local and state governments have devised innovative tax incentives designed to encourage the development of the renewable energy industry in their area. Montgomery County, Maryland, for example, has waived the county energy tax (approximately 1.2 cents per $\mathrm{kWh}$ for businesses) for firms that purchase clean energy. Identifying ideal sites for project implementation will depend heavily on the specifics of state and local governments' priorities. The Database of State Incentives for Renewable Energy (DSIRE) is a good source of information about specific incentive programs. $^{74}$

Additionally, economic development zones are typically created by state government (with urging from local officials). The goal is to encourage the development of a specific industry by providing tax or other financial incentives to companies in that industry that locate in the zone. Companies that set up shop in economic-development zones often commit to hiring a certain percentage of their employees from a pool of applicants that meet specific requirements, usually related to their economic status. Such programs help to build the economy of the designated areas.

In a similar effort, an Austin, Texas, partnership of technology firms, renewable energy services providers, the Austin Chamber of Commerce, and Austin Energy is promoting Austin as the center of clean energy technology through the Austin Clean Energy (ACE) Initiative. In parallel with that effort, the Austin Technology Incubator and NREL established the Clean Energy Incubator, providing a space for select clean energy start-ups to establish a business hub in Austin with the assistance of a range of financial and technical resources available. ${ }^{75}$ In exchange, the start-ups guarantee the incubator a $1 \%$ equity stake in the business (much less than

\footnotetext{
${ }^{74}$ See www.dsireusa.org.

75 "Welcome to the CEI website." Clean Energy Incubator. Available: http://www.cleanenergyincubator.com/
} 
a private investor would require), agree to attend networking events set up by the incubator, and pay rent on their space. ${ }^{76}$

Another Texas incentive is the franchise tax exemption, the Texan equivalent of a business tax exemption. Texas law exempts any business "engaged solely in the business of manufacturing, selling, or installing solar energy devices...from the franchise tax." ${ }^{, 77}$ No other state besides Texas is offering a similar incentive at the time of this writing.

\section{Value Chain Analysis}

In general, tax incentives are targeted at the firms deploying the technologies within an area. Whether that firm is the developer, distributor, or the end user will be unique in each situation.

\footnotetext{
76 "Admissions." Clean Energy Incubator. Available: http://www.cleanenergyincubator.com/admissions/requirements.php

77 "Renewable Energy Incentives: Green Industry Recruitment Incentives." (August 4, 2004) State and Environmental Resource Center. Available:

http://www.serconline.org/RenewableEnergyIncentives/greenIndustryRecruitmentIncentives.html [Accessed July $26,2005]$
} 


\section{Reduced Resource Use}

The production of conventional energy is extremely resource intensive, which adds to the cost of the energy produced. As population and the demands on natural resources increase, the prices of these inputs will increase as well, as the oil markets have demonstrated recently. By reducing the amount of resources used and finding ways to utilize the by-products of clean energy production, firms can help to reduce the cost of energy produced and generate new revenue streams with new products.

In this text, the term "resource" encompasses both natural resources and financial resources - in the energy business, the two are practically inseparable. Consequently, more efficient use of resources turns into a bottom-line issue. Identifying points in the production process where clean energy technologies help to reduce resource use can also reveal opportunities for cost savings, which directly impact the profitability of a firm.

\section{$\underline{\text { Reduce water use and consumption }}$}

IP/Tech. distributor Land owner Generator Distributor

End user

Demand on freshwater resources is growing worldwide. Energy producers not only compete with one another for access to water, they also compete with residential, commercial, and other industrial entities. Today, electric utilities consume more water than any other industry except agriculture. ${ }^{78}$ As population continues to grow and the need for food increases proportionally, the amount of water required for agriculture and for drinking water will increase as well. The United Nations Food and Agriculture Organization predicts that water withdrawals for irrigation in developing countries will increase by $14 \%$ by 2030 , for example. ${ }^{79}$

Today, existing thermoelectric power plants in the utility and industrial sectors - which include coal, natural gas, and nuclear technologies - represent $39 \%$ of the water use in the United States, using approximately 25 gallons per kWh produced. ${ }^{80}$ These plants, which make up more than $89 \%$ of U.S. electricity generation, will face increased competition from agriculture - if agricultural efficiencies remain stable. ${ }^{81}$ In response to such an increase in demand, the market price of water will increase - if no new regulations governing the price of water are promulgated. Additionally, water consumers will face the threat of water shortages, which poses a new risk for these industries.

\footnotetext{
${ }^{78}$ Morrison, J. and P. Gleick. (August 2004) "Freshwater Resources: Managing the Risks Facing the Private Sector." Pacific Institute. Available: www.pacinst.org

79 "Securing Food for a Growing World Population." (Chapter 8) in UN World Water Development Report - Water for People, Water for Life. Available: http://www.unesco.org/water/wwap/wwdr/pdf/chap8.pdf

${ }^{80}$ National Energy Technology Laboratory. (2005) "Water-Energy Interface: Power Plant Water Management." Available: http://www.netl.doe.gov/coal/E\&WR/water/power-gen.html

${ }^{81}$ U.S. Department of Energy - Energy Information Administration. (January 2005) "United States of America Country Analysis Brief. Available; www.eia.doe.gov/emeu/cabs/usa.html\#elec [Accessed July 21, 2005]
} 
Companies that own water rights today may be able to capitalize on the increased demand and higher prices, if they adopt clean energy technologies in place of conventional ones. Water law in the western United States is crystal clear about the fact that whichever entity owns the oldest water rights has the first right to the water; and the amount of water granted to the entity with "senior" water rights remains constant, regardless of the level of rainfall in a particular year. Consumers that hold "junior" water rights - rights that were obtained later than the senior rights - may not receive their water in years of drought, if the water runs dry before the senior waterrights holders use their quotas. ${ }^{82}$

\section{Value Chain Analysis}

In areas like the western United States (which base water rights on a doctrine of prior appropriation), a reduction in water use can boost the bottom line in one of two main ways. First, if the firm does not own water rights and purchases water from a local utility, the bottom-line benefit would be in the avoided costs of water; cost savings would vary, depending on the local utility and the amount of water saved. Alternatively, any entity that holds water rights in the West may rent, lease, or sell them at any time. In years of drought, if senior water-rights holders are able to reduce their water use, they may rent their water rights to junior water-rights holders, generating additional income. Generators that are junior water-rights holders may be able to avoid the cost associated with obtaining additional water rights in those years by adopting clean energy technologies that require little or no water.

In water-rich areas like the eastern United States, a system of riparian water rights allows access to reasonable use of water to all entities that own property along a body of water. ${ }^{83}$ In years with water shortages, water is often allocated according to the amount of land connected to the body of water. Trading is possible, but water may not be shifted outside the watershed.

Regardless of the type of water-rights law governing an area, reducing water use can create two additional cost savings for generators. Once a firm procures the water needed for its operations, it must determine whether or not the quality of the water is suitable for its intended use. Boilers, for example, require water with few impurities in it to avoid boiler-scaling, which can reduce the efficiency of the boiler and require additional maintenance each year. Some utilities have complained about the quality of water they are allotted, mainly due to the costs associated with treating the water before use. ${ }^{84}$ Reducing the amount of water required for operations can help reduce the cost of pretreatment as well.

Finally, in the case of thermoelectric plants, EPA regulations promulgated in 2004 require the installation of technology that will help reduce the environmental impacts of the cooling water

\footnotetext{
${ }^{82}$ Whiting, D. and R. Tolan and B. Mecham and M. Bauer. (2005) “Colorado's Water Situation." Colorado State University Cooperative Extension No. 7.750. Available: http://www.ext.colostate.edu/pubs/garden/07750.html

${ }^{83}$ Houston, L.L. and J.D. Kline and R.J. Alig. (July 2002) Economics Research Supporting Water Resource Stewardship in the Pacific Northwest. U.S. Dept. of Agriculture - Forest Service. Available: http://www.fs.fed.us/pnw/pubs/gtr550.pdf

${ }^{84}$ Hix, R. (March 10-13, 2003) "Current and Future Water Regulatory Issues Affecting Electric Utilities." Presented at 28th International Technical Conference on Coal Utilization and Fuel Systems:Clearwater, FL.
} 
intake process. These regulations apply only to facilities that meet certain criteria, including the amount of water used for cooling each day. If a utility is able to reduce its water use below that level - or if a new generator is able to avoid that cost - then the firm will realize cost savings or create a competitive advantage, respectively.

\section{Calculation}

Calculating the value of reduced water use will depend on the industry, the value of water rights, the cost of local water services, and the costs associated with regulation. These costs will vary significantly for different regions, states, and municipalities. Some existing research can be applied to these variable costs to derive an estimate, but the best overall sources will include local case studies and professional counterparts from nearby firms. Some possible sources include the following:

- In states such as Oklahoma, Oregon, California, Nevada, and Arizona, water leases during the 1990 s fetched (on average) between $\$ 113$ and $\$ 1,222$ per acre-foot. ${ }^{85}$ Significant reductions in water use could result in significant income from leasing water rights.

- State-level organizations of municipalities are likely to conduct surveys about the cost of utilities provided by their municipal members. The Texas Municipal League, for example, conducts regular surveys of this type; its 2005 survey found that the average cost of 5,000 gallons of water was $\$ 22.45 .{ }^{86}$ Typically, this type of an estimate includes residential, commercial, and industrial customers - but it may be used to approximate the cost savings in a general sense.

- In the EPA's final rule on the best technology available to reduce the environmental impacts of cooling water intake, it performed a rigorous economic analysis of costs at the facility level, at the firm level, and at the household level. ${ }^{87}$

\section{$\underline{\text { Reduce energy use }}$}

\section{IP/Tech. distributor $>$ Land owner $>$ Generator}

Alternative energy options and energy-efficient technologies and practices result in a reduction in the amount of conventional energy used. According to the Energy Information Administration (EIA), the average industrial customer spends more than $\$ 93,000$ per year on electricity costs alone. ${ }^{88}$ Reducing this cost over time - either by implementing energy-efficient technologies and

\footnotetext{
${ }^{85}$ Adams, J. and Crews, D. and Cummings, R. (April 2004) "The sale and leasing of water rights in Western states: An update to mid-2004." (Water policy working paper \#2004-004). North Georgia Water Planning and Policy Center. Available: http://www.h2opolicycenter.org/pdf documents/water_workingpapers/2004-004.pdf.

${ }^{86}$ Texas Municipal League. (2005) "2005 Water/Wastewater Survey Results.” Available: http://www.tml.org/surveys.html

${ }^{87}$ Federal Register Vol. 69 No. 131. (July 9, 2004) National Pollution Discharge Elimination System - Final Regulations to Establish Requirements for Cooling Water Intake Structures at Phase II Existing Facilities. 40 CFR Parts 9, 122, 123, 124, and 125.

${ }^{88}$ Department of Energy - Energy Information Administration. (November 2002) "Table 2a. U.S. average monthly bill by sector, census division and state, 2000." Available: http://www.eia.doe.gov/cneaf/electricity/epav2/html_tables/epav2t2p3.html
} 
practices or by installing distributed generation technologies - would result in a reduction in the cost of goods sold, enhancing profitability. One recent analysis estimates the cost of implementing energy efficiency measures at $\$ 0.02$ per $\mathrm{kWh}$; because the average cost of electricity in 2005 was $\$ 0.0745$ per $\mathrm{kWh},{ }^{89}$ the savings from energy efficiency measures can add up quickly. (Depending on the technology, distributed generation may require the firm to pay for fuel costs and/or operations and maintenance.)

In addition to traditional measures of economic benefits to firms, benefits of the reduction in energy use has a societal aspect. Improvements in energy efficiency since 1970 provide about $75 \%$ of all U.S. energy services, the equivalent of 8.9 times the energy value of our domestic oil production or 3.7 times that of our petroleum imports. ${ }^{90}$ The savings associated with avoiding such large amounts of natural resource extraction go beyond traditional measures of cost; the reduction also helps extend the number of years that oil is available for use.

\section{Value Chain Analysis}

Firms that use energy-efficient technologies or install distributed generation systems on-site would realize reductions in grid energy use. Almost any actor in the value chain can benefit from these reductions firsthand, although the amount of cost savings that can be realized varies according to the amount of energy that it uses and the utility standby rates in effect. In essence, each of the actors in the value chain benefits because they are end users of electricity.

The licensee may decide to install solar panels on his/her office, which may provide enough electricity to help him/her go off the grid when combined with energy efficiency measures. However, an office engaged in administrative work - such as the licensee - would save considerably less energy than a firm manufacturing the technology, because the manufacturer uses considerably more energy in the first place. Yet, both parties can reduce their grid energy costs on a monthly basis, if they choose to implement the available technology.

Some additional up-front costs are associated with installing distributed generation technologies and implementing energy-efficient technologies or practices. In addition to determining which energy-saving measure is most appropriate for a specific setting or installing a new technology, a firm will make a capital investment, invest in employee training to implement the measures, and/or incur administrative costs for monitoring progress. In the case of many energy efficiency measures, these costs are recouped quickly - sometimes in a few months, other times within two years. In the case of distributed generation, the firm may incur additional costs over the life of the equipment in the form of fuel or operations and maintenance; these may also be recovered over the life of the investment. Evaluating the payback periods for different options will help determine just how long it will take for the firm or individual to recover associated costs.

\footnotetext{
${ }^{89}$ Department of Energy - Energy Information Administration. (June 2005) “Table ES1.B. Total electric industry power statistics, year-to-date 2005 and 2004." Available: http://www.eia.doe.gov/cneaf/electricity/epm/tablees1b.html

${ }^{90}$ Laitner, J.A. (July 12, 2005) “How Far Energy Efficiency?" Presentation to the NREL Energy Analysis Office’s Monthly Seminar.
} 


\section{Calculation}

Because there are several different types of energy-efficient and distributed generation technologies and energy-efficient practices, the options for calculating the cost savings vary significantly. Payback time and annual cost savings are two very common methods for doing so. Here are some examples:

- The payback period of replacing old insulation with newer, more-effective materials can be calculated easily. DOE provides a fact sheet that outlines the process; ${ }^{91}$ a parallel process can be used for almost any energy-efficient technology by replacing the measures specifically related to insulation with metrics relevant to the other technology.

- Payback periods for energy-efficient motors used in a variety of industries can be found at http://www.motorsmatter.org/kit/case studies.html.

- The Energy Trust of Oregon also has a library detailing the cost savings of different energy-efficient technologies: www.energytrust.org/Pages/about/library/case_studies/.

\section{$\underline{\text { Lower production costs }}$}

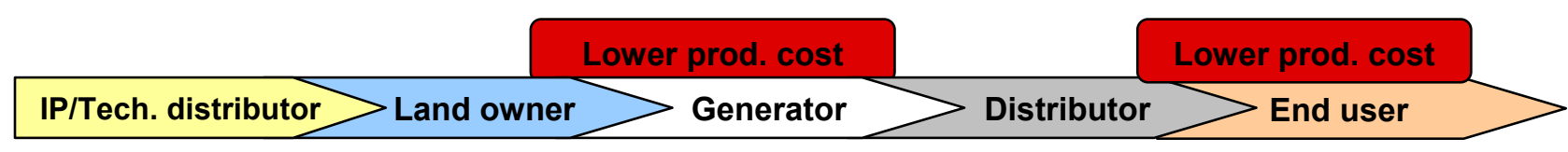

By reducing energy and materials costs alike, clean energy technologies can help firms reduce the cost of goods sold. If we examine the full footprint of clean energy technologies, it becomes evident that energy is not the only product generated. As a result, there are more opportunities for the products to help reduce costs in several downstream processes. A biorefinery, for example, does not just produce fuels for transportation and heating. In addition, one of the coproducts of refining can be used to produce a fabric (called Sonora ${ }^{\mathrm{TM}}$ ) that replaces existing oil-based fabrics like polyester. Other coproducts can be used as the base for chemicals that replace other chemicals typically produced from oil-based stocks.

In a similar way, a combined heat and power (CHP) facility produces electricity as well as steam. The steam can be used to heat a process or a space, reducing (and possibly eliminating) the cost associated with conventional heating, which would otherwise require the purchase of natural gas, which has increased in price dramatically in recent years. In some cases, a facility producing the steam cannot use it directly and instead pipes it to a nearby facility, which then pays the producer for the heat. The use of a by-product of electricity production as an input for another process provides financial benefits not typically captured in a conventional once-through cooling system.

In another vein, many studies attest to the fact that some renewable energy technologies require fewer expenditures on operations and maintenance (O\&M). Because there are fewer moving parts in a wind turbine or a PV panel than in a coal plant, fewer repairs are required over the life

\footnotetext{
${ }^{91}$ DOE Office of Energy Efficiency and Renewable Energy. (June 16, 2004) "Estimating the Payback Period of Additional Insulation." Available: http://www.eere.energy.gov/consumerinfo/factsheets/ea3.html (Accessed July 17, 2005)
} 
of the equipment. Additionally, the absence of a fuel cost for these types of technologies further reduces the cost of operation.

Not all clean energy technologies will result in lower costs of production than conventional processes, however. Biorefineries, for example, are still in the early stages of development, and the cost of producing and distributing ethanol is not yet cost-competitive with the market price of oil. Because these facilities are as complex as oil refineries, the cost of O\&M at a biorefinery is not expected to be significantly less than that at an oil refinery, unless the management of hazardous and toxic wastes is included. (See Benefits of Emissions Reductions section above.) As the industry matures, however, it is expected that the operation of biorefineries will become more efficient, although relative performance is still speculative at this stage.

\section{Value Chain Analysis}

Which actor benefits from lower costs of production associated with renewable sources of electricity generation will depend on the type of market regulation in place. In regulated markets, it is likely that the public utility commission will require the generator to detail its costs of production and will limit the level of profit that the generator may earn. In these cases, the benefits of the lower production costs will accrue mostly to the end user of electricity, thus creating a disincentive for regulated utilities to promote these technologies. In deregulated markets, the market is the only factor limiting the amount of return that a generator may earn; in these markets, the generator will have the option of retaining the savings, or he/she may pass it down to the distributor, who may pass it down to the end user of the electricity.

The value chain for a biorefinery that produces the raw materials for chemicals or other finished goods is slightly different, and it is not as linear as that of a typical electricity generator. In these cases, the value flows from the biorefinery, which can produce valuable chemical feedstocks as coproducts with the usual fuels produced. When bought by a manufacturer of chemicals or other finished products, the chemical feedstock creates new value, because it can reduce the cost of raw materials for the finished good (when compared with oil-based feedstocks). The bio-based feedstock may create additional value for the manufacturer, creating a premium product that generates additional revenue. Alternatively, the manufacturer may choose to hit a lower price point and pass these savings along to consumers.

\section{Calculation}

Since there are different components to the cost of production, calculating the value derived from lower production cost will require a variety of resources. Determining which are most appropriate for a given situation will depend on the technology assessed and the base case.

For clean energy technologies used to generate electricity, reduced costs of O\&M are the primary value drivers over conventional technologies when environmental costs are not considered. Methodologies on valuing O\&M for newer technologies are still evolving, and the range of estimates is quite broad. Here are a few sources to consult for background: 
- A 1999 DOE report that includes O\&M costs for conventional and clean energy technologies. ${ }^{92}$ Although the estimates for the clean energy technologies will have changed since the paper was written, this study is useful because it provides comparable data for all technologies examined and a consistent methodology.

- DOE's Office of Energy Efficiency and Renewable Energy's 2005 performance report explained the assumptions used to determine O\&M costs for wind. ${ }^{93}$

- A report commissioned by Americans for Solar Power estimates the O\&M value for solar and compares it to natural gas, based on a report prepared by Duke Energy. ${ }^{94}$

In the case of a biorefinery, it may be difficult to obtain comprehensive information on the economics of each element-O\&M, feedstocks, and finished products - in one report. The specific geographic location will impact the economics, as will the types of coproducts sold in addition to the ethanol. Some examples of available resources include the following:

- An assessment of the economics of ethanol from biomass in northwest Minnesota and northeastern North Dakota. This report includes information on O\&M, and sensitivity of bioethanol cost to feedstock price and to electricity cost. ${ }^{95}$

- An NREL study creates a more generic assessment of the costs of the corn stover to ethanol process design, capital costs, and O\&M. It also provides a cash-flow analysis based on the selling price of ethanol. ${ }^{96}$

- The Energy Trust of Oregon estimated O\&M for several types of biomass-to-energy technology: large anaerobic biogas, small anaerobic biomass, and animal waste anaerobic digesters. ${ }^{97}$ Costs varied among these types of biomass, which should indicate the importance of examining the costs and benefits on a technology-by-technology basis.

- The Copernicus Institute has developed current cost estimates for the production of FischerTropsch diesel from biomass and methanol and hydrogen from biomass. ${ }^{98,99}$ Other follow-up studies may be expected.

\footnotetext{
${ }^{92}$ Market-Based Advanced Coal Power Systems. (May 1999) Department of Energy. Available: http://www.fossil.energy.gov/programs/powersystems/publications/MarketBasedPowerSystems/MarketBased_Advanced_Coal_Power_Systems.html

${ }^{93}$ Office of Energy Efficiency and Renewable Energy. (2005) FY05 Government Performance and Results Act (GPRA) Benefits Report. Available: http://www.eere.energy.gov/office eere/gpra_estimates fy05.html

${ }^{94}$ Americans for Solar Power. (2005) "Build-up of PV Value in California." See Methodology section. Available: http://www.forsolar.org/?q=node/98

${ }_{95}$ Mann, M.D. and Bryan, M. (May 2001) "Feasibility of Producing Ethanol from Biomass in Northeastern North Dakota and Northwestern Minnesota." Prepared for Western Regional Biomass Energy Program, North Dakota Division of Community Services, Red River Regional Council, Red River Resource Conservation and Development Council (RCDC), Pembina Trail RCDC, WesMinn RCDC, Lake Agassiz RCDC, Minnesota Department of Natural Resources. Available: http://www.westbioenergy.org/reports/mm-ethanol.htm

${ }^{96}$ Aden, A. et al. (June 2002) Lignocellulosic Biomass to Ethanol Process Design and Economics Using Co-Current Dilute Acid Prehydrolysis and Enzymatic Hydrolysis for Corn Stover. National Renewable Energy Laboratory Document No. NREL/TP-510-32438.

${ }^{97}$ Itron. (December 2004) Biomass Market Assessment: Final Report. Prepared for the Oregon Energy Trust.

${ }^{98}$ Hamelinck, C.N. and A.P.C. Faaij and H. den Uil and H. Boerrigter. (March 2003) Production of FT

Transportation Fuels From Biomass; Technical Options, Process Analysis and Optimisation, and Development Potential. University of Utrecht Copernicus Institute.

${ }^{99}$ Hamelinck, C.N. and A.P.C. Faaij. (September 2001) Future Prospects for Production of Methanol and Hydrogen from Biomass. University of Utrecht Copernicus Institute.
} 
- Spath and Dayton conducted an economic analysis of several types of bio-based fuels and products: hydrogen, methanol, Fischer Tropsch, ethanol, mixed ethanol, and olefin. ${ }^{100}$ They assessed minimum product-selling prices, which could help firms considering the production or use of these products to assess the associated benefits.

- Werpy et al. identify markets for the top 12 chemicals from biomass and assesses the potential values associated with several of them, including 2,5-furan dicarboxylic acid (FDCA) glucaric acid, luvulinic acid, and glycerol. ${ }^{101}$

${ }^{100}$ Spath, P. and D. Dayton_Preliminary Screening - Technical and Economic Assessment of Synthesis Gas to Fuels and Chemicals with Emphasis on the Potential for Biomass-derived Syngas, NREL Technical Report NREL/TP510-34929, December 2003)

${ }^{101}$ Werpy, T. and G. Petersen et al. (August 2004) “Top Ten Value Added Chemicals From Biomass: Volume I Results of Screening for Potential Candidates from Sugars and Synthesis Gas.” NREL Report No. TP-510-35523. 


\section{Corporate Social Responsibility}

In addition to the direct cost savings or revenue boosters discussed above, clean energy technologies create value for firms developing, distributing, or using these technologies by enhancing the firms' CSR practices. In the literature, the term "CSR" is often interchanged with others, such as corporate citizenship, sustainable development, business ethics, and corporate sustainability. For the purposes of this paper, rather than narrowly defining the term CSR, it will encompass a broad range of metrics that are often included in indices that measure the performance of CSR and these related concepts - human rights, environmental performance, ethics, workplace conditions, stakeholder relations, transparency, and others.

By extending the definition of CSR in a broad sense, future financial analyses can build on the experience of a wealth of studies about the benefits (and risks) associated with such practices. Scholars have been evaluating the financial implications of CSR practices for more than 30 years. They have explored many different methodologies, controls, and criteria. Rather than examining each study in detail, we include the results of two meta-analyses - those studies that have aggregated the data in scores of existing studies to arrive at an overall conclusion.

- Orlitzky, Schmidt, and Rynes analyzed 52 existing studies that examined the link between corporate social performance (CSP) and corporate financial performance (CFP). They found a positive correlation between the two across studies. It was not clear, however, whether good CSP caused good CFP or the other way around; the causation went both ways. ${ }^{102}$

- Margolis and Walsh considered 85 existing studies that evaluated a similar link. Of those 85 studies, 55 were found to have identified a positive correlation between better social performance and better financial performance. ${ }^{103}$

In another recent study, Derwall et al. found that the financial performance of firms with the highest measure of eco-efficiency exceeded that of firms with the lowest-ranking eco-efficiency scores by 6\% percent between 1995 and 2003; this difference could not be explained by differences in portfolio risk, investment style, or sector exposure. ${ }^{104}$ Building on Derwall's research, the winners of the 2005 Moskowitz Prize, Guenster et al, found a correlation between poor environmental performance and poor financial results. Further, they found that companies with superior environmental performance had neither superior nor inferior financial results compared to the control group, leading to the conclusion that sound environmental policies need not be viewed as threats to corporate financial performance. ${ }^{105}$

\footnotetext{
102 Orlitzky, M. and Schmidt, F.L. and Rynes, S.L. (2003) "Corporate Social and Financial Performance: A MetaAnalysis." Organization Studies 24(3): 403-441.

${ }^{103}$ Margolis, J. and Walsh, J. (2001) People and Profits? The Search for a Link Between a Company's Social and Financial Performance Lawrence Erlbaum Associates: Mahwah, N.J.

${ }^{104}$ Derwall, J. et al. (2004) “The Eco-Efficiency Premium Puzzle.” Financial Analysts Journal, 61(2): 51-63.

${ }^{105}$ Guenster, N. et al. (2005) "The Economic Value of Corporate Eco-Efficiency." Available: http://www.sristudies.org/GuensterPaper.pdf
} 
Companies that demonstrate their ability to devise, implement, and monitor CSR practices tackle one of the most complex challenges facing corporations today. Because of the diversity of parties involved in undertaking such an effort and the high levels of uncertainty that they must address, management teams that address CSR are regarded as extremely sophisticated - management quality is the primary driver of stock returns. Thus, companies with above-average CSR performance are expected to have the capacity to address typical corporate performance issues just as well. ${ }^{106}$

Despite the growing literature demonstrating the benefits of CSR to firms, criticisms of these models remain. Some critics assert that only government should concern itself with questions about social justice, the availability of public goods, and the problems created by externalities these critics support Milton Friedman's quip, "The business of business is business." the central arguments of this group of critics is that a corporation's responsibility is to generate profits for its owners; firms concerned with these other issues are simply distracting themselves from that responsibility. ${ }^{108}$ What these critics fail to see is that if firms employ the practices supported by CSR as part of their strategic planning process, CSR can actually enhance the ability of firms to fulfill the responsibility to generate profits. ${ }^{109}$

The value associated with CSR goes beyond the favorable public relations that it might generate. Indeed, proactive approaches to addressing stakeholder concerns - one aspect of CSR - can help reduce transaction costs and avoid entangling lawsuits. Open lines of communication with the public and with organizations concerned about social and environmental issues related to a firm's core business can also create opportunities for the firm to identify and capitalize on trends in consumer preferences earlier than insular competitors. ${ }^{110}$ Further, the market value of companies that invest in CSR may increase, due to their enhanced ability to demand higher prices for their stocks and products. The following subsections elaborate on these points.

\section{Improve stakeholder relations}

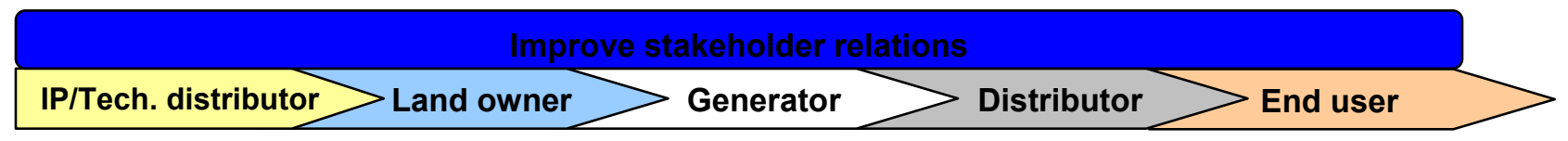

As the protests before and during the World Trade Organization (WTO) meetings in Seattle in 1999 demonstrated, businesses are no longer affected by only their employees, customers, and shareholders. Today, companies must acknowledge that they operate in a much larger sphere and address the concerns of the community members who live near their facilities, as well as people who are concerned about environmental stability, regulators, and other interested parties around

\footnotetext{
${ }^{106}$ Dixon, F. (December 2003) "Total Corporate Responsibility: Achieving Sustainability and Real Prosperity." Ethical Corporation Magazine.

107 "The Ethics of Business." (January 20, 2005) The Economist.

108 "The Ethics of Business." (January 20, 2005) The Economist.

109 "The Biggest Contract. (May 26, 2005) The Economist.

110 “The Biggest Contract. (May 26, 2005) The Economist.
} 
the world. Increasingly, fair and inclusive treatment of stakeholders is viewed as an effective strategy for improving both financial performance and overall organizational performance. ${ }^{111}$

Nevertheless, the support of traditional stakeholders - like employees - remains crucial. CSR can help with that concern, too. For example, a company that pays attention to the social and environmental implications of its core business can create a work environment more attractive to higher-quality employees, providing the firm with a sustained competitive advantage over its rivals. ${ }^{112}$ More satisfied employees mean more productive employees, which translates into dollars on the financial statements every quarter.

Further, shareholder activism has become a more popular strategy for affecting firm behavior in recent years. While the assets committed to shareholder advocacy decreased between 2001 and 2003 , the number of shareholder resolutions increased from 269 to 310 during the same time period. ${ }^{113}$ Chevron Texaco, General Electric, and American Electric Power, for example, all saw resolutions pass in 2003 related to GHG emissions and reporting, and renewable energy investment. ${ }^{114}$ In the eyes of the public, it is much better for a firm to proactively address issues that might threaten its business than to have such efforts mandated by a stakeholder resolution.

In the end, investments in clean energy technologies can generate support among stakeholders, because they are seen as a step toward sustainability - a step that helps the company as well as current and future stakeholders. By incorporating stakeholder concerns into business decisions, firms can avoid some of the legal and public relations difficulties that have plagued multinational firms in recent years. That helps create a more attractive balance sheet.

\section{Value Chain Analysis}

Direct financial benefits of solid stakeholder relationships accrue to several actors:

- The firm benefits from increased worker productivity, decreased costs associated with high turnover rates, avoided costs of legal action, and a less restricted "license to operate" resulting from enhanced trust with external stakeholders.

- Firms that are well-connected to the public - and to organizations concerned about social and environmental issues - can foresee and capitalize on changes in consumer preferences and shifts in the market earlier than competitors that only respond to those changes after the organizations have mounted destructive public campaigns to build awareness about the issue.

\footnotetext{
${ }^{111}$ See Waddock, S. and Graves, S. (1997) "Finding the link between stakeholder relations and quality of management." Social Investment Forum. Available: http://www.socialinvest.org/Areas/Research/Moskowitz/1997 full.htm

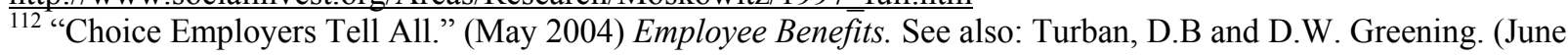
1997) "Corporate Social Performance and Organizational Attractiveness to Prospective Employees." Academy of Management Journal 40(3): 658-672. AND Bauer, T.N. and Aiman-Smith, L. (1996) "Green Career Choices: The influence of ecological stance on recruiting." Journal of Business and Society 10(4) 445-458, as cited in Bevan, S. and Isles, N. and Emery, P. and Hoskins, T. (March 2004) Achieving High Performance: CSR at the Heart of Business. The Work Foundation: London. Available: http://www.theworkfoundation.com/pdf/184373017.pdf

${ }^{113}$ Social Investment Forum. (2003) 2003 Report on Socially Responsible Investing Trends in the United States. Available: http://www.socialinvest.org/areas/research/trends/sri trends_report_2003.pdf

${ }^{114}$ Ibid.
} 
- If the firm's reputation for attending to stakeholder concerns becomes notable, evidence shows that stock prices will reflect the benefits of that practice, which evidence has shown beneficial during economic downturns. ${ }^{115}$

- If stakeholder relations are solid, all parties involved avoid the cost of protracted litigation and the associated expenses when firm decisions conflict with the values of the community or other stakeholders.

- These benefits may accrue to the firms or their shareholders at any position in the value chain for clean energy technologies, whether it is the licensee, generator, distributor, or end user.

\section{Calculation}

Depending on which aspect of the value of stakeholder relationships is to be quantified, several different approaches have been examined. The following is a sample:

- By examining the performance of firms scoring well in Fortune's "Most Admired Firms in America" against the performance of other firms during the stock market crash of October 13, 1989, Jones et al. drew a connection between reputation and stock value. Those firms included in the "Most Admired" list endured lower market-value losses than the others. ${ }^{116,117}$

- Similarly, the stock performance of Fortune 500 companies with reputations for CSR ( $1 \%$ decline) was impacted less than the stock performance of Fortune 500 companies without reputations for CSR $(2.36 \%$ decline) following the WTO protests in Seattle in 1999. For the average firm in the sample examined by the researchers, that difference equated to a $\$ 378$ million shareholder loss. ${ }^{118}$

- Firms that sign on to the UN Global Compact agree to follow its nine principles in the categories of human rights, labor standards, and the environment. A recent study showed that the firms within the Dow Jones Sustainability Index that had signed the UN Global Compact performed better during the June 2001-June 2004 period than mainstream firms in the Morgan Stanley Capital Index by 3.7\%. ${ }^{119}$

\footnotetext{
${ }^{115}$ Jones, G., Jones, B. and Little, P. (2000) "Reputation as a Reservoir: Buffering against loss in times of crisis." Corporate Reputation Review 3(1) 21-29, as cited in Schnietz, K. and Epstein, M.J. (2005) "Exploring the Financial Value of a Reputation for Corporate Social Responsibility During a Crisis." Corporate Reputation Review 7(4) 327345 .

${ }^{116}$ Jones, G., Jones, B. and Little, P. (2000) "Reputation as a Reservoir: Buffering against loss in times of crisis." Corporate Reputation Review 3(1) 21-29, as cited in Schnietz, K. and Epstein, M.J. (2005) "Exploring the Financial Value of a Reputation for Corporate Social Responsibility During a Crisis." Corporate Reputation Review 7(4) 327345 .

${ }^{117}$ Waddock and Graves demonstrated a strong relationship between a corporation's appearance on the Fortune 500 Most Admired list and its CSR performance. See Waddock, S. and Graves, S. (1997) "Finding the link between stakeholder relations and quality of management." Social Investment Forum. Available: http://www.socialinvest.org/Areas/Research/Moskowitz/1997 full.htm

${ }^{118}$ Schnietz, K. and Epstein, M.J. (2005) "Exploring the Financial Value of a Reputation for Corporate Social Responsibility During a Crisis." Corporate Reputation Review 7(4) 327-345.

${ }^{119}$ Fussler, C. (Winter 2004) "Responsible Excellence Pays!” JCC 16, 33-44. Study was performed by Sustainable Asset Management (SAM).
} 


\section{Satisfy SRI portfolio criteria}

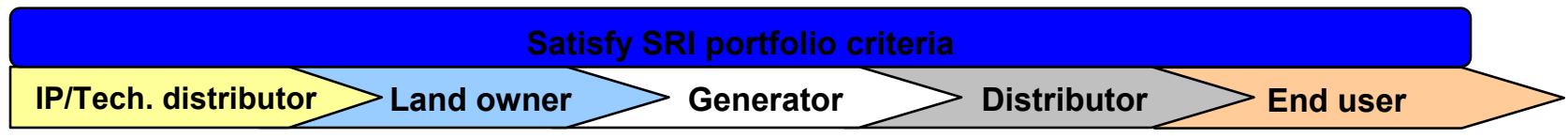

In the past decade, the socially responsible investing (SRI) market segment has grown exponentially - and faster than the conventional investment marketplace. ${ }^{120}$ Pax World Funds started the first SRI fund in 1971, and that number surpassed 200 funds by 2003, driven in large part by individual investors' interest, rather than institutional investors. ${ }^{121,122}$ More investors are choosing to invest in corporations that pass through the filter of SRI indices such as the Dow Jones Sustainability Index, FTSE4GOOD, and of SRI investment portfolios including Domini and Calvert. Between 1995 and 2003, for example, the amount of money invested in SRI investments grew $40 \%$ faster than all professionally managed investment assets taken together. ${ }^{123}$ When asked, an increasing number of consumers would opt to conduct business with sustainable companies if given the choice - earning a place among such companies can help firms attract new customers.

SRI funds select firms to include in their portfolios and pursue the "socially responsible" aspect of investment using several different methods. Some SRI funds simply screen out firms involved in certain products (e.g., tobacco or alcohol), avoiding any investment in firms that manufacture those products - or derive more than a certain percentage of their revenue from them. Alternatively, an SRI fund may establish a specific set of criteria (including, e.g., number of women in executive positions, commitment to environmental performance) and research corporate performance based on those criteria. Those firms that meet the benchmark are eligible for inclusion, while those that fall below it are excluded. ${ }^{124}$

While market demand for SRI indices and portfolios continues to grow, debate continues about how to compare their performance to that of more traditional investment options. The determination of which corporations fit under the socially responsible umbrella often lies at the heart of this debate. These definitions vary from one index to another, making it difficult to aggregate SRI funds and portfolios in an analysis. Further, the credibility of these funds sometimes suffers because investors (and critics) lack access to information about the process employed for selecting firms for inclusion. ${ }^{125}$

\footnotetext{
${ }^{120}$ Social Investment Forum. (2001) Report on Socially Responsible Investing Trends in the United States, as cited in Goodman, S.B. and Kron, J. and Little, T. (2001) The Environmental Fiduciary: The Case for Incorporating Environmental Factors into Investment Management Policies. The Rose Foundation for Communities and the Environment. Available: http://www.rosefdn.org/images/EFreport.pdf

${ }^{121}$ Social Investment Forum. (2003) 2003 Report on Socially Responsible Investing Trends in the United States. Available: http://www.socialinvest.org/areas/research/trends/sri trends_report_2003.pdf

${ }^{122}$ Gunsauley, C. (October 1, 1999) "Grass roots support, good returns boost socially responsible funds." Employee Benefit News.

${ }^{123}$ Social Investment Forum. (2003) 2003 Report on Socially Responsible Investing Trends in the United States. Available: http://www.socialinvest.org/areas/research/trends/sri trends_report_2003.pdf

${ }^{124}$ Schepers, D.H. and S. Prakash Sethi. (Spring 2003) "Do Socially Responsible Firms Actually Deliver What They Promise?" Business and Society Review 108(1): 11-32.

${ }^{125} \mathrm{Ibid}$
} 
Other questions remain about the direction of causality: Does superior CSR cause higher returns on investments? Or do firms with more capital and better established brand names tend to invest more in CSR? Research in this area continues to explore these relationships; the Guenster et al. study that was cited in the introduction to the CSR subsection made significant progress in this area. As that dialogue continues, investors continue to support firms with strength in CSR categories.

Despite these imperfections, some EU Member States now require institutional investors to disclose their process for considering the social, environmental, and ethical aspects of their portfolio and of any future investments. ${ }^{126}$ Although the law does not require investment houses to invest exclusively in socially responsible companies, it does increase the transparency of these issues. It also enables investors to make better-informed decisions about which institutions to entrust with their finances.

\section{Value Chain Analysis}

Every actor in the value chain may reap financial benefits from its involvement with clean energy technologies by qualifying for SRI funds and indices. Manufacturers, distributors, and users of clean energy technologies can earn notoriety as firms that care about the environment and are "walking the talk." If the firm is also engaged in the other activities required for it to be included in an SRI fund, then the clean energy technology can translate into a larger market cap for the firm and build their brand, generating more interest in their products.

Further, a firm involved in any aspect of the value chain can gain competitive advantage through the conception of its CSR report, which is an integral element in determining acceptance into almost any SRI portfolio. ${ }^{127}$ If the firm creates metrics that help decision makers identify opportunities for progress and then integrates the information provided in strategic decisions, the CSR report is not solely a public relations device. At that point, it becomes a tool for analyzing business decisions that may involve efficient use of materials or labor, stakeholder input, and waste reduction - all of which can result in lower costs of doing business.

Larger corporations with extensive supply chains have recently moved to increase their control over suppliers. In many cases, this entails mandating the implementation of specific corporate governance tactics, including aspects of CSR. For example, Ford, General Motors, and DaimlerChrysler have required all of their suppliers to develop environmental management systems (EMSs) for their operations. ${ }^{128}$ One report called supply-chain issues the "sleeping giant in the CSR field," $" 129$ and another paper proposed a rationale for why engineers should consider

\footnotetext{
${ }^{126}$ Communication from the Commission concerning Corporate Social Responsibility: A business contribution to sustainable development. (July 2002) Commission of the European Communities.

${ }^{127}$ Friend, G. (January-February 2003) "Truth and Transparency: The why and how behind world-class corporate environmental reporting.”Green@Work.

128 "Environmental Supply Chain Management." Five Winds International. Available: http://www.fivewinds.com/uploadedfiles shared/EnvironmentalSupplyChainManagement040127.pdf

${ }^{129}$ Barrett, M. et al. (Winter 2003) "The Future of Corporate Social Responsibility." Concern for Community. Canadian Co-op Association. Available:

http://www.coopscanada.coop/newsletter/CSR/Winter2003/\#GrowthInImportance
} 
environmental issues in supply-chain management. ${ }^{130}$ Firms that integrate CSR practices into their operations can use their CSR as a competitive advantage when submitting bids for such large corporations, turning it into a financial benefit if they win the bid.

Shareholders of such firms may also see benefits in the form of higher stock prices.

\section{Calculation}

In response to critics who believe that socially responsible behavior will weaken corporate financial performance, the bulk of available studies points to the fact that SRI indices perform as well as or better than their conventional counterparts. These resources help quantify how the benefit translates into financial terms (to either the corporation or its shareholders), or at least demonstrate that such SRI funds do not perform differently than their conventional counterparts:

- Dowell, Hart, and Yeung found that the market value of firms adopting global environmental standards was higher than that of firms that adopted (less-stringent) local standards. $^{131}$

- During 2001 and 2002, the value of assets under management in socially screened portfolios evaluated by the Social Investment Forum grew 7\%, while the value of assets invested in portfolios that were not socially screened fell by $4 \%{ }^{132}$

- A 1993 study by Hamilton, Jo, and Statman found that the difference between the growth of socially responsible mutual funds and the growth of conventional mutual funds was not statistically significant. ${ }^{133}$

- Similarly, Guerard Jr.'s 1997 study demonstrated no statistically significant difference in the growth of socially screened portfolios when compared to unscreened portfolios during the period 1987-1996. ${ }^{134}$

- Bauer, Koedijk, and Otten found no statistically significant difference among 103 riskadjusted socially screened mutual fund portfolios and conventional counterparts between 1990 and 2001. Once betas are considered, however, U.S. SRI funds underperform their domestic counterparts, while British SRI funds outperform their domestic counterparts. Further, the authors found that older funds perform better after a "learning period,"

\footnotetext{
${ }^{130}$ Beamon, B.M. (2005) "Environmental and Sustainability Ethics in Supply Chain Management." Science and Engineering Ethics 11(2): 221-234.

${ }^{131}$ Dowell, G. and S. Hart and B. Yeung. (August 2000) "Do Corporate Global Environmental Standards Create or Destroy Market Value?" Management Science 46(8): 1059-1074.

${ }^{132}$ Social Investment Forum. (December 2003) 2003 Report on Socially Screened Investing Trends in the United States. SIF Industry Research Forum: Washington, D.C.

${ }^{133}$ Hamilton, S. and H. Jo and M. Statman. (November-December 1993) "Doing Well While Doing Good? The Investment Performance of Socially Responsible Mutual Funds.” Financial Analysts Journal. NOTE: The value of assets included in this study ( $\$ 600$ billion) is considerably less than that considered in more recent studies (on the order of $\$ 2.1$ trillion).

${ }^{134}$ Guerard Jr., J.B. (Winter 1997) “Additional evidence on the cost of being socially responsible.” Journal of Investing 6(4): 31-35.
} 
compared with younger SRI funds, which typically underperform compared to their conventional counterparts. ${ }^{135}$

- Approximately $20 \%$ of SRI mutual funds earned a five-star rating in Morningstar's ranking system, compared with only $10 \%$ of all mutual funds. ${ }^{136}$ Morningstar's rankings depend on the previous 60 months of a mutual fund's performance data compared to similar funds. ${ }^{137}$

On the other hand, a firm that develops CSR principles and practices - and implements and monitors them - incurs additional costs in administration, training, and other areas, depending on the industry. For example, a CSR report for a large corporation could cost into the hundreds of thousands of dollars by the time data collection, report design, compilation, and printing are completed. ${ }^{138}$ Studies on this aspect of CSR are not prevalent, as the costs vary significantly by firm and by industry. These would need to be assessed, however, in order to develop a comprehensive cost-benefit analysis.

\footnotetext{
${ }^{135}$ Bauer, R. and K.C.G. Koedijk and R. Otten. (July 2002) "International Evidence on Ethical Mutual Fund Performance and Investment Style.” Centre for Economic Policy Research Discussion Paper No. 3452.

${ }^{136}$ Gunsauley, C. (October 1, 1999) "Grass roots support, good returns boost socially responsible funds." Employee Benefit News.

${ }^{137}$ Morningstar Research. (March 2005) “The Morningstar Rating Methodology.” Available: http://www.morningstar.com.au/marketing/aws/Rating methodology.pdf

${ }^{138}$ Friend, G. (January-February 2003) "Truth and Transparency: The why and how behind world-class corporate environmental reporting." Green@Work
} 


\section{Societal Economic Benefits}

Thus far, the financial benefits of clean energy technologies discussed could be calculated for individual actors along the value chain. Some of the benefits of clean energy technology, however, do not accrue directly to the companies that invest in the technologies. Some of the financial benefits accrue to the surrounding community or to society as a whole. The benefits in this societal category fall outside of the traditional value chain, almost as by-products of the benefits that are traditionally examined in a business case.

Despite the fact that companies may not be able to calculate direct value in these cases, these byproducts can help build support for the projects within the community, facilitating the process of stakeholder buy-in and reducing transaction costs. By building positive relationships early on, the company can avoid negative publicity by groups that protest the project or take legal action to prevent it. Alternatively, these values may be able to be included in the price of the products. In general, further research is needed to explore effective ways for actors along the value chain to capture these benefits.

These farther-reaching benefits do benefit the firm as a part of society, however. Avoided costs of transmission and distribution expansion, for example, will accrue to a generator investing in clean energy technology in the same way it will accrue to a homeowner. Because such markets ignore so many externalities, however, the benefits of the avoided costs are difficult to allocate to individual market players. As a result, these values are not usually considered in traditional analyses, but they should be acknowledged - either to heighten awareness about the need for further study or to identify externalities that distort the market, making it more difficult for clean energy technologies to enter the market.

\section{$\underline{\text { Rural Revitalization }}$}

As rural America struggles to find jobs to support its populations, identifying additional revenue streams is vital to its continued existence. Even urban Americans identify with the idyllic image of the American farmer - and firms that enable them to continue that existence generate favor with many Americans. In the end, this creates value to the companies involved in the relevant technologies in the form of goodwill, which can affect the balance sheet.

\section{Value Chain Analysis}

Clean energy technologies can contribute significantly to the revitalization of rural economies. In the case of wind, farmers can generate extra income on their properties by leasing small portions of their fields - either active or inactive - to wind developers without significantly affecting their regular operations. ${ }^{139}$ These turbines may also increase tourism to rural parts of the country, creating a new industry or further developing an existing one.

In the case of biomass technologies, new markets are created for some of the residues associated with agriculture (e.g., corn stover) in most cases, and for the entire commodity in some cases.

${ }^{139}$ U.S. DOE/EERE. "Wind Energy for Rural Economic Development." Available: http://www.nrel.gov/docs/fy04osti/33590.pdf 
Instead of producing just one finished product (food), the agricultural products and by-products can be used to generate several value streams (e.g., food, energy, and DuPont's Sonora ${ }^{\mathrm{TM}}$ fabric), increasing the value of the feedstocks and enabling farmers to charge a premium for their goods. As an added benefit, some methods of collecting the agricultural residues actually help reduce the amount of carbon that escapes from the soil. ${ }^{140}$ When carbon regulations are instituted in the United States, this may create yet another revenue stream for farmers, separate from the GHG reductions seen at the point of generation.

\section{$\underline{\text { Jobs }}$}

Whether clean energy technologies are built or utilized in rural, suburban, or urban areas, jobs are created to support the new industry in manufacturing, transportation, project construction, and operations and maintenance (O\&M). Some studies show that clean energy technologies (such as wind) actually create more permanent jobs in a community than conventional technologies (such as coal or natural gas), based on the amount of electricity produced. ${ }^{141}$ Estimates of regional job growth from clean energy technologies have become more prevalent in recent years. ${ }^{142}$ Furthermore, these jobs are high-quality and sustainable jobs; many of them require skilled labor or post-secondary education. As a result, communities will be more willing to accept such businesses into their community and may even be willing to provide companies with tax incentives. (See Direct Policy Incentives section above.)

Some critics argue that the adoption of clean power technologies detracts from the conventional energy industry. As long as the demand for energy continues to grow (which it is projected to do for the next two decades), ${ }^{143}$ the adoption of clean energy technologies will not reduce the number of existing jobs in those fields. In many cases, jobs in conventional energy fields are already decreasing, due to consolidation within the field and automation within the plant and mining operations. ${ }^{144}$ Clean energy technologies do not impact those processes.

\footnotetext{
${ }^{140}$ Sheehan, J. (2004) "Energy and Environmental Aspects of Using Corn Stover for Fuel Ethanol.” Journal of Industrial Ecology 7(3-4): 117-146.

${ }^{141}$ Renewable Energy Technology and Environmental Coalition's testimony before the New York Public Service Commission's hearing on Case 03-E-0188. (28 March 2003) Citing a study conducted by the New York State Energy Research and Development Authority (NYSERDA) that asserted that wind energy creates 27 percent more jobs than coal and 66 percent more jobs than a natural gas-fired power plant to produce the same amount of energy. SEE ALSO: Kammen, D. and K.Kapadia and M. Fripp. (April 2004) Putting Renewables to Work: How many jobs can the clean energy industry generate? Renewable and Appropriate Energy Laboratory Report: University of California, Berkeley.

${ }^{142}$ See, e.g., Regional Economics Applications Laboratory. (December 2002) Job Jolt: The economic impacts of repowering the Midwest: The Clean Energy development plan for the Heartland. Environmental Law and Policy Center, Chicago.

See also, Southwest Energy Efficiency Project. (November 2002) The New Mother Lode: The Potential for More Efficient Electricity Use in the Southwest. A report in the Hewlett Foundation Energy Series.

${ }^{143}$ Department of Energy - Energy Information Administration. (January 2005) Annual Energy Outlook 2005 With Projections to 2025.

${ }^{144}$ Kammen, D. and K.Kapadia and M. Fripp. (April 2004) Putting Renewables to Work: How many jobs can the clean energy industry generate? Renewable and Appropriate Energy Laboratory Report: University of California, Berkeley.
} 


\section{Value Chain Analysis}

The direct financial benefits of jobs accrue to those who obtain the jobs. Of course, the money they earn will be spent within the larger economy, generating indirect and induced economic benefits, which will add to the overall impact of the direct job creation. In the next section, these broader implications of the new jobs are explored.

\section{$\underline{\text { Economic development }}$}

Although jobs can be considered part of the economic development equation, they are separated in this context because of their ability to quickly generate support from local and state elected officials and community members. Other, more complex, aspects of economic development are quantifiable using a variety of techniques; but the public's attention to these broader implications is much less than its attention to the more tangible benefits of new jobs. Elected officials and other decision makers do consider these broader economic benefits more than the public does, however. Thus, the benefits associated with broader economic development goals (both financial and nonmonetary) are different than those associated with jobs and are discussed separately.

The broader economic implications of clean energy technologies are diverse. Koren and Tenreyro argue that a diverse technology portfolio can help stabilize the GDP, in much the same way that a diverse stock portfolio can help stabilize annual returns. ${ }^{145}$ At the same time, new clean energy businesses - like any new businesses - expand the tax base, whether it is at the local, state, or federal level. More locally, firms engaged in clean energy technology development may attract additional attention by locating in economic development zones focused on clean energy; and the community in which the firm locates can gain additional notoriety as a clean energy technology haven, which may attract even more business.

The economic benefits of clean energy technologies quickly disperse throughout a community, far beyond the additional salaries provided to employees or the capital investment in new infrastructure. Economic multipliers for clean energy technologies vary by technology, but Table 5 provides a sample set of multipliers for PV for the state of California. The Analysis of State Solar Economic Trade-offs Databank (ASSET) can provide similar multipliers for solar in any state. Multipliers for other technologies are also available through other data banks.

Table 5. Lifetime Benefits per Installed MW of Photovoltaics (Solar Electricity) for California ${ }^{146}$

\begin{tabular}{|c|c|c|c|c|c|c|c|}
\hline \multicolumn{4}{|c|}{ If total cost is $\$ 8 \mathrm{M}$ per $\mathrm{MW}$} & \multicolumn{4}{|c|}{ If total cost is $\$ 10 \mathrm{M}$ per $\mathrm{MW}$} \\
\hline $\begin{array}{l}\text { Total } \\
\text { cumulative } \\
\text { GSP increases } \\
\text { (\$M) }\end{array}$ & $\begin{array}{l}\text { Total } \\
\text { increase in- } \\
\text { state job } \\
\text { years }\end{array}$ & $\begin{array}{l}\text { Increase in } \\
\text { Earnings } \\
(\$ M)\end{array}$ & $\begin{array}{l}\text { Household } \\
\text { Income } \\
\text { Increase per } \\
\text { MW in \$ }\end{array}$ & $\begin{array}{l}\text { Total } \\
\text { cumulative } \\
\text { GSP increases } \\
(\$ M)\end{array}$ & $\begin{array}{l}\text { Total } \\
\text { increase in- } \\
\text { state job } \\
\text { years }\end{array}$ & $\begin{array}{l}\text { Increase in } \\
\text { Earnings } \\
(\$ M)\end{array}$ & $\begin{array}{l}\text { Household } \\
\text { Income } \\
\text { Increase per } \\
\text { MW in \$ }\end{array}$ \\
\hline 7.7 & 112 & 6.30 & 0.46 & 12.5 & 152 & 7.88 & 0.58 \\
\hline
\end{tabular}

\footnotetext{
${ }^{145}$ Koren, M. and S. Tenreyro. (December 2004) Technological Diversification. Federal Reserve Bank of Boston Working Paper 05-1.

${ }^{146}$ Million Solar Roofs Initiative / Segue Energy Consulting. (June 6, 2005) "California Solar Benefits Analysis.”
} 
Some states considering the adoption of an RPS have also completed economic impact analyses that may include economic multipliers at the state level. ${ }^{147}$ Such studies, while limited in number, may provide a good reference for higher-level business cases.

At a much higher level, clean energy technologies contribute to gross domestic product (GDP) growth while creating jobs. While these are small increases relative to the size of the entire economy, they require only small investments.

\section{Value Chain Analysis}

The broader economic impacts of either locating a clean energy technology firm in a specific area or implementing the technology are spread to many different constituencies. For example:

- This increased spending multiplies within the community and is shared among many actors - everyone from the stylist at the local beauty parlor to the owners of the car dealership.

- Property values may increase as a result of the installation of new technology (whether wind turbines, solar PV, or a biorefinery), which can contribute to an increased tax base. In turn, the amount of funding available for education, local government, and government services increases as well.

- On an international level, rural electrification has been shown to result in higher levels of education, which increases an individual's long-term earning potential. ${ }^{148}$

Quantifying which actors specifically receive the benefits of clean energy in this context is extremely difficult. Hence, it is characterized as a societal benefit. Although it is difficult to capture these types of values in pricing, studies quantifying the benefit to a community may create leverage for firms when negotiating with government agencies for business incentives.

\section{Avoided environmental costs of fuel extraction/transportation}

The extraction of fossil fuels from the earth and their transport to the site of use can contribute significantly to the amount of water used in the production of energy and to the amount of pollutants released during the fuel's life cycle. For example:

- During the production of electricity using coal, the extraction process accounts for roughly half of the water used. The oil used to transport the coal to the plant can account for between $45 \%$ and $95 \%$ of the oil used during the entire process of generating electricity. ${ }^{149}$

- When producing electricity using a natural gas combined-cycle system, about one-quarter (124.5 g CO2-equivalent per kWh produced) of the GHGs emitted result from the production and distribution of natural gas. Furthermore, it actually takes more energy to

\footnotetext{
${ }^{147}$ See, e.g., Center for Energy, Economic, and Environmental Policy. (December 2004) Economic Impact Analysis of New Jersey's Proposed 20\% Renewable Portfolio Standard. Prepared for NJ Board of Public Utilities - Office of Clean Energy.

${ }^{148}$ Rural Electrification in the Philippines: Measuring the Social and Economic Benefits. (May 2002) Joint UNDP/World Bank Energy Sector Management Assistance Program (ESMAP): Washington, D.C.

${ }^{149}$ Spath, P.L. and M.K. Mann and D.R. Kerr. (June 1999) Life Cycle Assessment of Coal-fired Power Production. National Renewable Energy Laboratory, Golden, CO.
} 
produce electricity using natural gas than the process produces in the form of electricity for every $1.0 \mathrm{MJ}$ of energy put into the system, only $0.4 \mathrm{MJ}$ are produced. The extraction and transport steps consume $93 \%$ of the nonfeedstock energy used to produce electricity (1.58 MJ/kWh produced) and 94\% (by weight) of the solid waste produced.

- Comparatively speaking, environmental impacts of using willow biomass for electricity production are relatively small. ${ }^{150}$ Producing and transporting the willow feedstock releases GHGs with a global warming potential 38\%-52\% less per MWh than GHGs produced for the average U.S. grid electricity. Willow produces 55 times more energy output than the fossil energy it takes to grow and harvest it.

- For technologies such as wind and solar, there is no fuel. Consequently, there is no environmental cost of extracting or transporting the fuel. There are environmental costs associated with the production of generating technology (e.g., emissions from the production of steel for wind turbines) that are separate from the fuel extraction and transport processes. Thus, they are not included in this section.

Other environmental costs of fuel extraction and transportation include

- the aesthetic implications of mining, especially strip mining or oil extraction,

- the noise and pollution associated with trucks carrying fuel through town,

- the potential for oil spills in open water during extraction or transport, and

- the ecosystem disruption caused by construction of oil or natural gas pipelines.

\section{Value Chain Analysis}

Because these costs are generally externalized from the pricing of power or fuel - meaning that society, as a whole, pays for them - the value of eliminating them accrues to society, in general. Economic costs associated with fuel extraction and transport are accounted for in the Reduced Resource Section, above.

\section{$\underline{\text { Avoided costs of transmission and distribution infrastructure expansion }}$}

According to Patrick Wood III, chairman of the Federal Energy Regulatory Commission, our electricity transmission system currently is the weakest link in our electric supply system. ${ }^{151}$ At the same time, it is one of the most expensive components to upgrade. Due to a combination of cost and regulatory hurdles, utilities have been reluctant to invest in additional T\&D infrastructure. Although electricity demand is anticipated to grow by $20 \%$ over the next 10 years, utilities have planned to expand the transmission system by only $6 \%$ during that time. ${ }^{152}$

With a limited supply of transmission infrastructure available, electric customers may opt to install distributed generation technologies at their facilities or pursue energy efficiency measures. In doing so, they not only improve the reliability of electric service to their site but also reduce the amount of additional infrastructure required to serve the utilities' load. A rule of thumb

\footnotetext{
${ }^{150}$ Information about electricity production from willow biomass taken from Heller, M.C., G.A. Keoleian, M.K. Mann, and T.A. Volk. (2004) Renewable Energy 29 (1023-1042).

${ }^{151}$ Federal Energy Regulatory Commission. (8 June 2005) "FERC Chairman urges Congressional action to improve transmission, the 'weakest link' in U.S. power supply system.” Available: http://www.ferc.gov/press-room/prarchives/2005/2005-2/06-08-05.asp

${ }^{152}$ Ibid.
} 
estimates the cost of high voltage transmission lines at approximately $\$ 1,000$ per $\mathrm{MW}$-mile and the cost of modernizing the entire U.S. grid at somewhere between $\$ 50$ billion and $\$ 100$

billion. ${ }^{153}$ Avoided costs in this area add up quickly but do not accrue to one individual actor.

\section{Value Chain Analysis}

A debate is raging in the United States today over who will pay for the expansion of the transmission and distribution infrastructure. Advocates for utility-scale generation installations hope that the government will invest in new infrastructure designed to bring that power to market. Meanwhile, the government is attempting to restructure the T\&D markets to encourage private investment in the grid.

In either case, it is not clear whether ratepayers or taxpayers will bear the cost of the new equipment, because expanded T\&D infrastructure does not benefit just the homes to which it delivers electricity. New T\&D infrastructure will also relieve congestion on other lines, reducing prices for the customers served by that infrastructure as well.

Because of this ambiguity, the benefits of new T\&D infrastructure do not accrue to one actor in the value chain. Because no specific actor is paying for the expansion, no specific actor will receive the benefits of the avoided investment. Thus, distributed generation's ability to reduce the need for new T\&D infrastructure accrues to everyone from the end users of electricity, to the transmission companies, vertically integrated utilities, government regulators, and local land-use policy makers. In other words, society benefits as a whole.

${ }^{153}$ LaCommare, K.H. and J.H. Eto. (September 2004) Understanding the Costs of Power Interruptions to U.S. Electricity Consumers. Lawrence Berkeley National Laboratory Document No. 55718, citing Fialka, J. (August 25, 2003) "Power Industry Sets Campaign to Upgrade Grid." Wall Street Journal, p. A3. and Schieffer, B. (August 17, 2003) Face the Nation with Bob Schieffer. Washington, D.C. 


\section{The Value Chain: A Summary}

Traditional valuation methods fail to capture the total value proposition of clean energy technologies, in part, because they focus primarily on the steps necessary to convert physical raw materials into finished goods and bring them to market. ${ }^{154}$ In many cases, however, information and other "virtual values" - anything from rights of intellectual property, to rights for emissionsreduction credits, to improvements in stakeholder relations - lack a physical component directly related to production, but they still create value for a firm.

Building on the general overview of value chains associated with clean energy technologies presented at the front of this paper and the description of the virtual, physical, and nontraditional financial values of clean energy technologies developed in the main section of this paper, this section aims to summarize the values analyzed.

Figure 2 provides an example of how the values of centralized clean energy technologies are distributed across the value chain (horizontal axis). Each bar represents a specific value discussed in this paper. The color-coding represents the categories of values - Risk Management, Direct Policy Incentives, etc. - which are identified along the vertical axis. In cases where a value can accrue to different actors in the value chain, the bar crosses over both or all of the actors that may benefit from the value stream. Because of the wide range of technologies included in the "centralized electricity generation" group, the relative size of the bars is not proportional to the financial benefits associated with a specific value in this figure. As case studies on specific technologies are performed, however, it may be appropriate to include such scaling effects.

Because some values do not accrue to one specific actor or even a group of actors, they are attributed to "Society" in the diagrams. Societal actors benefit from clean energy technologies at all stages of production, distribution, and use - at the same time, the actors in the value chain benefit from society's support. The double arrows are intended to capture such an exchange. Although the values to society are more difficult to quantify than others examined in this paper, they indeed can be monetized and should be captured in a total value proposition.

To capture the total value proposition of clean energy technologies for one specific actor along the value chain, the values in that column would be summed and added to the conventional value proposition of the technology (e.g., sales, increased market share). The total value proposition of the technology would amount to the sum of the TVPs for the actors in the value chain including the benefits to society.

As depicted in Figure 3, the allocation of values is slightly different for technologies whose effects are seen on a distributed basis, such as EE and DG technologies. ${ }^{155}$ The same guidelines for interpreting the previous figure should be applied to this one.

\footnotetext{
${ }^{154}$ For more information about the split between the physical and virtual value chains, see Rayport, J.F. and J.J. Sviokla. (November-December 1995) "Exploiting the Virtual Value Chain." Harvard Business Review 73(6): 75-85.

${ }^{155}$ Note that the distribution of the sales and property tax incentives in Figure 3 will depend on local policies.
} 
Figure 2: Summary value chain analysis for centralized electricity generation technology.

To calculate the total value for one actor in the value chain, sum the values in a column.

To calculate the total value of the technology, sum the values for all actors in the value chain.

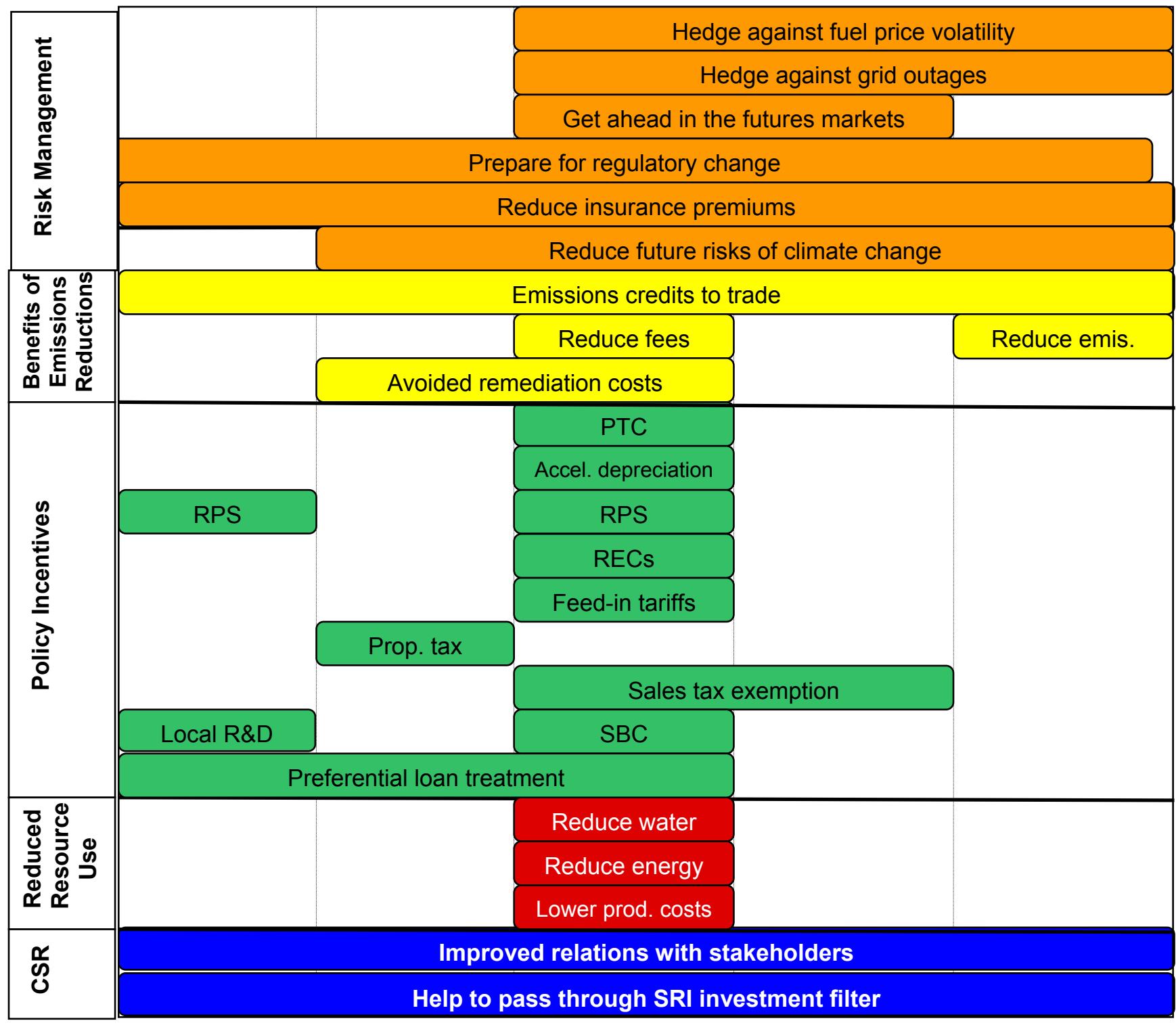

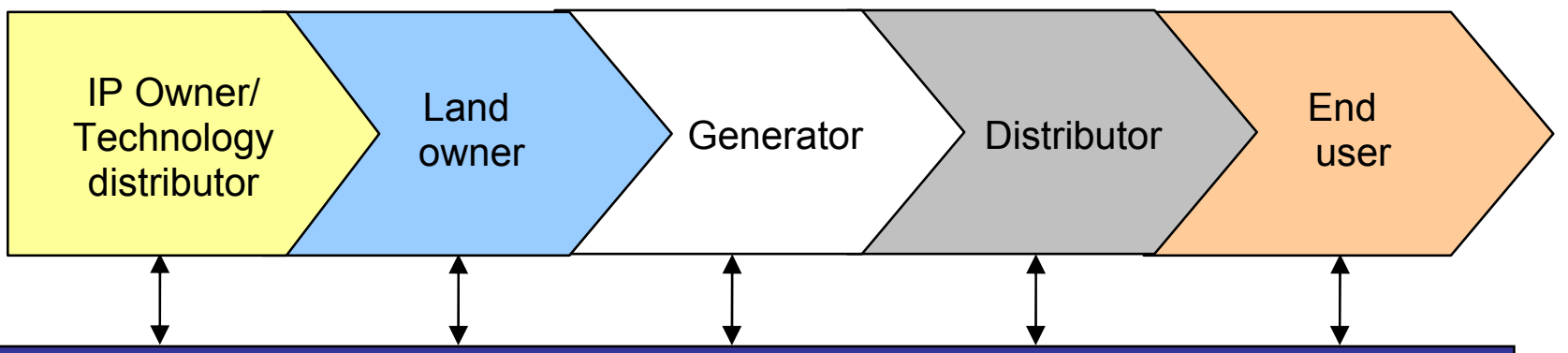

Society, Investors, Shareholders, Insurance companies

- Rural revitalization

- Jobs

- $\quad$ Economic development

- Avoided environmental costs of fuel extraction and transport 
Figure 3: Summary value chain analysis for distributed generation, energy efficiency

To calculate the total value for one actor in the value chain, sum the values in a column.

To calculate the total value of the technology, sum the values for all actors in the value chain.

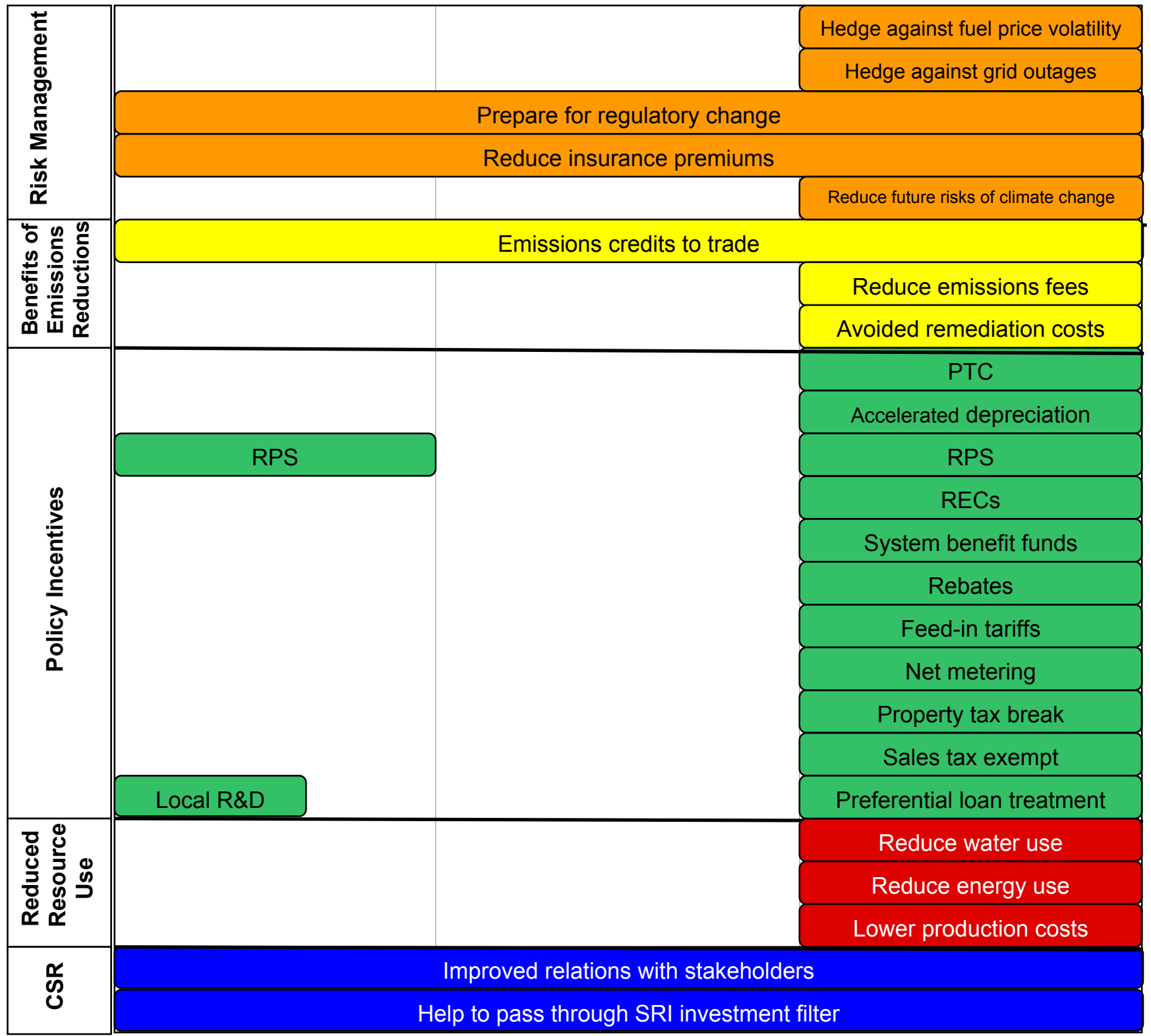

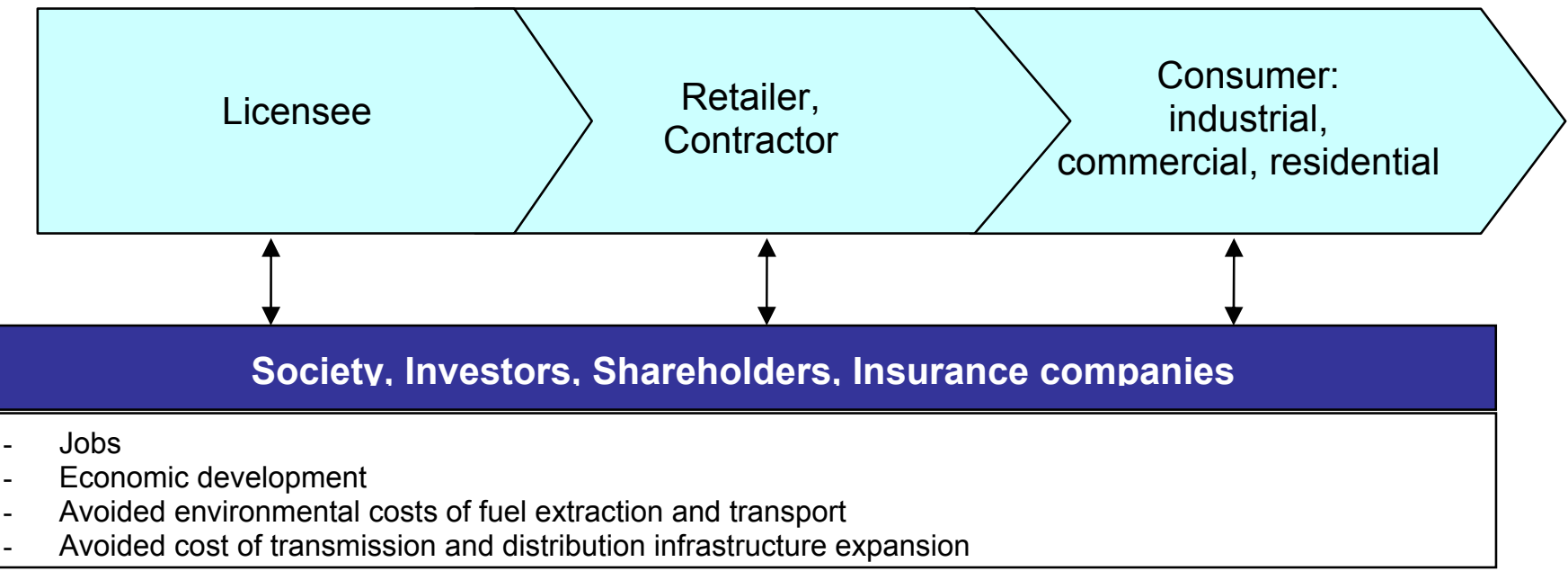




\section{Next Steps}

The purpose of this paper is to provide a more robust framework for capturing the total value of clean energy technologies than has been available before. Previous researchers have sought to understand and describe different aspects of the value of these technologies, and some have quantified parts of the value proposition for individual technologies. It is hoped that this paper will serve as the starting point for integrating all of those individual values into a more comprehensive framework for evaluating the financial benefits associated with clean energy technologies.

The next step involves building on the broad qualitative and anecdotal quantitative scope of this framework by applying it to specific classes of clean energy technologies in different settings. Because so many of the values explored in this framework vary significantly from one context to another, case studies must be developed and used to clearly delineate technological, geographic, and market constraints before developing credible value analyses. Many of these conditions will change over time, and new case studies will undoubtedly unveil additional values that should be added to subsequent versions of the framework.

Users of this framework must understand its dynamic nature. Markets, policy incentives, and regulatory conditions are constantly changing. That does not render the process futile, however. Instead, it suggests the inclusion of a secondary exploratory value proposition for any case studies developed, which postulates how the technology's value may change in light of changing circumstances. This element of analysis will help to create a more comprehensive picture of how a shift in conditions will affect value.

Partnerships between NREL and industry colleagues will be key in creating useful case studies. This is because many of the values examined in this framework lie outside of the industry's conventional valuation methods, although existing peer-reviewed journals have published the analytical assessments where data is available. To determine how to overcome the obstacles that prevent decision makers from integrating the total value of clean energy technologies into business decisions, it is vital that we work with companies that are willing to explore strategies for including these values as we move forward - and further build and implement this framework. Their insight into how decisions are made at the firm level and the unique attributes of their market-ready technology will help to further develop a methodology for quantifying the value for clean energy technologies.

In addition to industry collaborations, the development of technology-specific case studies will require additional work on quantification methodologies $\backslash$. As mentioned throughout the paper, further analysis would be useful in the Risk Management, Reduced Resource Use, Corporate Social Responsibility, and Jobs and Economic Development categories. As the technologies mature, many of the values will become easier to understand and quantify. In the meantime, however, many factors affecting these values - from interconnection standards, to regulatory mechanisms, to standardized reporting for SRI funds - are becoming clearer. While the quantification case studies are most immediately relevant to the future of this framework, 
collaboration with those involved in laying the groundwork for the characterization of value is important as well.

After NREL and industry partners develop several case studies, a more generalized approach to the process will be developed and shared with industry. As the partners gain experience in preparing case studies, similarities and patterns will likely emerge. Further, as the process becomes more structured, NREL can develop a tool that enables industry representatives to develop a total value proposition for their technology. This may take the form of an Excel spreadsheet with embedded formulas, which enables the user to adjust inputs to suit their technology and particular business and market conditions. Moreover, it has the potential to compile the most effective strategies used for assessing the component values. In either case, the lessons learned through early case studies can be shared with others in the field.

In order to protect the proprietary information shared by industry partners, any information presented in the generalized approach will be aggregated across parties. Company identities will be protected, and the information presented will be for illustrative purposes only - but it will be useful as a tool for presenting possible impacts of using the TVP framework. The high-level trends and impacts identified by the aggregate analysis can be used for policy and program planning purposes to identify strategies to promote the adoption of clean energy technologies.

Clearinghouses - or centralized databases - of valuation studies should be developed to facilitate access to the available information on quantification. Although firms will have the best sense of how to quantify certain criteria, many of the values presented here are new to corporate accounting. The ability to search a database for existing methodologies will help firms implement the valuation strategy more quickly. Similarly, NREL's Energy Analysis Office (EAO) is currently developing a PV benefit-cost clearinghouse and methodology. The clearinghouse categorizes studies that examine different aspects of PV's value based on the study's focus; the methodology is contained in a value calculator that enables the user to change inputs based on their needs. The result is a custom value calculation tailored to the user's situation. Similar tools for other technologies will help facilitate the spread of the total value proposition concept. 


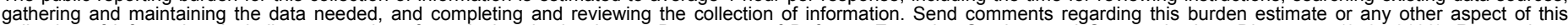

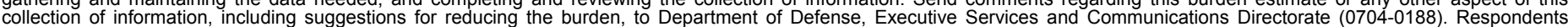

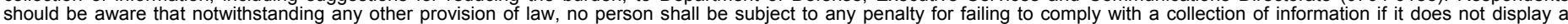

currently valid OMB control number.

PLEASE DO NOT RETURN YOUR FORM TO THE ABOVE ORGANIZATION.
1. REPORT DATE (DD-MM-YYYY) February 2006
4. TITLE AND SUBTITLE
A Framework for Evaluating the Total Value Proposition of Clean Energy Technologies

3. DATES COVERED (From - To)

5a. CONTRACT NUMBER

DE-AC36-99-G010337

5b. GRANT NUMBER

5c. PROGRAM ELEMENT NUMBER

5d. PROJECT NUMBER

NREL/TP-620-38597

5e. TASK NUMBER

6001.1104

5f. WORK UNIT NUMBER
7. PERFORMING ORGANIZATION NAME(S) AND ADDRESS(ES)

National Renewable Energy Laboratory

1617 Cole Blvd.

Golden, CO 80401-3393
8. PERFORMING ORGANIZATION REPORT NUMBER

NREL/TP-620-38597

9. SPONSORING/MONITORING AGENCY NAME(S) AND ADDRESS(ES)

10. SPONSOR/MONITOR'S ACRONYM(S) NREL

11. SPONSORING/MONITORING AGENCY REPORT NUMBER

12. DISTRIBUTION AVAILABILITY STATEMENT

National Technical Information Service

U.S. Department of Commerce

5285 Port Royal Road

Springfield, VA 22161

13. SUPPLEMENTARY NOTES

14. ABSTRACT (Maximum 200 Words)

Conventional valuation techniques fail to include many of the financial advantages of clean energy technologies. By omitting benefits associated with risk management, emissions reductions, policy incentives, resource use, corporate social responsibility, and societal economic benefits, investors and firms sacrifice opportunities for new revenue streams and avoided costs. In an effort to identify some of these externalities, this analysis develops a total value proposition for clean energy technologies. It incorporates a series of values under each of the above categories, describing the opportunities for recapturing investments throughout the value chain. The framework may be used to create comparable value propositions for clean energy technologies supporting investment decisions, project siting, and marketing strategies. It can also be useful in policy-making decisions.

15. SUBJECT TERMS

analysis; total value proposition; clean energy technologies; financial incentives; risk management; emissions reductions; policy incentives; societal economic benefits; corporate social responsibility; renewable portfolio standard; production tax credit; renewable energy certificate; system benefit funds; reduced resource use; Jane Pater

\begin{tabular}{|c|c|c|c|c|}
\hline \multicolumn{3}{|c|}{ 16. SECURITY CLASSIFICATION OF: } & \multirow{2}{*}{$\begin{array}{l}\text { 17. LIMITATION } \\
\text { OF ABSTRACT } \\
\text { UL }\end{array}$} & \multirow{2}{*}{$\begin{array}{l}\text { 18. NUMBER } \\
\text { OF PAGES }\end{array}$} \\
\hline $\begin{array}{l}\text { a. REPORT } \\
\text { Unclassified }\end{array}$ & $\begin{array}{l}\text { b. ABSTRACT } \\
\text { Unclassified }\end{array}$ & $\begin{array}{l}\text { c. THIS PAGE } \\
\text { Unclassified }\end{array}$ & & \\
\hline
\end{tabular}

19b. TELEPHONE NUMBER (Include area code) 